\title{
An update of the Worldwide Integrated Assessment (WIA) on systemic insecticides. Part 2: impacts on organisms and ecosystems
}

\author{
Lennard Pisa $^{1} \cdot$ Dave Goulson $^{2} \cdot$ En-Cheng Yang ${ }^{3} \cdot$ David Gibbons $^{4} \cdot$ \\ Francisco Sánchez-Bayo ${ }^{5}$ - Edward Mitchell ${ }^{6}$ - Alexandre Aebi ${ }^{6,7}$ • Jeroen van der \\ Sluijs $^{8,9,10}$ • Chris J. K. MacQuarrie ${ }^{11}$ - Chiara Giorio ${ }^{12}$ • Elizabeth Yim Long ${ }^{13}$. \\ Melanie McField ${ }^{14}$ - Maarten Bijleveld van Lexmond ${ }^{15}$. \\ Jean-Marc Bonmatin ${ }^{16}$ (D)
}

Received: 25 July 2017 / Accepted: 25 September 2017 / Published online: 9 November 2017

(C) The Author(s) 2017. This article is an open access publication

\begin{abstract}
New information on the lethal and sublethal effects of neonicotinoids and fipronil on organisms is presented in this review, complementing the previous Worldwide Integrated Assessment (WIA) in 2015. The high toxicity of these systemic insecticides to invertebrates has been confirmed and expanded to include more species and compounds. Most of the recent research has focused on bees and the sublethal and ecological impacts these insecticides have on pollinators. Toxic effects on other invertebrate taxa also covered predatory and parasitoid natural enemies and aquatic arthropods. Little new information has been gathered on soil
\end{abstract}

Responsible editor: Philippe Garrigues

Jean-Marc Bonmatin

bonmatin@cnrs-orleans.fr

1 Utrecht University, Utrecht, The Netherlands

2 School of Life Sciences, University of Sussex, Brighton BN1 9QG, UK

3 Department of Entomology, National Taiwan University, Taipei, Taiwan

4 RSPB Centre for Conservation of Science, The Lodge, Sandy, Bedfordshire SG19 2DL, UK

5 School of Life and Environmental Sciences, The University of Sydney, 1 Central Avenue, Eveleigh, NSW 2015, Australia

6 Laboratory of Soil Biodiversity, University of Neuchâtel, Rue Emile-Argand 11, 2000 Neuchâtel, Switzerland

7 Anthropology Institute, University of Neuchâtel, Rue Saint-Nicolas 4, 2000 Neuchâtel, Switzerland

8 Centre for the Study of the Sciences and the Humanities, University of Bergen, Postboks 7805, 5020 Bergen, Norway organisms. The impact on marine and coastal ecosystems is still largely uncharted. The chronic lethality of neonicotinoids to insects and crustaceans, and the strengthened evidence that these chemicals also impair the immune system and reproduction, highlights the dangers of this particular insecticidal class (neonicotinoids and fipronil), with the potential to greatly decrease populations of arthropods in both terrestrial and aquatic environments. Sublethal effects on fish, reptiles, frogs, birds, and mammals are also reported, showing a better understanding of the mechanisms of toxicity of these insecticides in vertebrates and their deleterious impacts on growth, reproduction,
Department of Chemistry, University of Bergen, Postboks 7805, 5020 Bergen, Norway

10 Copernicus Institute of Sustainable Development, Environmental Sciences, Utrecht University, Heidelberglaan 2, 3584 CS Utrecht, The Netherlands

11 Natural Resources Canada, Canadian Forest Service, 1219 Queen St. East, Sault Ste. Marie, ON P6A 2E5, Canada

12 Aix Marseille Univ, CNRS, LCE, Marseille, France

13 Department of Entomology, The Ohio State University, 1680 Madison Ave, Wooster, OH 44691, USA

14 Smithsonian Institution, 701 Seaway Drive Fort Pierce, Florida 34949, USA

15 Task Force on Systemic Pesticides, Pertuis-du-Sault, 2000 Neuchâtel, Switzerland

16 Centre National de la Recherche Scientifique (CNRS), Centre de Biophysique Moléculaire, Rue Charles Sadron, 45071 Orléans, France 
and neurobehaviour of most of the species tested. This review concludes with a summary of impacts on the ecosystem services and functioning, particularly on pollination, soil biota, and aquatic invertebrate communities, thus reinforcing the previous WIA conclusions (van der Sluijs et al. 2015).

Keywords Systemic insecticides $\cdot$ Neonicotinoids $\cdot$ Fipronil • Insects · Pollinators · Soil biota $\cdot$ Aquatic organisms ·

Vertebrates $\cdot$ Ecosystem services $\cdot$ Review

\section{Introduction}

Since the publication of the first Worldwide Integrated Assessment (WIA) review (Bijleveld van Lexmond et al. 2015) on the impact of neonicotinoids and fipronil systemic insecticides on invertebrates (Pisa et al. 2015), vertebrates (Gibbons et al. 2015), ecosystem services (Chagnon et al. 2015), and its conclusions (van der Sluijs et al. 2015), there has been a surge in publications related to this important issue. In particular, research on the impacts of these insecticides on bees and other pollinators has grown exponentially (Fig. 1) and IPBES published a review report on pollinators, pollination, and food production (IPBES 2016a), showing the great interest that this topic has raised worldwide. In this update, we have strived to collect all new information that has been published since 2014 onwards on the same topics covered by the WIA in 2015.

The first review paper of the updated WIA (Giorio et al. 2017 , this special issue) deals with the mode of action of neonicotinoids and fipronil, their metabolism, synergies with other pesticides or stressors, degradation products, and the contamination of the environment by neonicotinoids and fipronil, including new insecticides introduced on the market.

For this second review paper, a broad-scaled literature search was performed using the Web of Science ${ }^{\mathrm{TM}}$ and Scopus ${ }^{\circledR}$ as reported by Gibbons et al. (2015) and restricted to the years 2014-early 2017. Search terms were [product] or "neonicotinoids," and either "insects," "invertebrates," "vertebrates," "mammals," "birds," "reptiles," "amphibians," "fish," "soil biota," "aquatic organisms," and "ecosystem services," where [product] was a placeholder for the name of each considered active ingredient (a.i.): imidacloprid, clothianidin, thiamethoxam, nitenpyram, acetamiprid, thiacloprid, dinotefuran, cycloxaprid, imidaclothiz, paichongding, sulfoxaflor, guadipyr, flupyradifurone, and fipronil. In addition, specific searches were made on a few common toxicity test species (e.g., rat) and by following up references cited in the publications found by the search. Therefore, the present review paper covers the effects on organisms, from aquatic and terrestrial invertebrates to vertebrates, and their impacts on ecosystems.

The updated WIA is divided in three parts, corresponding to effects on invertebrates (part A), vertebrates (part B), and ecosystems (part C).

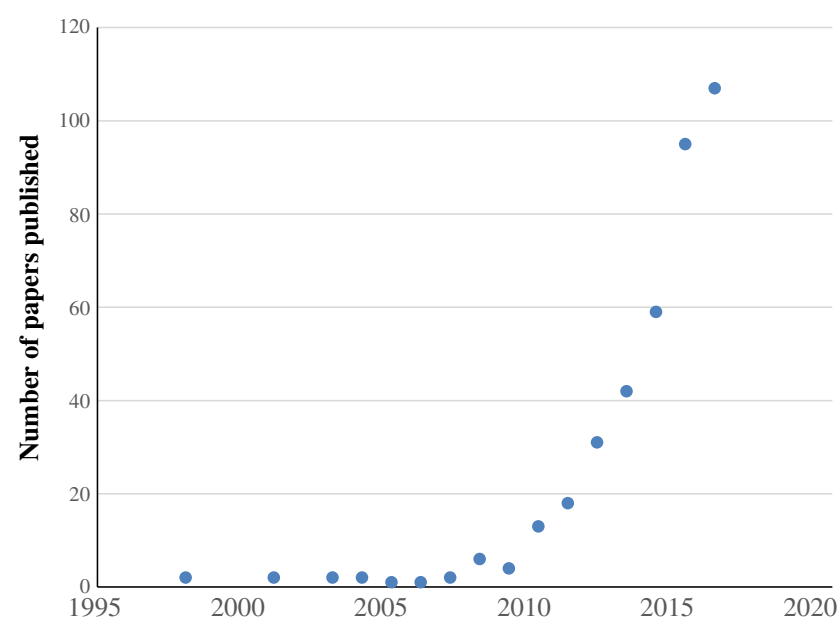

Fig.1 Number of research papers on pollinators and neonicotinoids published since 1998

Note that the third paper of the updated WIA discusses the efficacy of neonicotinoids and fipronil in agriculture and proposes some alternatives to the use of these products for pest control (Furlan et al. 2017, this special issue). It also summarizes the current regulations in Europe and other countries concerning these widely used systemic insecticides.

\section{Part A: invertebrates}

\section{Effects of neonicotinoids and fipronil on pollinators}

\section{Honeybees (Apis mellifera)}

Since the publication of the WIA document on the effects of neonicotinoid insecticides and fipronil on non-target invertebrates, research on this matter has continued. Lundin et al. (2015) provide a systematic review of research approaches, evaluating 268 publications on bees in general (honeybees, bumblebees, solitary bees). Another overview of scientific advances in the field of neonicotinoids and pollinators was made by Godfray et al. (2015). Van der Sluijs and Vaage (2016) reviewed the implications of the present pollinator crisis for global food security and concluded that it threatens global and local food security, can worsen the problems of hidden hunger, erodes ecosystem resilience, and can destabilize ecosystems that form our life support system. They call for an international treaty for global pollinator stewardship that simultaneously addresses its key drivers: creation and restoration of floral and nesting resources, a global phase out of prophylactic use of neonicotinoids and fipronil, improvement of test protocols in authorization of agrochemicals (see Sánchez-Bayo and Tennekes, 2017 for the changes that are needed), and restoration and maintenance of independence in regulatory science. 
In the paragraphs below, results of recent studies with regard to honeybees (Apis mellifera) are listed, considering effects in vivo (field and semi-field situation) and in vitro (laboratory experiments).

\section{Field studies}

Field studies to investigate effects of pesticides are observational in nature, making it hard to state causal relations between observed environmental variables and honeybee losses or honeybee health as these are dependent on a multitude of factors including weather, nutrition, genetics, pathogens and diseases, presence of multiple toxic compounds, potentially contrasting behavioral characteristics of the studied colonies, and very different methodological approaches.

Calatayud-Vernich et al. (2016) addressed this problem by using time series of counting dead bees in traps connected to hives in agricultural areas (Spanish citrus plantations), measuring the concentration of 58 different pesticides present in dead bees using LC-MS/MS. In this way, a change in mortality rate over time could be correlated to a differential presence of pesticides. The largest increases in mortality rate were associated with increased presence of dimethoate and chlorpyrifos. Imidacloprid was the fourth most present insecticide in dead bee samples, at concentrations varying between 12 and $223 \mathrm{ng} / \mathrm{g}$ dead bees. These concentrations are known to cause at least sublethal effects on bees (Decourtye et al. 2005), but increased exposure to imidacloprid presence could not be associated with bee mortality due to the presence of other pesticides. Kasiotis et al. (2014) used LC-ESI-MS/MS multiresidue analysis to investigate the presence and concentration of 115 pesticides in dead bees, pollen or honey collected by bees, focusing on pollen and honey collected by individuals or public authorities who evidenced specific high losses or bee death incidents in 2011,2012, and 2013. Among the analyzed dead bees $(n=44), 50 \%$ were positive for clothianidin, $14 \%$ for chlorpyrifos, $9 \%$ for thiamethoxam, and $4.5 \%$ for imidacloprid. Concentrations of these compounds were mostly below the oral LD50 values for the compound detected, leading authors to state that more research is needed to determine the causal relations. However, the authors did not look at toxic metabolites of active compounds, possibly leading to an underestimation of compound presence.

An association between the presence of acetamiprid and thiacloprid in colonies (investigated by LC-MS/MS) and successive winter mortality was found by Van der Zee et al. (2015). In their observational study, the presence of these pesticides in any of the bee matrices (bees, pollen, wax and honey) was the second best predictor of winter loss in the observed population, the first being the amount of Varroa destructor in colonies in October. Their results indicate that the presence of acetamiprid and thiacloprid in honey is a better predictor of loss than its presence in bees and pollen. A similar field study by Budge et al. (2015) found a correlation between imidacloprid use in oilseed rape and colony mortality at the landscape level. Alburaki et al. (2015) monitored hives in neonicotinoid-treated corn areas and found elevated levels of acetylcholine esterase gene expression (a biomarker for physiological stress) in combination with higher pathogen and Varroa mite loads in hives from treated locations. In a later study, the same authors monitored colony performance and pesticide content of foragers and trapped pollen of colonies set up in neonicotinoid-treated corn fields and untreated corn fields (control) (Alburaki et al. 2017). They found no neonicotinoid compounds in foragers but sublethal amounts of thiamethoxam and clothianidin in trapped pollen. Mogren and Lundgren (2016), looking at pesticide presence in flowers seeded for pollinators adjacent to crop lands, found an association between presence of clothianidin and nutritional status of bees. Bees with increasing amounts of clothianidin had decreasing amounts of glycogen, lipids and protein.

Tsvetkov et al. (2017) measured long-term exposure (2 summers) to neonicotinoids in Canadian corn areas and matched their laboratory exposure parameters to this data. They found an association between field-realistic exposure to clothianidin and thiamethoxam and decreased colony immunity and survival. Moreover, both neonicotinoids became twice as toxic in the presence of field-realistic amounts of the fungicide boscalid. Using a large experimental design, Woodcock et al. (2017) allocated insecticide treatments (thiamethoxam, clothianidin, betacyfluthrin, lambda-cyhalothrin), fungicide treatments (thriam, prochloraz, fludioxonil, metalaxyl-M) and standardized colonies of Apis mellifera, Bombus terrestris, and units of Osmia bicornis to a total of 33 sites with oilseed rape in the UK, Hungary, and Germany. They found partly significant negative effects on honeybee worker numbers and egg laying in the UK and Hungary, but not in Germany. Their results suggest interaction effects of treatment with the environment, available flora, and residues of earlier treatments not part of the experiment. It should also be noted that all treatments including controls also received fungicide treatments and that different fungicides were used in the three different countries. Rolke et al. (2016) carried out a large field study of the effects of clothianidin-dressed oilseed rape on honey bees, finding no adverse effect of treatment on numbers of adult bees or brood, although the study had no replication (only one treated and one control site) and therefore these results should be accorded little weight.

Wegener et al. (2016) have measured 28 biochemical, biometrical, and behavioral aspects of honeybees (A. mellifera) to investigate the effect of imidacloprid and fenoxycarb on colony productivity and survival. Imidacloprid affected honey yield, total number of bees, and the activity of the enzyme phenoloxidase in worker bees.

Pilling et al. (2013) exposed hives to corn and oilseed rape plots treated with thiamethoxam and found no effects on colony parameters (mortality, colony strength, amount of brood and honey). However, this study co-published by the 
manufacturer (Syngenta Ltd) was criticized by Hoppe et al. (2015), who pointed to several weaknesses: the use of a noncommercial pesticide formulation, lower than field-realistic doses, flawed experimental design, and lack of statistical analysis. The latter was also subject to criticism by Schick et al. (2017) who pointed to the low quality of the data and consequent lack of power to estimate effects.

Garbuzov et al. (2015) added to the discourse on honeybee field studies with their findings that oil seed rape, a potential exposure crop to neonicotinoid pesticides, elicited less foraging then expected by its presence in the landscape.

An example of the requirements of large field studies and their implementation is given by Heimbach et al. (2016). A wider review of neonicotinoid field studies by the industry can be found in Schmuck and Lewis (2016). Bakker (2016) points at shortcomings in the current field study protocols as used by the European Food Safety Authority (EFSA) and proposes ideas to disentangle effect measurements of acute and sublethal effects in experiments. Improvement of research methods (sampling and measuring exposure) is also addressed by Benuszak et al. (2017). Hesketh et al. (2016) provide arguments for an increased exposure time ( $>240 \mathrm{~h}$ ) to better identify sublethal effects in honeybee toxicity test, the current standard being $96 \mathrm{~h}$ of exposure.

A modeling approach for sublethal effects of pesticides on colony level, using the BEEHAVE model, can be found in Thorbek et al. (2017a). Their model study suggests that monitoring of field experiments must continue for at least 1 month to identify sublethal effects. In another publication the authors criticize the Khoury bee population model used by EFSA to set exposure values for colony losses related to pesticides as too conservative (Thorbek et al. 2017b).

An interesting study that tries to bridge the gap between field and laboratory studies has been done by Henry et al. (2015). In their study, they show that a mixture of effects on individual bees leads to demographic effects in the colony and can lead to negative outcomes at the population level.

Reports on pesticide presence in dead bees generated by investigating reported colony losses by monitoring agencies give information about the variety and quantity of pesticides used in the bees' environment. A review on recent acute bee poisonings, with a focus on Eastern Europe, is given by Kiljanek et al. (2017). Kiljanek et al. (2016) and Kimura et al. (2014) provide information of poison incidents in a Japanese region. A recent study in France (Daniele et al. 2017) has shown that neonicotinoids and boscalid were the most detected pesticides in honeybees, beebread, and wax, for numerous samples primarily taken from symptomatic colonies during springs 2012-2016.

As stressed in the introduction to this section, observational studies do not suffice to demonstrating causality and other pesticides or other environmental factors may be involved in the observed responses. However, an increasing number of field studies include physiological and behavioral analyses (linking field- to controlled laboratory studies) that allow more causal interpretations of the impact of neonicotinoids on bees. These studies converge in clearly demonstrating the existence of a significant detrimental impact on bees.

\section{Semi-field studies}

Sandrock et al. (2014b) used a fully crossed experimental design (sister queens, in-hive pollen feeding) to test effects of clothianidin ( $2 \mathrm{ppb}$ in pollen) and thiamethoxam (5 ppb in pollen) administered during two brood cycles on colony performance and queen supercedure. They found that the number of bees and brood rearing decreased and queen supercedure increased in treated colonies. After winter, treated colonies exhibited a lower swarming tendency, possibly related to their lower growth rate. Interestingly, they found a difference in effect for the 2 races of honeybees they used (A. m. mellifera and $A . m$. carnica), with bees originating from an area with intensive agriculture including pesticide application (A. $m$. carnica) experiencing less effects of the treatments than bees from a more natural habitat (A. m. mellifera), possibly pointing toward a genetic adaptation. Though not a semifield study, the results of Rinkevich et al. (2015) also indicate dramatic differences between races in sensitivity to neonicotinoids.

In a semi-field study by Henry et al. (2015) thiamethoxamcoated oilseed rape was sown in a specific study area (total of 288 ha in 2 years) and hives were placed at various distances and directions to generate a range of exposure levels. Monitoring of colony demographics showed that more exposed colonies had a greater loss of forager bees, but the numbers of foragers were buffered by colony regulation response. However, the effects of population changes within the beehive (larvae, nurses, workers, foragers) could weaken the colony. Dively et al. (2015) conducted a 3-year study feeding pollen supplements laced with imidacloprid $(5,20$, and $100 \mu \mathrm{g} / \mathrm{kg}$ ). They found an association between higher doses (20 and $100 \mu \mathrm{g} / \mathrm{kg}$ ) and reduced winter survival. Higher dose colonies also had a higher Varroa mite load. Exposure to imidacloprid and clothianidin lead to colony collapse symptoms at the end of winter in half of the small study population used by Lu et al. (2014).

Tison et al. (2016) used harmonic radar to track bees at feeders spiked with low doses of thiacloprid and unspiked controls. They found that foraging life of bees using the spiked feeder was shorter and that exposed bees made more navigation errors, had less homing success, and showed impaired social communication.

Stanley et al. (2015b) tested a range of pesticides, including acetamiprid, imidacloprid, and thiamethoxam in both laboratory assays (topical application and filter paper contact) and in semi-field settings (pesticides applied to potted plants moved 
to field, application of pesticides in field directly) for toxicity and repellent effects, using both Apis mellifera and Apis cerana. The neonicotinoids had less direct toxicity (less lethal) than for example deltamethrin and malathion but big differences were found between topical, filter paper, and field applications for several tested substances.

\section{Experimental (in vitro) studies}

In comparison to field and semi-field studies, where it is extremely difficult to control unwanted (and unknown) influences, properly conducted experimental assays allow for causal arguments about exposure-effect relationships. Exposure of bees to pesticides is most often done by feeding bees with known amounts of the active substance and measuring the lethal or sublethal responses. Whereas lethality is easily observed, sublethal effects can vary greatly in their way of occurrence (including cascade effects) and intensity in a honeybee colony.

\section{Sublethal effects on memory, behavior, and locomotion}

Karahan et al. (2015) found that feeding honey bees with field-realistic doses of imidacloprid ( 0.36 to $7.20 \mathrm{ng} / \mathrm{bee}$ ) negatively affected the number of foraging trips, number of foragers returning, and flowers visited. Roat et al. (2014) found changes in the brain proteome of Africanized honeybees for doses of $10 \mathrm{pg}$ fipronil per day during 5 days. Concentrations of several brain proteins involved in detoxification, glycolysis, and cell growth were altered, possibly leading to memory and learning impairment and to a reduced life span. Zaluski et al. (2015) also used Africanized honeybees in their study about effects of fipronil on colony development and bee motoric control and behavior. Treated adult bees (1/500th of the LD50) bees showed reduced motor activity and became lethargic, while treated colonies showed a reduction in egg laying and larval numbers.

Tan et al. (2015) investigated the effect of imidacloprid on adult bee memory and learning behavior by feeding total doses of $0.24 \mathrm{ng}$ to larvae of A. cerana. They found that long-term memory, but not short-term or larval survival, was affected by the treatment. Also using Apis cerana in an earlier study, these authors found that trained exposed bees foraged less and had a lower avoidance of predators (i.e., Asian hornet Vespa velutina) (Tan et al. 2014). Wright et al. (2015) used a choice assay with imidacloprid and thiamethoxam influencing olfactory memory. They found that low acute doses affect olfactory memory negatively, with this effect being greater than the effect on memory. Doses of imidacloprid (11.25 ng/ bee), clothianidin ( $2.5 \mathrm{ng} / \mathrm{bee})$, and thiacloprid (1.25 mg/bee) given to trained forager bees resulted in less successful returns and a lower ability to navigate (Fischer et al. 2014). Effects on learning and memory were also found by Mengoni Goñalons and Farina (2015) who fed sublethal doses of imidacloprid to young bees. They postulate that impaired memory and sensitivity to rewards of individual bees affects colony performance.

Peng and Yang (2016) found a reduction of mushroom bodies in parts of the brain responsible for olfactory and visual processing. At the molecular level, interaction between odor binding proteins and imidacloprid has been studied in A. cerana by Li et al. (2015a), who found that presence of imidacloprid decreased the affinity of a specific odor binding protein and a flower volatile.

A 24-h exposure of adult bees to imidacloprid, dinotefuran, clothianidin, and thiamethoxam at sublethal field-realistic doses $(0.323$ to $0.481 \mathrm{ng} / \mathrm{bee})$ resulted in behavioral changes. Bees walked less and groomed more (Williamson et al. 2014). Blanken et al. (2015) used flight cages to determine effects of imidacloprid (about $6 \mathrm{ng} / \mathrm{mL}$, weekly feeding of $660 \mathrm{~mL}$ in a 13-week period) on flight capacity of forager bees, in combination with differential Varroa destructor mite loads of the bee donor colonies. Their results showed an interaction between physiological stressed caused by Varroa and imidacloprid, with imidacloprid possibly affecting the body mass of bees and lower body mass causing decreased flight capacity. An interesting finding is that of Kessler et al. (2015). Their data generated by choice assays (sucrose laced with imidacloprid or thiamethoxam versus plain sucrose) suggest that bees prefer solutions with imidacloprid and thiamethoxam. Another study investigating effects on food consumption found that thiamethoxam decreased bees' response to higher sucrose concentrations (Démares et al. 2016). Alkassab and Kirchner (2016) exposed winter bees to sublethal doses of clothianidin and measured behavioral effects. Chronic exposure to $15 \mathrm{ppb}$ was found to significantly affect long-term memory. Both deltamethrin and acetamiprid were used in retrieval assays (conditional proboscis response) by Thany et al. (2015). Their results showed that retrieval was impaired at lower doses of acetamiprid compared to deltamethrin.

Papach et al. (2017) present the first evidence of impaired learning and memory in adult bees that were fed thiamethoxam $(0.6 \mathrm{ng} / \mathrm{bee})$ during the larval stage. Colony survival critically depends on successful learning and memory. Chronic larval exposure to sublethal doses of this neonicotinoid resulted in alterations of associative behavior in adults. Similar delayed effects on learning and memory following larval exposure have been reported for other neonicotinoids such as imidacloprid (these studies are reported in the WIA 2015 study).

Effects of sublethal doses of thiacloprid on social interactions and network structure established by a group of honeybee worker individuals has been quantified in a study by Forfert and Moritz (2017) using experimental groups. Bees fed with thiacloprid $(0.17$ and $0.80 \mu \mathrm{g}$ thiacloprid in $20 \mu \mathrm{L}$ 2.7 M sucrose solution) significantly reduced their network 
centrality, but they nevertheless exchanged more food to other group members, which resulted in a dilution of the contaminated food. The authors argue that although thiacloprid may act as a general perturbator of social network structure, it still may play a role in the dynamics of disease transmission in the colony if pathogens are transmitted via food exchange.

Using flight mills, Tosi et al. (2017) found that flight activity (duration and distance) was increased after a single sublethal dose and decreased (duration, distance, velocity) after 12 days of chronic exposure.

To understand how neonicotinoids affect behavior and immunity at the molecular level, Christen et al. (2016) looked at transcriptional regulation of 8 genes in caged honeybees fed with field-realistic concentrations of acetamiprid, clothianidin, imidacloprid, and thiamethoxam. They found downregulation of transcription of two genes involved in memory and increased transcription of the gene responsible for vitellogenin, the latter possibly affecting foraging behavior. A follow-up study confirmed these results and looking at effects of binary mixtures of acetamiprid, clothianidin, imidacloprid, and thiamethoxam on memory and vitellogenin gene transcription, found smaller effects of mixtures opposed to single substance application on gene regulation (Christen et al. 2017).

\section{Sublethal effects on immunity and metabolism}

Gene expression profiles in honeybee midgut showed that insecticide treatments (imidacloprid or fipronil) had no impact on detoxifying genes but led to a significant downregulation of immunity-related genes, suggesting a possible immunotoxicity of neonicotinoid and phenylpyrazole insecticides under chronic exposure (Aufauvre et al. 2014). This study also showed that $N$. ceranae + fipronil and $N$. ceranae + imidacloprid combinations do not systematically lead to a synergistic effect on honeybee mortality. Brandt et al. (2016) found that imidacloprid, thiacloprid, and clothianidin caused reduced hemocyte density, encapsulation response, and antimicrobial activity after a relatively short exposure $(24 \mathrm{~h})$ to field-realistic concentrations. Looking specifically at the interaction of thiacloprid and the pathogens Nosema ceranae and black queen cell virus, Doublet et al. (2014) found that thiacloprid increased the viral load of larvae and so negatively affected larval survival, as well as aggravating the effect of Nosema on adult mortality. A similar study by Gregorc et al. (2016) combined exposure to Nosema ceranae and thiamethoxam and showed no synergistic effects of the two. Reviews of the relation between nicotinoid pesticides and honeybee disease can be found in Sánchez-Bayo and Desneux (2015) and Sánchez-Bayo et al. (2016b).

Badawy et al. (2015) measured the effects of oral and topical application of four pesticides (acetamiprid, dinotefuran, pymetrozine, pyridalyl) on detoxifying enzyme activity (acetylcholinesterase, carboxylesterase, glutathione-S-transferase and polyphenol oxidase). They found dinotefuran to be the most toxic, pyridalyl second and acetamiprid/pymetrozine the least toxic. Carboxylesterase and glutathione-Stransferase were able to detoxify low doses of acetamiprid, pymetrozine, and pyridalyl but not dinotefuran. Böhme et al. (2017) were feeding pollen containing mixtures of pesticides at field-realistic (sublethal) doses to determine synergistic effects, as exposure to multiple substances through pollen is common but little studied. They found that larval weight was higher and acini diameters of the hypopharyngeal glands of nurse bees were smaller in the experimental group. Renzi et al. (2016) also looked at hypopharyngeal glands and found that dietary exposure to thiamethoxam was associated with smaller acini and lower total protein content of bee heads.

Exposure to thiamethoxam was also found to alter thermoregulation in individual bees, with effects dependent on ambient temperature and dose (Tosi et al. 2016). At higher temperatures $\left(33{ }^{\circ} \mathrm{C}\right)$, body temperature of exposed bees increased, whereas lower temperatures $\left(22^{\circ} \mathrm{C}\right)$ lead to lower body temperature 60-90 min post treatment. In both exposed groups, body temperatures were lower than control group the following day.

An interesting finding was done by Rittschof et al. (2015), who investigated aggressive behavior of honeybees as a result of early-life social experience, using acetamiprid as a stressor to identify effects on the immune system. Their results found that aggressive bees had less immunosuppressive effects of acetamiprid than less aggressive bees.

\section{Sublethal effects on reproduction}

Sublethal effects on honeybee reproduction were not mentioned in the original WIA article on invertebrates (Pisa et al. 2015) but might be of considerable importance, as specific effects on, for example, sperm viability and queen mating success might directly affect population numbers. Williams et al. (2015) found that queens exposed to clothianidin and thiamethoxam had larger ovaries and reduced quality and quantity of sperm stored in the spermatheca. Very low doses of imidacloprid, alone and in combination with the parasite Nosema ceranae, were found to increase activity of detoxifying enzymes and decrease survival of queens (Dussaubat et al. 2016).

Drones that were raised in semi-field and laboratory conditions and exposed to fipronil through feeding showed a decrease in quantity of spermatozoa and increased mortality of spermatozoa (Kairo et al. 2017). This confirmed earlier research by the same authors had shown that queens inseminated with sperm of fipronil exposed drones had less and less viable spermatozoa stored in their spermatheca (Kairo et al. 2016). They found that several pesticides, among them fipronil, imidacloprid, and thiamethoxam, reduced sperm viability (in vitro sperm assay). Effects on drones were also found by Straub et al. (2016), who reported reduced drone life span as well as decreased sperm 
quality (low quantity of spermatozoa, reduced viability by $40 \%$ ). Number of newly emerged adults and drone body mass was unaffected. Sublethal dose of imidacloprid ( $2 \mathrm{ppb})$ decreased also sperm viability by $50 \% 7$ days after treatment in another study (Chaimanee et al. 2016).

Wu-Smart and Spivak (2016) fed small (1500-7000 bees) colonies with different doses of imidacloprid $(0,10,20,50$, and $200 \mathrm{ppb}$ ) in syrup for 3 weeks to investigate its effect on queen productivity. They observed a decrease in egg laying rate and queen motility associated with exposure, as well as negative effects on foraging, hygienic behavior of worker bees, and on colony development in all treated colonies. Independent of colony size, number of eggs laid per $15 \mathrm{~min}$ was reduced by approximately $50 \%$ by $10 \mathrm{ppb}$ imidacloprid compared to control. These findings demonstrate that chemical exposure may affect sperm quality in the spermatheca of honey bee queens, queen fecundity, threatening the reproductive success and survival of the colony.

An interesting study on honeybee reproductive metabolism was done by Wessler et al. (2016). They looked at the effect of thiacloprid and clothianidin on the secretion of acetylcholine by the hypopharyngeal gland. Acetylcholine is a key compound of larval food and royal jelly. Release of acetylcholine and its presence in larval food decreased by $80 \%$ after 4 weeks of exposure to high doses of both neonicotinoids. Fieldrealistic doses (200 ppb for thiacloprid, 1 to $10 \mathrm{ppb}$ for clothianidin) lowered acetylcholine in larval food and showed negative effects on brood development.

\section{Sublethal effects due to ontogenic exposure}

Residue analyses of pollen, honey or bee wax revealed the presence of a cocktail of multiple insecticides accumulating at the same time (Bonmatin et al. 2015; David et al. 2016; Krupke and Long 2015; Mullin et al. 2010; Daniele et al. 2017; Giorio et al. 2017 this special issue). However, relatively few investigations have focused on the sublethal effects of pesticides on the honeybee brood.

It has been clearly shown that rearing brood in contaminated combs causes delayed development of larvae and emergence as well as a shortened adult life span (Wu et al. 2011). An additive interaction between black queen cell virus (BQCV) and thiacloprid on host larval survival was also observed (Doublet et al. 2014). A recent study by López et al. (2017) demonstrated a synergistic interaction when larvae are exposed to sublethal doses of dimethoate or clothianidin in combination with Paenibacillus larvae, the causative agent of American foulbrood (AFB). It is evident that the cellular response of larvae to individual and combined stressors allows for unmasking previously undetected sublethal effects of pesticides on colony health (Giorio et al. 2017, this special issue).

Bee larvae that were fed sublethal doses of thiamethoxam by Tavares et al. (2015a) showed condensed cells and early cell death in the optical lobe part of the brain, as well as dosedependent effects on development speed and body size.

By exposing a hive to imidacloprid, Yang et al. (2012) discovered that honey bee larvae fed with a sublethal dose of imidacloprid still completed their development into adult bees, but they did so with a decreased olfactory learning ability. This impairment occurred with a dose that could be as little as $0.04 \mathrm{ng}$ per larva. These results demonstrate that sublethal dosages of imidacloprid given to the larvae affect the subsequent associative ability of the adult honeybee workers. Peng and Yang (2016) further revealed the effect of sublethal doses of imidacloprid on the neural development of the honeybee brain by immune-labeling synaptic units in the calyces of mushroom bodies. This not only links a decrease in olfactory learning ability to abnormal neural connectivity but also provides evidence that imidacloprid damages the development of the nervous system in regions responsible for both olfaction and vision during the larval stage of the honeybee.

To reveal the potential spectrum of sublethal effects of imidacloprid exposure in the larval stage, $\mathrm{Wu}$ et al. (2017) measured changes in global gene expression in the heads of newly emerged adults. They found that multiple physiological changes could be induced by the sublethal exposure to imidacloprid, affecting detoxification, immunity, sensory processing, neuron development, metabolism, mitochondria, and synthesis of royal jelly.

\section{Other pollinators}

\section{Direct lethality of neonicotinoids to wild bees}

Around 2000 bee species are known from Europe, with 400 of these classified as endemic (Nieto et al. 2014). The biology, behavior, and ecology of each of these species differ from those of honeybees, for example, some bees ingest pollen for transport (e.g., Hylaeus sp.), which might provide much greater exposure than carrying pollen in corbiculae. Consequently, extrapolating from the limited toxicological data available for 19 bee species to the effects of neonicotinoids on the wider European fauna is fraught with difficulties given the wide variation in relative sensitivity, ecology, and behavioral traits. Conversely to the results of Cresswell et al. (2012) who exposed bumble bees and honey bees to high doses, current data suggests that wild bees are equally to slightly less sensitive to neonicotinoids compared to honeybees when considering direct mortality (e.g., Sánchez-Bayo et al. 2017). However, care must be taken when considering individual bee species, genera, and families, as different taxonomic groups may show consistently different individuallevel sensitivity. Most European wild bees are smaller than honeybees and there is the potential for them to be more sensitive on a basis of a few ng/bee exposure. In general, continuing to use honeybee neonicotinoid sensitivity metrics is 
likely to be a reasonable proxy measure for the direct sensitivity of the wild bee community to neonicotinoids (Arena and Sgolastra 2014), but further work is needed in this area to cover the wide range of bee species present in agricultural environments.

In large parts of Asia, the ecological niche of Apis mellifera is occupied by the similar but distinct sister species A. cerana. As agriculture has intensified and pesticide use increased strongly, effects can be expected on this bee species but little toxicological research has been conducted so far. The study of Yasuda et al. (2017) addresses this knowledge gap. They used the subspecies A. cerana japonica to determine LD50 values for acute contact toxicity for commonly used pesticides. Of the neonicotinoid group, dinotefuran proved to be most toxic $(1.4 \mathrm{ng} / \mathrm{bee})$, followed by thiamethoxam $(2.4 \mathrm{ng} / \mathrm{bee})$, clothianidin ( $3.4 \mathrm{ng} / \mathrm{bee})$, imidacloprid $(3.6 \mathrm{ng} / \mathrm{bee})$, and acetamiprid (278 ng/bee). This LD50 for fipronil was determined at $2.5 \mathrm{ng} / \mathrm{bee}$. The authors note that $A$. cerana is generally more sensitive to pesticides and that results obtained for A. mellifera cannot be generalized to A. cerana.

Arena and Sgolastra (2014) conducted a meta-analysis comparing the sensitivity of wild bees to pesticides relative to the sensitivity of honeybees. This analysis combined data from 47 studies covering 53 pesticides from six chemical families with a total of 150 case studies covering 18 bee species (plus A. mellifera). The authors calculated a sensitivity ratio $(R)$ between the lethal dose for species a (A. mellifera) and for species s (other than A. mellifera), where $R=\mathrm{LD} 50 \mathrm{a} / \mathrm{LD} 50 \mathrm{~s}$. A ratio of over 1 indicates that the other bee species is more sensitive to the selected pesticides than A. mellifera and vice versa. There was high variability in relative sensitivity ranging from 0.001 to 2085.7 , but across all pesticides a median sensitivity of 0.57 was calculated, suggesting that $A$. mellifera was generally about two times more sensitive to pesticides than other bee species. In the vast majority of cases (95\%), the sensitivity ratio was below 10 .

Combining data for all neonicotinoids (acetamiprid, imidacloprid, thiacloprid, and thiamethoxam) and for both acute contact and acute oral toxicity, nine studies covering nine bee species (plus A. mellifera) were found. These studies showed a median sensitivity ratio of 1.045 which is the highest median value of all the analyzed pesticide chemical families. The most relatively toxic neonicotinoids to other bees were the cyano-substituted neonicotinoids acetamiprid and thiacloprid as these pesticides exhibit lower toxicity to honeybees than the nitro-substituted neonicotinoids imidacloprid and thiamethoxam.

In 2013, the EU installed a partial ban on imidacloprid, clothianidin, thiamethoxam, and fipronil while allowing continued use of acetamiprid and thiacloprid. Searching for studies about effects of the banned compounds including both acute contact and acute oral toxicity, 12 studies covering 10 bee species (plus A. mellifera) were found. These studies showed a median sensitivity ratio of 0.957 which is close to the calculated sensitivity ratio for all neonicotinoids. Studies on Bombus terrestris consistently report a lower sensitivity ratio between 0.005 and 0.914 , median 0.264. Bombus terrestris is widespread in Europe and is the most commonly used non-Apis model system for assessing the effects of neonicotinoids on wild bees. Differences in bee body weight have been proposed to explain these differences, with sensitivity to pesticides inversely correlated with body size (Devillers et al. 2003). However, this has not been consistently demonstrated and other mechanisms have been suggested such as species-level adaptation to feeding on alkaloid-rich nectar (Cresswell et al. 2012). With the limited data available, Arena and Sgolastra (2014) could not comment on the strength of these claims and further experiments are needed.

Spurgeon et al. (2016) calculated various toxicity measures of clothianidin on honeybees, the bumblebee species $B$. terrestris and the solitary bee species Osmia bicornis. Acute oral toxicity 48, 96, and $240 \mathrm{~h}$ LD50s for honeybees were 14.6, 15.4, and $11.7 \mathrm{ng} /$ bee, respectively. For $B$. terrestris, the corresponding values were $26.6,35$, and $57.4 \mathrm{ng} / \mathrm{bee}$, respectively. For O. bicornis, the corresponding values were 8.4, 12.4, and $28.0 \mathrm{ng} / \mathrm{bee}$, respectively. These findings are generally in line with the findings of Arena and Sgolastra (2014), with $B$. terrestris less sensitive than A. mellifera at all time points and $O$. bicornis less sensitive at $240 \mathrm{~h}$.

Sgolastra et al. (2017) calculated relative sensitivity to clothianidin to these same three species over a range of time periods from 24 to $96 \mathrm{~h}$. The highest LD50 values were obtained after $24 \mathrm{~h}$ for A. mellifera and B. terrestris and after $72 \mathrm{~h}$ for $O$. bicornis. At these time points, $O$. bicornis was the most sensitive of the three species, with LD50 measurements of $1.17 \mathrm{ng} /$ bee and $9.47 \mathrm{ng} / \mathrm{g}$, compared to $1.68 \mathrm{ng} /$ bee and $19.08 \mathrm{ng} / \mathrm{g}$ for A. mellifera and $3.12 \mathrm{ng} /$ bee and $11.90 \mathrm{ng} / \mathrm{g}$ for $B$. terrestris. These results are in line with the values calculated by Spurgeon et al. (except for the $240 \mathrm{~h}$ values), with decreasing sensitivity in the order of $O$. bicornis $>A$. mellifera $>B$. terrestris. Together, these studies support the position that small bodied species show greater sensitivity to neonicotinoids.

Czerwinski and Sadd (2017) found detrimental interactions of imidacloprid exposure and bumblebee immunity. Adult workers of Bombus impatiens received 6-day pulses of either low $(0.7 \mathrm{ppb})$ or high $(7 \mathrm{ppb})$ field-realistic doses of imidacloprid. This was followed by an assay to test immunity and survival following a nonpathogenic immune challenge. The results showed that high-dose imidacloprid exposure reduces constitutive levels of phenoloxidase, an enzyme involved in melanization. Hemolymph antimicrobial activity initially increases in all groups following an immune challenge, but while heightened activity is maintained in unexposed and low imidacloprid dose groups, it is not maintained in the high exposure dose bees, although exposure had ceased 6 days prior. When imidacloprid exposure was followed by an 
immune challenge, a significantly decreased in survival probability was observed relative to control bees and those only immune challenged or imidacloprid exposed. A temporal lag for immune modulation and combinatorial effects on survival suggest that resource-based trade-offs may, in part, contribute to the detrimental interactions. These findings are particularly relevant because such impairment of the immune system at field-realistic exposure to neonicotinoids is likely to have health consequences for pollinators that in real life often face multiple stresses of sublethal neonicotinoid exposure and pathogens. It also raises a broader question whether impairment of the immune system by neonicotinoids is limited to insects or whether it also affects other non-target species that are exposed.

Baron et al. (2017) provides the first evidence of impacts of thiamethoxam on the ovary development and feeding of spring-caught wild queens of four bumblebee species: Bombus terrestris, B. lucorum, B. pratorum, and B. pascuorum. In a laboratory experiment testing the impacts of field relevant doses (1.87-5.32 ppb) of thimethoxam, they found that 2 weeks of exposure to the higher concentration of thiamethoxam caused a reduction in feeding in two out of four species, suggesting species-specific anti-feedant, repellency, or toxicity effects. The higher level of thiamethoxam exposure resulted in a reduction in the average length of terminal oocytes in queens of all four species. Further, the authors highlight that the discovery of species-specific effects on feeding has significant implications for current practices and policy for pesticide risk assessment and use.

Stingless bees (Apidae: Meliponini) are pan-tropical eusocial bees that are important pollinators for wild plants and crops (Barbosa et al. 2015). Little research on exposure and toxicology has been done for this diverse and abundant clade that is under pressure of habitat loss and intensification of agriculture. Lima et al. (2016) provide an overview of general agrochemical stressors on stingless bees.

Of the available studies involving neonicotinoids or fipronil, several indicate that the species studied are more sensitive to certain pesticides than A. mellifera and that results and testing procedures cannot be generalized. Topical LD50 (2.41 ng/bee $24 \mathrm{~h}, 1.29 \mathrm{ng} / \mathrm{bee} 48 \mathrm{~h}$ ) and oral LC50 (2.01 ng/ $\mu \mathrm{L} 24 \mathrm{~h}, 0.81 \mathrm{ng} / \mu \mathrm{L} 48 \mathrm{~h}$ ) values for Melipona scutellaris for imidacloprid were lower than those of A. mellifera (Costa et al. 2015). Lourenco et al. (2012) found that for fipronil topical LD50 (0.6 ng/bee $48 \mathrm{~h})$ and oral LC50 $(0.011 \mathrm{ng} / \mu \mathrm{L}$ $48 \mathrm{~h}$ ) were also lower than that of the honeybee. Rosa et al. (2016) found decreased larval survival feeding field-realistic doses (0.004 to $4.375 \mathrm{ng}$ /larva) of thiamethoxam to Scaptotrigona depilis larvae in vitro. Low doses of fipronil $(0.27 \mathrm{ng} /$ bee topical, $0.24 \mathrm{ng} /$ bee oral) affected brain morphology by apoptosis or necrosis of mushroom bodies of Scaptotrigona postica (Jacob et al. 2015), comparable to its effect on mushroom bodies of A. mellifera (Roat et al. 2014).
Tomé et al. (2012) also found effects of imidacloprid on mushroom bodies and behavior in Melipona quadrafasciata and showed that imidacloprid impaired respiration and flight activity in this species. Valdovinos-Núñez et al. (2009) compared the toxicity of different pesticides for three stingless bee species (Melipona beechei, Trigona nigra, Nannotrigona perilampoides) and found neonicotinoids (imidacloprid, thiamethoxam, and thiacloprid) to be more toxic than permethrin and diazinon.

\section{Synergistic effects of additional pesticides with neonicotinoids}

Sgolastra et al. (2017) investigated the interaction between clothianidin and the ergosterol biosynthesis inhibiting (EBI) fungicide propiconazole in three bee species, A. mellifera, $B$. terrestris, and $O$. bicornis. Each species was administered a LD10 dose of clothianidin $(0.86,1.87$, and $0.66 \mathrm{ng} / \mathrm{bee}$, respectively, a non-lethal dose of propiconazole $(7 \mu \mathrm{g} / \mathrm{bee})$ and a combination of the two treatments. Bees were then observed for a 96-h period and mortality quantified. Some synergistic effects were recorded. In A. mellifera, mortality was significantly higher for the combined dose in the first two time periods (4 and $24 \mathrm{~h}$ ). Mortality in B. terrestris for the combined dose was only significantly higher in the first time period, after $4 \mathrm{~h}$. However, in O. bicornis, exposure to the combination of clothianidin and propiconazole resulted in significantly higher mortality at all time points.

Spurgeon et al. (2016) conducted similar experiments to Sgolastra et al., investigating the effect of a combination of clothianidin and propiconazole on A. mellifera, B. terrestris, and $O$. bicornis. In order to calculate an LD50, clothianidin concentrations were varied and propiconazole concentrations were held at zero, a low dose and a high dose. The low dose was taken from the EFSA Panel on Plant Protection Products (EFSA 2012) reported environmental concentrations, and the high dose was 10 times the low dose to represent a plausible worst-case scenario. Mortality was quantified over 48, 96, and $240 \mathrm{~h}$. For A. mellifera, clothianidin LD50s with and without propiconazole were always within a factor of 2 , with no clear negative trend at higher propiconazole concentrations. For $B$. terrestris, clothianidin LD50s with propiconazole were between 1.5- to 2-fold lower. For $O$. bicornis, clothianidin LD50s with propiconazole was up to 2-fold lower with a negative trend as propiconazole concentrations increased. Spurgeon et al. concluded that the clothianidin and propiconazole combination had no to slight synergy for A. mellifera and slight to moderate synergy for $B$. terrestris and O. bicornis.

In an additional trial, Thompson et al. (2014) demonstrated that the dose of fungicide applied is a key factor determining neonicotinoid toxicity using propiconazole and thiamethoxam mixtures. The authors argue that their low rates of significant synergies between neonicotinoids and fungicides was because of their lower, more field-realistic fungicide doses of 161- 
$447 \mathrm{ng} /$ bee compared to $10,000 \mathrm{ng} /$ bee used by Iwasa et al. (2004), an early study demonstrating this interaction. The values of 161-447 ng/bee were calculated as realistic worstcase exposures based on approved application rates for UK crops. In a study of pesticide residues in pollen collected by B. terrestris in the UK, David et al. (2016) found concentrations of DMI fungicides up to $84 \mathrm{ppb}$, while Sanchez-Bayo and Goka (2014) report residues of propiconazole in honeybee-collected pollen up to $361 \mathrm{ppb}$. At the latter concentration a bee would need to consume approximately $28 \mathrm{~g}$ of pollen to receive the dose used in the Iwasa et al. (2004) study, which is not realistic. However, data are lacking demonstrating true field-realistic exposure rates to fungicides for free flying bees.

Overall, these studies support the position that neonicotinoids can act synergistically with fungicides, increasing their lethality to bees. However, the dose rate of both neonicotinoids and fungicides, time of exposure, neonicotinoid and fungicide chemical class, and length of time after exposure are all important explanatory factors affecting this relationship. The concentration of fungicide used in laboratory studies appears to be the most important factor determining synergistic lethality. Fungicides are regularly sprayed during the period when flowering crops are in bloom under the assumption that these compounds are safe for bees. Further work is needed in this area to establish realistic levels of chronic exposure to fungicides for free flying bees in order to assess the likely impact of neonicotinoid/fungicide synergies on bee populations.

Studies to date have only examined pairwise interactions between pesticides. It is clear that bees and other non-target organisms inhabiting farmland are routinely exposed to far more complex cocktails of pesticides than any experimental protocol has yet attempted to examine (e.g., David et al. 2016; Giorio et al. 2017 this special issue). A major challenge for scientists and regulators is to attempt to understand how chronic exposure to complex mixtures of neonicotinoids, fipronil, and other chemicals affects wildlife, this with or without other natural stressors (infectious agents, parasitism) and adverse abiotic conditions.

\section{Population-level effects of neonicotinoids on wild bees}

Nothing was known about the population-level effects of neonicotinoids on wild bees in 2014. As a managed domesticated species, population trend data are available for honeybees, but not for wild bees. One study has attempted to investigate the impact of neonicotinoids on wild bee population trends. Woodcock et al. (2016) used an incidence dataset of wild bee presence in $10 \times 10 \mathrm{~km}$ grid squares across the UK. The dataset is comprised of bee sightings by amateur and professional entomologists and is probably the most complete national bee distribution database currently available. Sixtytwo wild bee species were selected and their geographic distance and persistence over an 18-year period between 1994 and 2011 was calculated. Neonicotinoid seed-treated oilseed rape was first used in the UK in 2002, and so the authors calculated spatially and temporally explicit information describing the cover of oilseed rape and the area of this crop treated with neonicotinoids. The 62 species were split into two groups-species that foraged on oilseed rape $(n=34)$ and species that did not $(n=28)$. Species persistence across this time period was then compared with expected neonicotinoid exposure. Over the 18-year period, wild bee species persistence was significantly negatively correlated with neonicotinoid exposure for both the foraging and nonforaging group, with the effect size three times larger for the oilseed rape foraging group. Overall, the study suggests that bee species were more likely to disappear from areas with a high exposure to neonicotinoids as measured by the amounts applied as seed dressings to oilseed rape and that this trend was more pronounced for species known to forage on oilseed rape. While more work is needed, this is a major correlational study that suggests a link between levels of neonicotinoid exposure and bee community persistence at a national scale.

Rundlöf et al. (2015) conducted an extensive field trial of the effects of clothianidin-treated oilseed rape on wild bees. Sixteen oilseed rape fields separated by at least $4 \mathrm{~km}$ were selected across southern Sweden and were paired on the basis of similar landscape composition. In each pair, one of the fields was randomly selected to be sown with oilseed rape treated with $10 \mathrm{~g}$ clothianidin $/ \mathrm{kg}$ of seed and the other field was sown without a neonicotinoid seed treatment. Twentyseven cocoons of the solitary bee $O$. bicornis ( 15 male, 12 female) were placed out alongside each field a week before the oilseed rape began to flower, and six colonies of $B$. terrestris were placed alongside each field on the day the oilseed rape began to flower. The $O$. bicornis placed adjacent to treated oilseed rape showed no nesting behavior and did not initiate brood cell construction. O. bicornis adjacent to untreated fields showed nesting behavior in six of the eight fields studied. Bumblebees placed next to treated oilseed rape showed reduced colony growth and reproductive output. Bumblebee colonies were collected and frozen when new queens began to emerge, with this happening between the 7 th of July and 5th of August depending on each colony. The number of queen and worker/male cocoons present was counted. At the point of freezing, colonies placed next to treated oilseed rape fields had significantly fewer queen and worker/male cocoons present.

Sterk et al. (2016) performed a similar field experiment to Rundlöf et al. Two areas of $65 \mathrm{~km}^{2}$ in northern Germany were selected in which the only flowering crops comprised of winter-sown oilseed rape. In one area, the oilseed rape was treated with the same seed coating used by Rundlöf et al. of $10 \mathrm{~g}$ clothianidin $/ \mathrm{kg}$ seed. The other area was an untreated control. In each area, ten $B$. terrestris colonies were placed 
at each of six localities. Colonies were left adjacent to oilseed rape between April and June, covering its main flowering period. After this the colonies were moved to a nature reserve. No differences were found in colony weight growth, number of workers produced, or reproductive output as measured by the production of new queens.

It is interesting to note that the latter field studies, using the same neonicotinoid seed dressing, found markedly different results. The major difference is that while Rundlöf et al. used spring-sown oilseed rape, Sterk et al. used winter-sown oilseed rape. The length of time between sowing and peak flowering is much greater for winter-sown oilseed rape (mid-August to May) than for spring-sown oilseed rape (April/May to mid-June). As such, there is more time for neonicotinoids to degrade, and for them to leach into soil and water for winter-sown oilseed rape, reducing the amount of active ingredient available to be taken up by the crop. Indeed, the mean loads of clothianidin in the Rundlöf et al. study were $13.9 \mathrm{ppb}$ in honeybee pollen, and 5.4 (bumblebee) and 10.3 (honeybee) ppb in nectars, whereas those in the German study were $0.50-0.97 \mathrm{ppb}$ in honeybee pollen, 0.88 in bumblebee pollen, and $0.68-0.77 \mathrm{ppb}$ in honeybee nectar (Rolke et al. 2016). Such a difference as revealed by exposure to the insecticide for honeybees (14-27 times less for pollen and 13-15 times less for nectar in the latter study) could explain the difference in reported colony growth and number of gynes and drones produced, since concentrations of clothianidin in the food of bees below $1 \mathrm{ppb}$ are not supposed to produce any effect that were measured (Piiroinen et al. 2016). An additional difference is that in the Sterk et al. (2016) study, colonies were moved to a nature reserve consisting of forests, lakes, and heathland after the flowering period of oilseed rape ended. The quality of available foraging area at this nature reserve is likely to have been of both a higher quality and quantity than what was available in a conventional agricultural landscape and is not typical of the experience of a bumblebee colony located in such a landscape that will have to continue foraging there after crops such as oilseed rape cease flowering. In addition, a major problem with the experimental design of Sterk et al. is that only one treated and one control area were used, so there is no true sitelevel replication, as opposed to Rundlöf et al. who used eight treated and eight control fields. All these differences in experimental design highlight the difficulty of developing a single experimental design that may answer risk assessment questions for every potentially affected species. It also highlights the importance of evaluating the experimental design in terms of resulting data quality when considering the differences in results between Rundlöf et al. (2015) and Sterk et al. (2016).

Only one study is available that looked at the impact of neonicotinoids on the reproductive success of a solitary bee in controlled conditions. Sandrock et al. (2014a) established laboratory populations of $O$. bicornis, a solitary stem nesting bee. Bees were fed on sugar solution treated with $2.87 \mathrm{ppb}$ thiamethoxam and $0.45 \mathrm{ppb}$ clothianidin along with untreated pollen. There was no impact of neonicotinoids on adult female longevity or body weight. However, treated bees completed $22 \%$ fewer nests over the course of the experiment. Nests completed by treated bees contained $43.7 \%$ fewer total cells and relative offspring mortality was significantly higher, with mortality rates of 15 and $8.5 \%$ in the treated and untreated groups, respectively. Overall, chronic neonicotinoid exposure resulted in a significant reduction in offspring emergence per nest, with treated bees producing $47.7 \%$ fewer offspring. These results suggest that exposure to these low-level, fieldrealistic doses of neonicotinoids $(<3.5 \mathrm{ppb})$ did not increase adult mortality but did have sublethal impacts on their ability to successfully build nests and provision offspring.

\section{Colony-level impact on bumblebees}

Laycock et al. (2014) fed microcolonies of four B. terrestris workers thiamethoxam-treated sugar solution at a range of concentrations up to $98 \mathrm{ppb}$. Pollen was not treated with thiamethoxam. Sugar solution consumption was significantly reduced at the 39 and $98 \mathrm{ppb}$ treatments. Worker mortality was only increased at the highest dose of $98 \mathrm{ppb}$. Worker oviposition failure was only significantly higher at the 39 and 98 ppb treatments, with no significant differences seen between the lower concentration treatments between 0 and $16 \mathrm{ppb}$.

Scholer and Krischik (2014) exposed greenhouse queenright colonies of Bombus impatiens to imidaclopridand clothianidin-treated sugar syrup at concentrations of 0 , $10,20,50$, and $100 \mathrm{ppb}$ for 11 weeks. Queen mortality was significantly increased at 6 weeks for the 50 and $100 \mathrm{ppb}$ treatments and at 11 weeks for the $20 \mathrm{ppb}$ treatment for both clothianidin and imidacloprid. Surprisingly, no significant impact was found on numbers of workers or new queens produced, though this was in part because very low numbers of new queens were produced across all treatments (average of four per colony). Colonies in treatments above $10 \mathrm{ppb}$ imidacloprid and $20 \mathrm{ppb}$ of clothianidin gained significantly less weight over the course of the study.

Cutler and Scott-Dupree (2014) placed B. impatiens colonies adjacent to maize fields during pollen shed in Ontario, Canada. Four neonicotinoid-treated conventional and four untreated organic fields were used. Colonies were placed adjacent to each field on the first day of major pollen shed. Colonies were left for 5-6 days and then transported to an area of semi-natural habitat for 30-35 days, after which they were frozen. Colonies placed next to treated maize produced significantly fewer workers than those placed next to organic farms. All other metrics (colony weight, honey and pollen pots, brood cells, worker weight, male and queen numbers and weights) were not significantly different. However, 
bumblebees collected less than $1 \%$ of their pollen from maize and neonicotinoid residues in collected pollen were very low (mean of $0.4 \mathrm{ppb}$ ) for bees foraging adjacent to treated fields and always below the LOD $(0.1 \mathrm{ppb})$ for bees adjacent to organic fields. Given that it is well-known that bumblebees collect very low volumes of maize pollen, the relevance of this study is unclear.

FERA (2013) also conducted a field trial with B. terrestris colonies placed out adjacent to oilseed rape treated with either clothianidin, imidacloprid or an untreated control. Colonies were allowed to forage freely for 6-7 weeks while the oilseed rape flowered and then were moved to a non-agricultural area to continue developing. The initial aim was to measure colony growth and development across these three treatments and compare this with neonicotinoid concentrations collected from food stores within the nests, but the study was criticized for a number of methodological problems such as variable placement date and initial colony size, lack of site-level replication, and contamination of control colonies with neonicotinoid residues during the experiment. The study was ultimately not published in a peer reviewed journal but it came to the conclusion that there was no clear relationship between bumblebee colony success and neonicotinoid concentrations. Goulson (2015) reanalyzed the FERA data using linear models and retaining two colonies excluded in the original study as outliers, but which do not meet the statistical definition of this term. This reanalysis showed that the concentration of clothianidin in nectar (range 0 to $0.28 \mathrm{ppb}$ ) and the concentration of thiamethoxam in pollen (range 0 to $1.6 \mathrm{ppb}$ ) significantly and negatively predicted both colony weight gain and production of new queens. Very similar findings emerged from the recent large field trial of Woodcock et al. (2017) who exposed B. terrestris colonies to oilseed rape fields treated with either clothianidin, thiamethoxam or controls at field sites in the UK, Germany, and Hungary. Total neonicotinoid levels in the range 0 to 8 ppb in colony food stores negatively predicted colony reproductive output.

Most research on neonicotinoids and bees has focused on the three compounds subject to the EU moratorium. Thiacloprid is considered to be less dangerous to bees, since it has a much higher acute LD50. As a result, it is sometimes sprayed on crops or trees at or near flowering, potentially exposing bees to much higher doses than they would obtain from neonicotinoids applied as seed dressings. Ellis et al. (2017) placed B. terrestris colonies adjacent to raspberry crops that had been sprayed with thiacloprid following normal farming practice, and compared these to control nests placed next to unsprayed raspberry crops. Exposed colonies were more likely to die, grew more slowly, and produced $46 \%$ fewer reproductive than control colonies. This study strongly argues that thiacloprid should not be regarded as safe to bees.

Studies produced since 2014 have advanced our knowledge in several key areas. Laboratory studies have continued to demonstrate negative effects of neonicotinoids on bumblebee reproductive output at generally high concentrations, with the lowest sublethal effects on reproductive output detected at $10 \mathrm{ppb}$. Field studies using bumblebees demonstrate that exposure to neonicotinoid-treated flowering crops can have significant impacts on colony growth and reproductive output depending on the levels exposed to, with crop flowering date relative to sowing and availability of uncontaminated forage plants likely to explain variation in the detected residues among the available studies. Our understanding of the impact on solitary bees is much improved with the findings of Sandrock et al. (2014a) suggesting substantial impacts on solitary bee reproductive output at field-realistic concentrations of $3.5 \mathrm{ppb}$. Field studies demonstrating this under real-world conditions are limited with the work of Rundlöf et al. (2015) and Woodcock et al. (2017), demonstrating no nest-building activity at the neonicotinoid treatment sites.

Feltham et al. (2014) exposed B. terrestris colonies to sugar solution treated with $0.7 \mathrm{ppb}$ and pollen treated with $6 \mathrm{ppb}$ of imidacloprid for 2 weeks. Colonies were then placed out in an urban area in Scotland. The foraging workers from each nest were then monitored for a further 4 weeks. There was no difference in the length of time spent collecting nectar or the volume of nectar collected between workers from treated and control colonies. However, treated workers collected significantly less pollen, bringing back $31 \%$ less pollen per time unit to their colonies. Treated workers also collected pollen less frequently, with $41 \%$ of foraging bouts collecting pollen versus $65 \%$ for control workers; a decline of $24 \%$.

Gill and Raine (2014) performed an experiment where $B$. terrestris colonies were exposed to sugar solution treated with $10 \mathrm{ppb}$ of imidacloprid while also having access to forage freely outside. Colonies and individual worker bumblebees were studied over a 4-week period. In common with their previous findings (Gill et al. 2012), imidacloprid-treated workers initiated significantly more foraging trips across all 4 weeks of the experiment. The authors note that this is likely driven by an acute individual-level response in the first weeks (neonicotinoids acting as a neural partial agonist, increasing desire to forage) and by a chronic colony-level response in the latter part of the experiment, with treated colonies allocating a higher proportion of workers to pollen collection. Pollen foraging efficiency of treated workers decreased as the experiment progressed with the smallest collected pollen loads recorded in week four, suggesting a chronic effect of imidacloprid on pollen foraging ability. It is not clear whether this is as a result of individual performance deteriorating or new emerging workers having been exposed for a greater period of time.

Stanley et al. (2015a) exposed B. terrestris colonies to 2.4 or $10 \mathrm{ppb}$ thiamethoxam-treated sugar solution for 13 days. Colonies were then moved to pollinator exclusion cages where they were allowed to forage freely on two varieties of apple 
blossom. Bees from colonies exposed to $10 \mathrm{ppb}$ spent longer foraging, visited fewer flowers and brought back pollen on a lower proportion of foraging trips compared to bees from control colonies. Stanley and Raine (2016) also exposed B. terrestris colonies to $10 \mathrm{ppb}$ thiamethoxam sugar solution for a 9- to 10-day period. At this point, colonies were moved to a flight arena provisioned with two common bird's-foot trefoil (Lotus corniculatus) and one white clover (Trifolium repens) plants. Worker bees were individually released and their interaction with the flowers was recorded. Significantly more treated workers displayed pollen foraging behavior compared to control workers. However, control workers learned to handle flowers efficiently after fewer learning visits.

Arce et al. (2016) placed B. terrestris nests out in an area of parkland for a 5-week period while also supplying them with sugar solution treated with $5 \mathrm{ppb}$ of clothianidin. The volume of sugar solution provided was estimated to be half that which colonies typically consume over the course of the experiment. No pollen was provided, so workers had to forage for this and to make up the shortfall in nectar resources. In contrast to the previous papers, only subtle changes to patterns of foraging activity and pollen collection were detected. There was no clear difference in colony weight gain between treatments or number of brood individuals. However, by the end of the experiment, treated colonies contained fewer workers, drones, and gynes when compared with control colonies.

Switzer and Combes (2016) studied the impact of acute imidacloprid ingestion on sonicating behavior of B. impatiens. Sonicating is a behavior whereby a bumblebee lands on a flower and vibrates loudly to shake pollen loose from anthers. Bumblebee workers were fed a dose of 0 , $0.0515,0.515$, or $5.15 \mathrm{ng}$ of imidacloprid in $10 \mu \mathrm{L}$ of sugar solution. These are equivalent to concentrations of $0,5.15$, 51.5 , and $515 \mu \mathrm{g} / \mathrm{L}(\sim \mathrm{ppb})$, with the highest volume consumed equivalent to $139 \%$ of the honeybee acute LD50, a moderate proxy for bumblebees, as bumblebees are generally less sensitive than honeybees. Bees were then allowed to forage from tomato (Solanum lysopersicum) plants and sonicating behavior was observed. At the lowest dose of $5.15 \mu \mathrm{g} / \mathrm{L}$ of imidacloprid, no impact was found on wingbeat frequency, sonication frequency or sonication length. No analysis could be made for higher doses, as bees in these treatments rarely resumed foraging behavior after ingesting imidacloprid. Given the neonicotinoid concentrations used in this study and sample size problems, it is difficult to draw many conclusions other than that levels of exposure above $50 \mu \mathrm{g} / \mathrm{L}$ impair bumblebee pollen foraging behavior.

Overall, these studies suggest that exposure to neonicotinoids in nectar at concentrations between $0.7-10 \mathrm{ppb}$ can have sublethal effects on the ability of bumblebees to collect pollen at both the individual and colony level. This shortfall in pollen and subsequent resource stress is a plausible mechanism to explain diminished colony growth and production of sexuals in the absence of increased direct worker mortality. Given that concentrations as high as $10 \mathrm{ppb}$ are at, but within, the upper limit of what bumblebees are likely to experience in the field, it is likely that wild bumblebees exposed to neonicotinoids in contemporary agricultural environments suffer from a reduced ability to collect pollen, with a subsequent impact on their reproductive output.

\section{Effects of neonicotinoids and fipronil on other invertebrates}

\section{Effects on target pests}

Fipronil induced Drosophila S2 cell apoptosis in vitro experiments (Zhang et al. 2015). This side effect occurs through caspase-dependent mitochondrial pathways and appears to coincide with a decrease in the mitochondrial membrane potential and an increase in reactive oxygen species. Other authors have shown significant increases in tumor frequencies on wing cells of Drosophila melanogaster, suggesting that this insecticide is mutagenic and carcinogenic in somatic cells of this fruit fly (de Morais et al. 2016a).

Wild strains of Drosophila melanogaster are rather resistant to imidacloprid with acute LD50s $>1304 \mu \mathrm{M}$ (>333.8 ppm) for both females and males (Charpentier et al. 2014). However, the same study has shown lethal effects of imidacloprid on chronically exposed $D$. melanogaster during 8 days: $27 \%$ of females died at $3.91 \mathrm{nM}$ and $28 \%$ of males at $39.1 \mathrm{nM}$. The latter concentrations were several orders of magnitude below chronic LC50s of 18 and $45 \mu \mathrm{M}$ for females and males, respectively. Moreover significant sublethal effects have been demonstrated on mating and fecundity at very low exposure concentrations (mating: both genders exposed at $0.391 \mathrm{nM}$; fecundity: females exposed at $3.91 \mathrm{nM}$ ), i.e., in the $0.1-1 \mathrm{ppb}$ range of concentration.

Stimulated reproduction of the green peach aphid (Myzus persicae) by exposure to sublethal doses of imidacloprid had been reported previously (Yu et al. 2010). This hermetic effect undermines the effectiveness of the insecticide in controlling the target pest, and it seems to be accompanied by a complex pattern of up- and downregulation of genes during exposure. A recent study suggests that such an effect is passed on to the second generation, although there is some adaptability to low doses of the insecticide (Ayyanath et al. 2014). In another study, the soybean aphid (Aphis glycines) showed significantly higher reproduction rate when treated at sublethal doses of imidacloprid $(0.05 \mathrm{mg} / \mathrm{L})$ than in non-treated controls $(\mathrm{Qu}$ et al. 2015). However, other sublethal doses (0.1 and $0.2 \mathrm{mg} / \mathrm{L}$ ) caused slower juvenile development, shorter reproductive periods, and reduced adult lifespan and fecundity, indicating that the threshold for hormetic responses is rather low. Stimulatory reproductive effects have also been observed with exposure of males of the Neotropical brown stink 
(Euschistus heros) to imidacloprid, but not with exposure of the females (Haddi et al. 2016).

A commercial mixture of a pyrethroid (b-cyfluthrin) and a neonicotinoid (imidacloprid) produced behavioral sublethal effects on bed bugs (Cimex lectularius) such as reduced locomotion, reduced feeding, and difficulties in host-finding that resulted in good control of the bugs by preventing their dispersal (Crawley et al. 2016). However, the bugs have already developed resistance to at least four neonicotinoids, acetamiprid, dinotefuran, imidacloprid, and thiamethoxam in several North American cities (Romero and Anderson 2016).

Efficacy of three neonicotinoids (acetamiprid, imidacloprid, and thiamethoxam) on controlling sand termites (Psammotermes hypostoma; Isoptera) has been demonstrated by Ahmed et al. (2015), the effect of all three lasting up to 60 days. Dembilio et al. (2015) also studied the lasting effect of imidacloprid applied by crown spray or stipe injection on palms to control the red palm weevil (Rhynchophorus ferrugineus; Coleoptera). Complete control (100\%) was achieved after 45 days of stipe injections at 4-10 mL, corresponding to $2 \mathrm{~g}$ a.i./plant. Spray application used larger volumes that stipe injections, were less efficient and resulted in larger losses of the insecticide by washoff from the palm fronds into the surrounding environment. In Brazil, plantations of eucalypts were treated by immersing the seedlings in a solution containing fipronil $(0.4 \%)$ to prevent attack by termites, as it has been shown to be protective for 56 days (dos Santos et al. 2016). A comparison of termites' diversity between treated and untreated plots did not show significant differences, although treated plots tended to have fewer species (Silva et al. 2016). The authors indicated that "any effect [of fipronil] is masked by the effects of the plantation itself", since both treated and untreated plantations of this tree had significantly less termite diversity than native savanna forests or regeneration forests.

Baits laced with fipronil are being used to control the expansion of the invasive Argentine ant (Linepithema humile) in Japan. Although the main super colonies of this species appear to be very susceptible to this insecticide, the treatment was also damaging for all other local ant populations. Fipronil bait treatments, therefore could lead to significant impacts on the local arthropod biodiversity (Hayasaka et al. 2015). Hydrogels containing $750 \mathrm{ppb}$ thiamethoxam killed $50 \%$ of the forager ants in 3 days, while baiting with 1500 and $750 \mathrm{ppb}$ provided $100 \%$ mortality of workers and queens within 8 days in the laboratory trials. These concentrations were lower than the ones required to control ants in highly infected areas as reported by Rust et al. (2015). At sublethal levels, imidacloprid may have different effects in red imported fire ants (Solenopis invicta) depending on the concentrations used; for example, concentrations of this insecticide in sugar water at $0.01 \mathrm{ng} / \mathrm{L}$ are attractive to the ants and increase their digging activity, whereas concentrations higher than $0.25 \mathrm{ng} / \mathrm{L}$ suppress their water consumption, digging and foraging behaviors (Wang et al. 2015e). At the latter concentration, newly mated queens reduced their brood tending ability, while the time to larval emergence was delayed significantly and no pupae or adult workers were produced (Wang et al. 2015d).

\section{Effects on butterflies}

Mulé et al. (2017) presented a systematic review of the effects of chemical insecticides on four common butterfly families: Lycaenidae, Nymphalidae, Hesperiidae, and Papilionidae. Only one study in their sample (Krischik et al., 2015) looked at the effects of a neonicotinoid (imidacloprid) on butterflies (Danaus plexippus and Vanessa cardui) illustrating a huge data gap. The systematic review concludes that the use of all the insecticides studied (dichlorvos, imidacloprid, malathion, naled, permethrin, and resmethrin) cause negative effects on the most common butterfly families, such as reduced survival rate, feeding interruption, and alteration of oviposition behavior.

\section{Effects on natural enemies of pests}

Compared to the research on pollinators, few studies on the toxic effects and population impacts of neonicotinoids and fipronil on other arthropods have been published in the past 2 years. Research in this case has been limited to beneficial insects used in biological control or integrated management programs (IPM), building upon the already known negative effects of these chemicals (Pisa et al. 2015). Recent studies have centered on the newly developed compounds (Giorio et al. 2017, this special issue), while the previous literature focused mainly on imidacloprid.

\section{Predators}

The efficacy of neonicotinoids and fipronil for pest control and the negative effects they inflict on beneficial predators are directly correlated. Both effects depend on the toxicity to pest and to their predators and on the residue level of exposure in plants (which have been treated or not). It has been shown that uptake of several neonicotinoids after seed treatment in cotton crops differed according to their water solubility, with nitenpyram, dinotefuran, and thiamethoxam showing the highest residues in plant tissues and lowest in the soil (Zhang et al. 2016b). Consequently, these three compounds were more effective against the cotton aphid Aphis gossypii than the other four neonicotinoids. However, residues in soil of all seven neonicotinoids reduced the soil fauna significantly $(p<0.05)$, in particular the larvae of hoverflies (Diptera: Syrphidae). Foliar sprays of all compounds produced similar effects to their seed treatments but the impacts on soil larvae were not significant (Zhang et al. 2016b). The authors 
acknowledge the efficient aphid control by the three neonicotinoids above while warning of the long-term negative effects derived of suppressing beneficial insect's larvae and also species that feed on extra floral nectar, such as some ladybugs and polyphagous parasitoids. Another study suggests that not only are there no significant negative impacts of seed-treated imidacloprid and clothianidin on the beneficial insects of winter wheat crops (i.e., ladybirds, hoverflies, or parasitoids) but both systemic treatments increased the density of spiders, despite residues in plants being present for 200 days (Zhang et al. 2016a). The latter field study was conducted throughout the winter season in northern China, with planting in October and harvest in June, when the soil larvae were dormant or going through diapause - hence the lack of negative effects, contrasting with those observed in summer crops and the high toxicity of neonicotinoids to coccinelid larvae (Lucas et al. 2004).

The variability of impacts on natural enemies of crop pests depends on the intrinsic toxicity of the active ingredients and co-formulants, and the rate of application to the crop. Thus, cotton plants grown from seeds treated with thiamethoxam at the recommended doses $(3 \mathrm{~g} / \mathrm{kg})$ reduced the populations of natural enemies of the cotton leafhopper by about $35 \%$, in particular those of Chrysoperla sp., Orius sp., and spiders, whereas cotton plants grown from seeds treated with imidacloprid $(5 \mathrm{~g} / \mathrm{kg})$ did not lead to significant reductions (i.e., $<10 \%$ ) of the same species (Saeed et al. 2016). Trials in South Dakota demonstrated the effectiveness of seed treatments of thiamethoxam and imidacloprid, whether alone or in combination with foliar sprays of beta-cyflutrin, for controlling aphids. However, thrips (Thysanoptera) increased in number in one of the locations regardless of the treatment used, and this effect was significantly correlated with their major predators, as several taxa of natural enemies declined (Regan et al. 2017).

Polyphagous ladybird beetles like Coleomegilla maculata and Hippodamia convergens feed occasionally on the nectar of sunflowers. Three routes of exposure of thiamethoxam for the ladybird Serangium japonicum that controls the whitefly Bemisia tabaci were tested. Predation of $S$. japonicum was most reduced under systemic exposure and least by contact with residues on the surface, following the same pattern as the lethal toxicity (Yao et al. 2015). In a similar way, oral exposure of the ladybird Eriopis connexa to acetamiprid at maximum recommended rates $(200 \mathrm{mg} / \mathrm{L})$ in water resulted in $90 \%$ mortality of adults after 15 days, while the survival of pupae treated in Petri dishes at half that rate $(100 \mathrm{mg} / \mathrm{L})$ was reduced only up to $15 \%$. However, $83 \%$ of the emerging adults had a number of malformations (Fogel et al. 2016). Residues of imidacloprid and thiamethoxam on filter paper appear to repel the predatory beetles Cycloneda sanguinea and Chauliognathus flavipes as well as the predatory bug Orius insidiosus (Fernandes et al. 2016), but tomato leaves and plants treated with foliar sprays of imidacloprid at $100 \mathrm{ppm}$ had residual activity and caused $62 \%$ mortality of the mirid bug Macrolophus basicornis a month after treatment (Wanumen et al. 2016a). The life span of Coccinella septempunctata adults exposed to sublethal doses of imidacloprid sprayed on leaves $(4.8 \mathrm{ppm})$ was reduced by $24-28 \%$, while their fecundity was reduced by $53-56 \%$ and the oviposition period was shortened significantly. Moreover, the fecundity of the $\mathrm{F} 1$ generation was also reduced considerably (Xiao et al. 2016). Foliar sprays of imidacloprid on okra crops in India at recommend label rates $(21-24.5 \mathrm{~g} / \mathrm{ha}) \mathrm{re}-$ duced the populations of spiders and ladybeetles significantly in the first 2 weeks after spraying, but the authors concluded that the insecticide was safe to natural enemies because they recovered after a while (Karthik et al. 2015).

Unfortunately, the rates of application of neonicotinoids in greenhouses, nurseries, and trees in urban landscapes are much higher than the rates applied to field crops. Thus, imidacloprid applied at $300 \mathrm{mg} / \mathrm{L}$ to pots containing the Mexican milkweed (Asclepias curassavica) resulted in very high concentrations of $6 \mathrm{ppm}$ in the flowers after one application and $21 \mathrm{ppm}$ after a second one done 7 months later. Consequently, the concentrations of imidacloprid in pollen of the nursery flowers were 793 to 1368 times higher than the typical residues $(7.6 \mathrm{ppb})$ obtained from seed-treated canola plants. Such residue levels caused significant mortality in three lady beetle species after 12 days, Coleomegilla maculata (50-65\%), Harmonia oxyridis (25-50\%), and Hippodamia convergens (30-50\%), but less in Coccinella septempunctata $(\sim 10-15 \%)$. Caterpillars of Danaus plexippus fed on the same plants experienced $>90 \%$ mortality after 1 week and were wiped out after 3 weeks. Vanessa cardui butterflies fed on flowers of globe thistle (Echinops ritro) treated at the same rate experienced mortalities of over 30\% after 1 week compared to untreated controls (Krischik et al. 2015).

In field experiments, sunflowers grown from seeds treated with thiamethoxam at the recommended dose $(0.5 \mathrm{mg} / \mathrm{kg}$ seeds) did not cause significant mortality of the predatory bug Orius insidiosus, but reduced its egg viability and female fertility resulting in a $40 \%$ reduction in nymph survival (Gontijo et al. 2015). The same treatment, however, caused $48 \%$ mortality of the predator Chrysoperla carnea after 8 days exposure (Gontijo et al. 2014). Thiamethoxam applied as seed treatment also delayed emergence of Coleomegilla maculata by prolonging the pupal period, whereas it reduced egg viability and skewed the sex ratio of Hippodamia convergens in favor of females (Moscardini et al. 2015).

Secondary poisoning has been shown with second instars of the ladybug Coleomegilla maculata, which have slower walking and predatory skills when feeding on aphids (Rhophalosiphum padi) grown on wheat plants seed-treated with thiamethoxam. Interestingly, only residues of its metabolite clothianidin were found in the aphids (Bredeson et al. 
2015). The omnivorous mirid predator Nesidiocoris tenuis experienced a mortality of $36 \%$ when feeding on eggs of Ephestia kuehniella (Lepidoptera, Pyralidae) that had been treated with sulfoxaflor at the highest recommended rates $(60 \mathrm{mg} / \mathrm{L})$ for controlling this pest. In addition, fecundity and longevity of the predatory bug were reduced significantly, indicating that this member of the fourth generation of neonicotinoids has undesirable sublethal effects on natural enemies (Wanumen et al. 2016b).

An update on the acute toxicity of seven neonicotinoids and fipronil to predatory arthropods is shown in Table 1. As most of the authors cited above have indicated, the sublethal effects of thiamethoxam on reproduction and predation ability of natural enemies and the residual activity of imidacloprid do not warrant the use of these insecticides in IPM programs.

\section{Parasitoids}

A "meta-analysis of nearly 1,000 observations from North American and European field studies revealed that seedapplied neonicotinoids reduced the abundance of arthropod natural enemies similarly to broadcast applications of pyrethroid insecticides" (Douglas and Tooker 2016). The study also indicates that seed-applied neonicotinoids are less toxic than pyrethroids to spiders and mites, so they might contribute to biological control in some particular agricultural systems.

Imidacloprid, dinotefuran, and thiamethoxam were more toxic to the filth fly parasitoid Spalangia endius (Hymenoptera: Pteromalidae) than to the target pest (Musca domestica), thus making it unsuitable for controlling the flies (Burgess and King 2015). Also S. endius was attracted to imidacloprid granular baits and experienced more grooming activity, but not to those containing dinotefuran or other insecticides. By contrast, another Pteromalidae parasitoid, Urolepis rufipes, did not show that behavior with either neonicotinoid tested (Burgess and King 2016). In semi-field tests designed to evaluate the toxicity of 19 new insecticides applied at label rates to cotton on the egg parasitoid Trichogramma pretiosum, fipronil (480 ppm) and dinotefuran (1040 ppm) showed almost $100 \%$ mortality in $24 \mathrm{~h}$, whereas acetamiprid (429 ppm) caused $80 \%$ mortality (Khan et al. 2015). Similarly, imidacloprid applied at the label rate on citrus trees (40 ppm) is harmful to the encyrtid parasitoid Ageniaspis citricola, causing over $89 \%$ mortality in $24 \mathrm{~h}$ and having residual activity on the leaves up to 17 days (de Morais et al. 2016b). Adults of the parasitoid Tamarixia triozae (Eulophidae) experienced 28 to $58 \%$ mortality after contact with pepper leaves that had been sprayed with imidacloprid (range 3 to $260 \mathrm{ppm}$ ); the highest dosage also caused cumulative $100 \%$ mortality after 2 days, whereas the lower treatments reduced emergence by $26-63 \%$ in a dose-related manner (Martinez et al. 2015). However, residues of imidacloprid on sprayed tomato leaves (1155 ppm) caused only $38 \%$ mortality in $24 \mathrm{~h}$ to the parasitoid Tamarixia triozae (Eulophidae), although its residual activity after 11 days was still noticeable and still caused $25 \%$ mortality (Luna-Cruz et al. 2015).

Laboratory tests using glass residues (contact toxicity) have demonstrated the high toxicity of imidacloprid, dinotefuran, nitenpyram, and thiamethoxam to the egg parasitoid Trichogramma ostrinae (Table 2), and all neonicotinoids except nitenpyram appear to pose a high risk in IPM: the fecundity is reduced by more than $50 \%$ in the case of thiamethoxam and dinotefuran, while emergence is reduced $54 \%$ in the case of imidacloprid exposure ( $\mathrm{Li}$ et al. 2015b). In the case of Trichogramma chilonis exposed to residues of commercial formulations of thiamethoxam and nitenpyram, mortalities of 98 and $96 \%$, respectively, were observed in $24 \mathrm{~h}$. This together with a reduction of parasitism in the larval stage: $20-37 \%$ for thiamethoxam and $14-45 \%$ for nitenpyram, and a reduced emergence of $12-33 \%$ for thiamethoxam and 21$29 \%$ for nitenpyram (Ko et al. 2015). Also, exposures by contact following the recommended paper disc tests of the International Organization for Biological Control (IOBC) showed the high acute toxicity of thiamethoxam, imidacloprid and acetamiprid when applied at 25, 30-40, and 60 ppm concentrations. Adult mortalities of the parasitoid Tamarixia radiata after 3 days were $100,61-78$, and $66 \%$ for the respective insecticides (Beloti et al. 2015). Therefore, these insecticides were classified in Class 4 (harmful) and not recommended for IPM programs (Veire et al. 2002).

Furthermore, females of the chalcid wasp Nasonia vitripennis exposed to sublethal concentrations of imidacloprid in syrup (2-100 ppb) not only experienced 20 $25 \%$ reduced fecundity but also altered the sex allocation of the offspring in favor of females while reducing the fitness when ovipositing with co-foundresses (Whitehorn et al. 2015). The reproductive impairment observed so far with various species of parasitoid wasps is evidence that links neonicotinoids to the decline of these beneficial and important species for pest control.

\section{Effects on non-target soil organisms}

Imidacloprid and thiacloprid are highly toxic to springtails (Collembola spp.), with LC50s of 0.44 and $9 \mathrm{mg} / \mathrm{kg}$ dry soil, respectively, for Folsomia candida. In multigenerational tests with this species, imidacloprid showed consistently high toxicity through three generations, whereas toxicity of thiacloprid was reduced in the second and third generation. The authors suggest that the higher persistence of imidacloprid in soil compared to that of thiacloprid could be the reason for this differential toxicity in time (van Gestel et al. 2017).

The only microcosm study available for terrestrial arthropods using imidacloprid was done by Uhl et al. (2015). The experimental setup consisted of a tritrophic system: strawberry plants, a ground cricket (Nemobius sylvestris) and a web spider (Pisaura mirabilis). Strawberry leaves were treated at 


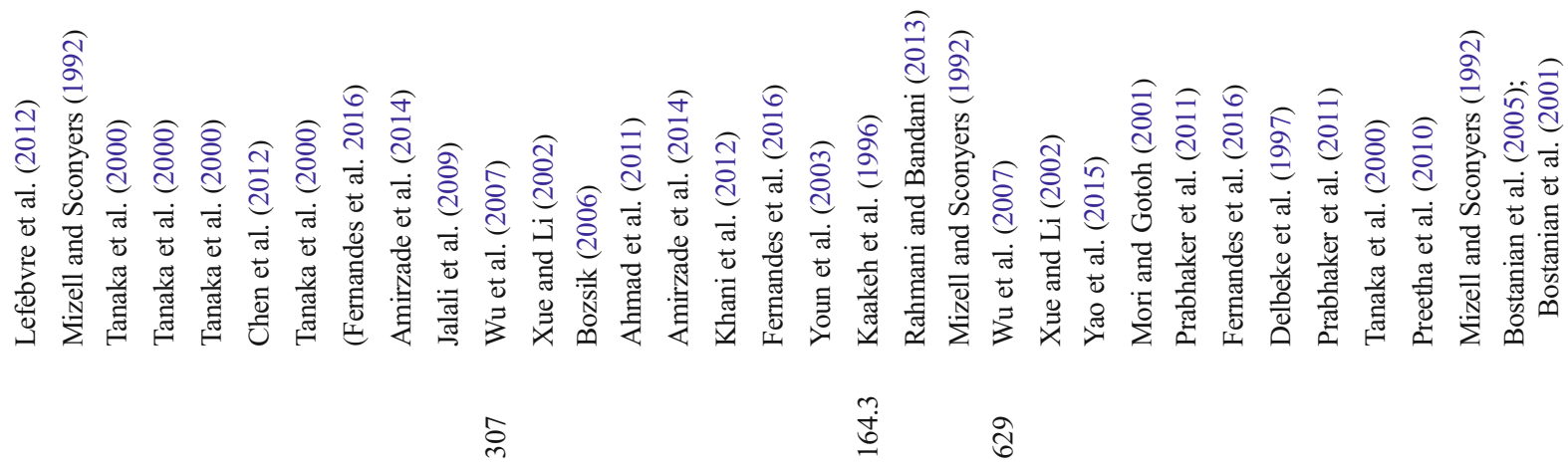

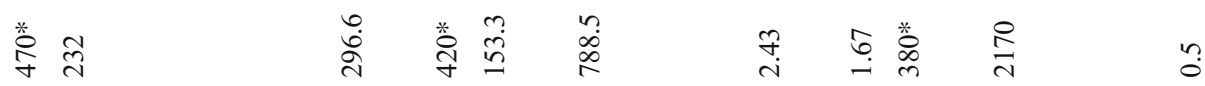

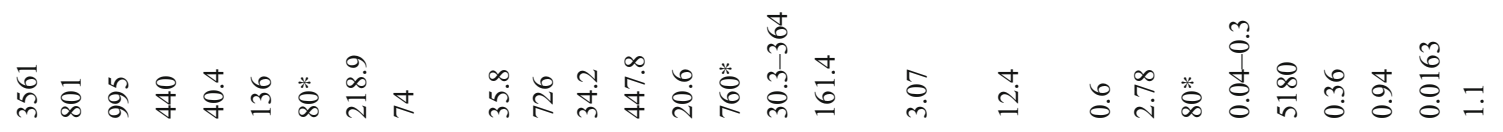
草

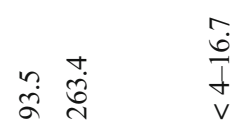
$\grave{o}$

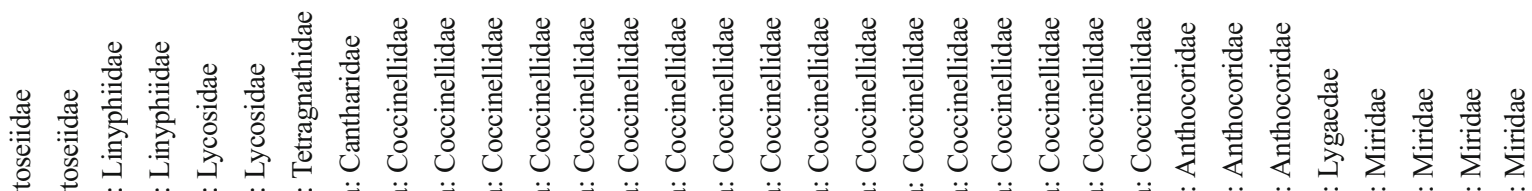

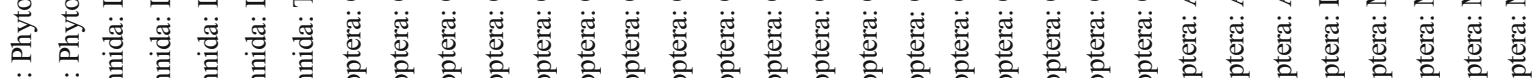

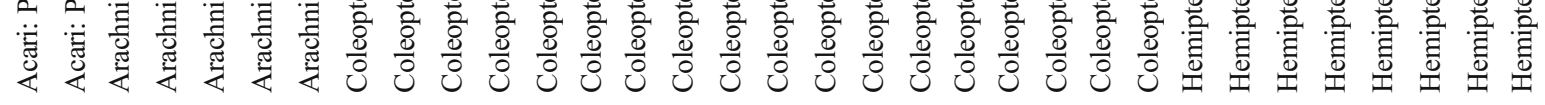

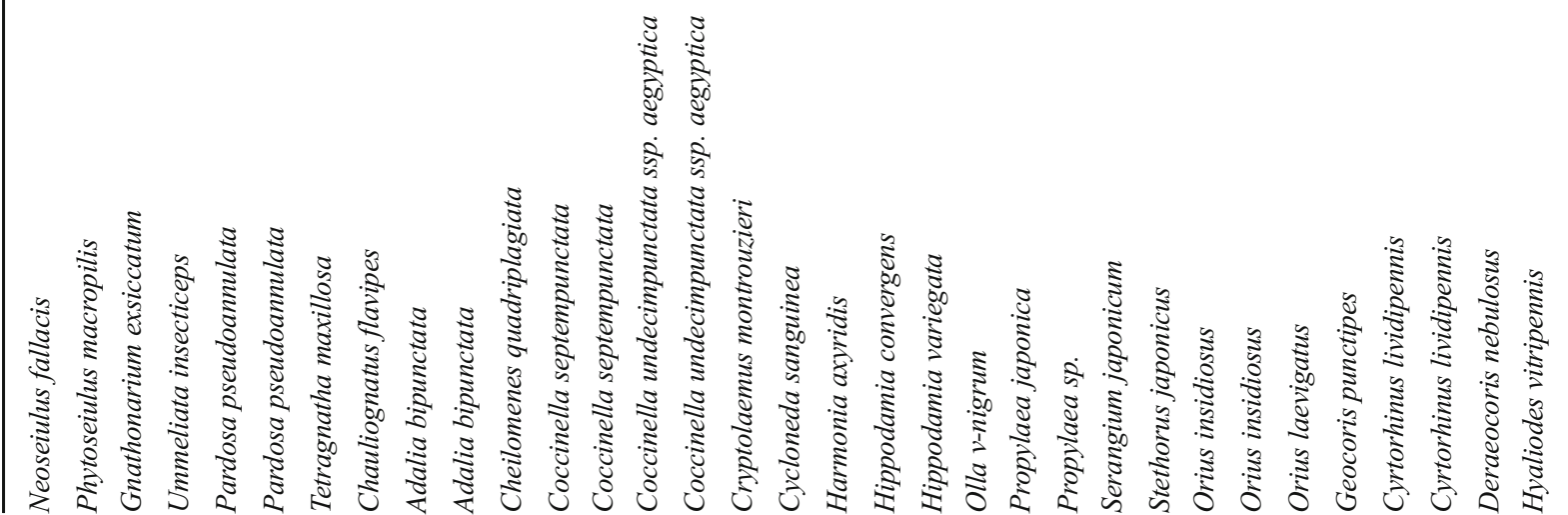


two different rates that reflected a typical dosage within the crop $\left(2.4 \mathrm{~g} / \mathrm{m}^{2}\right)$ and low exposure in field margins and forests $\left(0.24 \mathrm{~g} / \mathrm{m}^{2}\right)$. The treatments were sublethal, as cricket mortalities were low and evenly distributed among treatments and controls. However, crickets showed significantly less mobility and feeding behaviors with the high treatment, while both treatments resulted in significantly lower weight and thorax growth. The high treatment also increased the predation of crickets by the spider, while spiders tended to move more under such circumstances. However, and surprisingly, the low treatment resulted in higher survival of the crickets than in the controls. Overall, herbivory was reduced and predation increased at sublethal concentrations of imidacloprid, suggesting possible impacts through trophic interactions.

Significant changes in invertebrate community composition were observed immediately after spray applications of fipronil for locust (Chortoicetes terminifera) control in Queensland, Australia, though the richness and abundance of species caught in pan and pitfall traps were not significantly affected. The changes in species composition for the flying insects (pan traps) persisted for up to 79 days after spraying operations, whereas those for the ground-dwelling invertebrates (pitfall traps) lasted up to 189 days. The authors of this field study explained that a long drought period that occurred during their 2-year monitoring may have influenced the slow recovery of the invertebrate populations (Walker et al. 2016). The composition of arthropod communities was not significantly affected over time in another study that used fipronil sprays for locust control in New South Wales, Australia (Maute et al. 2017a). However, springtails, mites, beetles, crickets, psocopterans, and dipterans experienced short-term decreases in abundance. The highest reductions were observed in two ant species, one of which did not recover for longer than a year. Because arthropod abundance and community assemblage changed over the 2-year study, both in control and treatment sites, changes in patterns of local rainfall over the study period were larger than changes in abundance due to pesticide treatment (Maute et al. 2017a). The same authors found no impacts on wood-eating termites activity, measured as consumption of wooden baits, or species composition but such termites are soil dwellers, are scarce in arid Australia and may not have been exposed to the sprays (Maute et al. 2016). Equally, litter decomposition carried out by soil microbial communities was not affected by the fipronil sprays (Maute et al. 2017b).

The few species of earthworms used in toxicology tests are more tolerant to neonicotinoids than other soil invertebrates. However only few species have been studied and Eisenia fetida, the species on which most studies were performed is an epigean (i.e., surface-dwelling) compost worm and is not a common species in forest or agricultural soil. The acute toxicities (LC50s in $\mathrm{mg} / \mathrm{kg}$ soil) of five neonicotinoids to the earthworm Eisenia fetida after 14 days exposure were determined as 4.34 for nitenpyram, 3.05 for imidacloprid, 2.69 for acetamiprid, 2.68 for thiacloprid, and 0.93 for clothianidin 


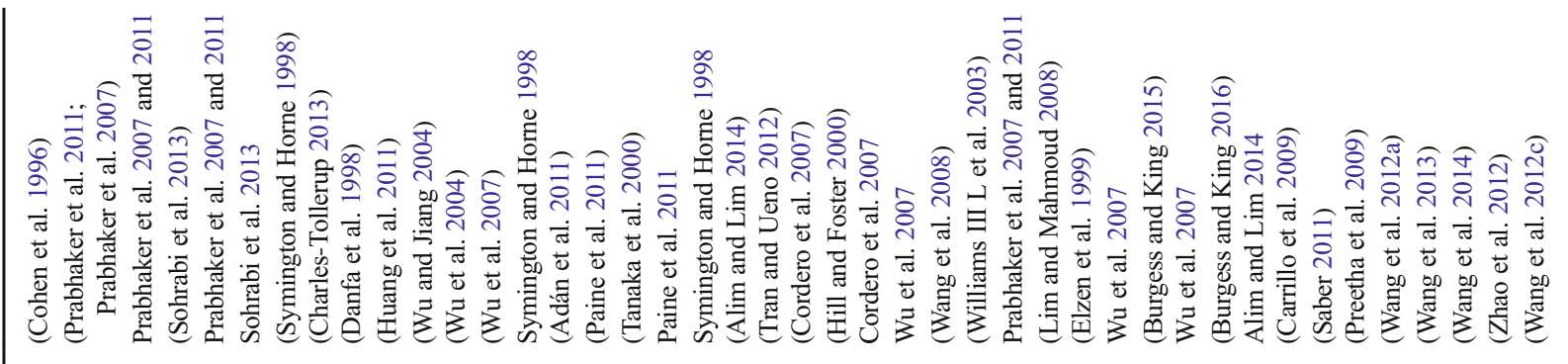

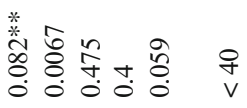
$\stackrel{\infty}{0} \stackrel{\infty}{0} \stackrel{0}{0}=\frac{0}{0}$ ¿ֶo

$\stackrel{\leftrightarrow}{\circ} \stackrel{0}{\circ} \stackrel{0}{\circ}$

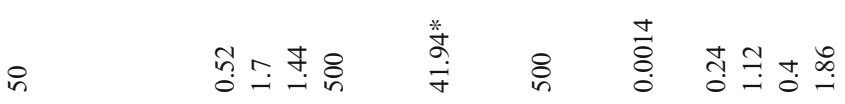

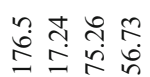

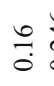

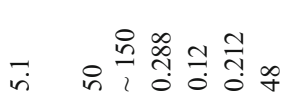

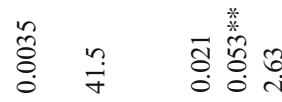

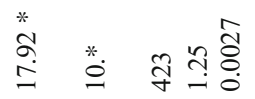

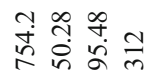

की

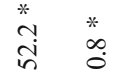

$$
\begin{aligned}
& \text { ্ָণ } \\
& \stackrel{m}{\circ} \\
& \text { ले ले ले }
\end{aligned}
$$$$
\stackrel{\circ}{\circ} \div \stackrel{n}{\circ}
$$$$
\stackrel{+}{\circ} \text { वे }
$$

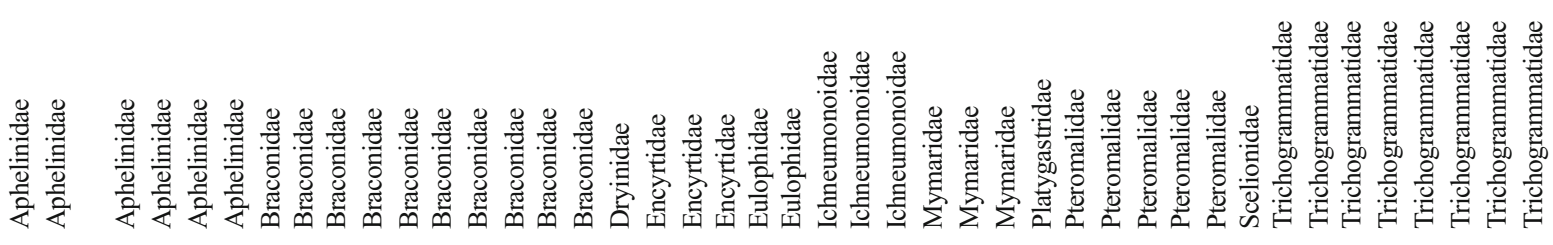

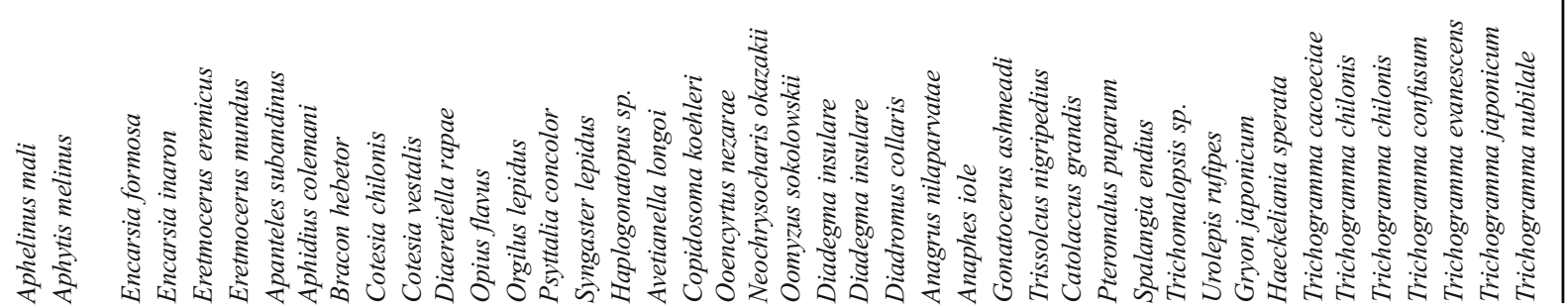


(Wang et al. 2015b). The authors reported that exposures in the range $0.8-2.0 \mathrm{mg} / \mathrm{kg}$ also reduced the fecundity of this species between 39.5 and $84 \%$ depending on the compounds, while causing significant disruption of epidermal and midgut tissues. The median number of hatched cocoons (EC50) for earthworms exposed to imidacloprid was determined as $0.92 \mathrm{mg} / \mathrm{kg}$ soil, and its lowest observed effect concentrations (LOECs) for hatchability, AChE activity, growth, and DNA damage were $0.02,0.1,0.5$, and $0.5 \mathrm{mg} / \mathrm{kg}$ soil, respectively (Wang et al. 2015c). Mixtures of imidacloprid and lambdacyhalotrin appear to have antagonistic toxicity in these earthworms (Wang et al. 2015f). Other authors have demonstrated the low toxicity of the new compound guadipyr to Eisenia fetida, as concentrations of this insecticide in soil below $100 \mathrm{mg} / \mathrm{kg}$ in did not affect the growth or the reproduction output. Only increases in enzymatic activities of superoxidase dismutase and catalase were observed in the first few days of exposure, returning to normal levels afterwards (Wang et al. 2015a). The 48-h LC50 for acute toxicity of nitenpyram to the earthworm Pheretima posthuma was determined at $0.29 \mathrm{mg} /$ $\mathrm{kg}$ soil (Hussain et al. 2017).

A study of the nematode communities in soils of corn fields treated with clothianidin, either as granules or in seed-coating, found significant differences in species richness and diversity compared to untreated control fields on two separate years. The main driver in community composition of nematodes was the year and month of sampling, but clothianidin treatments reduced the diversity of species significantly, with up to 5 species out of 36 being absent, even if total abundances between treatments and controls were statistically similar (Čerevková et al. 2017).

The enantiomers of fipronil appear to have different toxicity to the earthworm Eisenia fetida, with S-fipronil having a higher subchronic toxicity and bioaccumulation potential than R-fipronil (Qin et al. 2015). Weight reductions after 28 days exposure to concentrations in soil ranging $50-1000 \mathrm{mg} / \mathrm{kg}$ were $23-53 \%$ for the R-fipronil and $38-62 \%$ for the Sfipronil enantiomers. Residue accumulation in the earthworms reached a peak after 10 days exposure and then declined, following the dissipation pattern of the initial fipronil racemate in the soil. In tissues, fipronil, fipronil sulfone, and fipronil sulfide were detected, with bioaccumulation factors of $0.5-0.75$ and a biological half-life in the range 1.5-2.1 days (Qin et al. 2015).

Studies on the effect of systemic pesticides on soil organisms are limited to a few species and the chosen species may not be the most ecologically meaningful. Therefore, the true impact of systemic pesticides on soil organisms and associated functions remains an important knowledge gap.

\section{Effects on aquatic invertebrates}

A comprehensive review of the acute and chronic toxicity of neonicotinoids to 49 species of aquatic insects and 
crustaceans, spanning 12 invertebrate orders, indicates that differences in sensitivity among aquatic invertebrate species range several orders of magnitude (Morrissey et al. 2015). More than two thirds of the data refer to imidacloprid, for which acute LC50s range from $4 \mu \mathrm{g} / \mathrm{L}$ in the most susceptible insect orders (Ephemeroptera, Trichoptera, and Diptera) to values exceeding $44,000 \mu \mathrm{g} / \mathrm{L}$ in the most tolerant cladoceran crustaceans. It is unfortunate that the standard species used in regulatory assessments, namely Daphnia magna, has a typical LC50 of about $100,000 \mu \mathrm{g} / \mathrm{L}$, and this caused regulators to underestimate risks for some time. The study recommended ecological thresholds for neonicotinoids in water at concentrations below $0.2 \mu \mathrm{g} / \mathrm{L}$ for short-term acute exposures and $0.035 \mu \mathrm{g} / \mathrm{L}$ for long-term chronic exposures to avoid ecological impacts on aquatic invertebrate communities (Morrissey et al. 2015). Some of these impacts were described in a previous review (Pisa et al. 2015), and links between the toxic effects at the individual species, populations, and communities levels with impacts on aquatic and terrestrial ecosystems have been published more recently (Sánchez-Bayo et al. 2016a).

The decline of dragonflies and damselflies (Odonata) in Japan since the early 1990s has been blamed on the introduction of systemic insecticides in that country (Jinguji and Uéda 2015), but solid evidence was lacking. Impacts of these insecticides applied to rice seedlings in nursery-boxes at recommended rates were tested on the dragonfly Sympetrum frequens: none of the 50 nymphs introduced in experimental lysimeters treated with either imidacloprid or fipronil survived after 1 month, and only 13\% remained in those treated with dinotefuran. Although the rate of adult emergence in the dinotefuran treatment was similar to that in the controls, the average head width of the dragonflies in this treatment was significantly narrower (Jinguji and Uéda 2015). In a similar study using paddy mesocosms treated with either clothianidin, fipronil, or chlorantraniliprole, the abundance of Odonata species in the clothianidin and specially in the fipronil-treated paddies was very low compared to controls and the other treatment (Kasai et al. 2016). Plankton species also declined in the clothianidin and chlorantraniliprole treatments right after the applications, but they recovered when their initial concentrations decreased to minimal levels. Previous mesocosm studies in Japan had showed the toxicity of imidacloprid to Odonata species when applied at the recommended rates to rice paddies $(10 \mathrm{~kg} / \mathrm{ha})$. However, the study by Kobashi et al. (2017) also showed compensation among the predatory insects: while populations of Crocothemis servilia mariannae and Lyriothemis pachygastra nymphs were significantly reduced, those of Orthetrum albistylum speciosum increased slightly throughout the 5-month experimental period. Large decreases in the abundance of a common predator, Notonecta triguttata, were also observed, and the Guignotus japonicus disappeared, the effects on both species resulting from a delayed but measurable chronic toxicity (Kobashi et al. 2017). Other authors have determined the 48-h LC50 for clothianidin in North American dragonflies in the range 865 to $1245 \mu \mathrm{g} / \mathrm{L}$ (Miles et al. 2017).

Mayflies (Ephemeroptera) comprise other insect taxa very susceptible to neonicotinoids. The acute and chronic toxicity (28 days exposure) of thiamethoxam, thiacloprid, and imidacloprid to Cloeon dipterum, and their seasonal variability was studied by van den Brink et al. (2016). Thiacloprid was twice as toxic to the winter generation as the other two neonicotinoids, whereas both acute and chronic toxicity of imidacloprid to the summer generation was much higher than to the winter one. Camp and Buchwalter (2016) demonstrated that the higher susceptibility of 6 species of aquatic insects to imidacloprid during summer is due to the higher water temperatures during that season: the time-to-effect for sublethal impairment and immobility was significantly decreased with increasing temperature from 15 to $25^{\circ} \mathrm{C}$ because the intake of the toxicant and metabolism also increased accordingly. For Cloeon dipterum, lethal median concentrations (LC50s) of the studied neonicotinoids (thiamethoxam, thiacloprid, and imidacloprid) decreased by a factor of 3 to 6 times between 24 and $96 \mathrm{~h}$ of exposure in either season (van den Brink et al. 2016). The same result was found with the lotic mayfly Isonychia bicolor exposed to imidacloprid (Camp and Buchwalter 2016). Moreover, chronic exposures of C. dipterum resulted in LC50s of $0.30 \mu \mathrm{g} / \mathrm{L}$ for thiacloprid, $0.32 \mu \mathrm{g} / \mathrm{L}$ for imidacloprid and $0.8 \mu \mathrm{g} / \mathrm{L}$ for thiamethoxam, the latter LC50s being 270, 800 and 100 times lower than their respective ones at $24 \mathrm{~h}$ (van den Brink et al. 2016). Also, LC50s for acute exposure of the freshwater amphipod Gammarus kischineffensis to thiamethoxam dropped from $75.6 \mu \mathrm{g} / \mathrm{L}$ at $24 \mathrm{~h}$ to $3.7 \mu \mathrm{g} / \mathrm{L}$ at $96 \mathrm{~h}$, that is a 20 -fold decrease in concentration in 4 days to achieve the same mortality effect (Uğurlu et al. 2015). These studies confirm the delayed and extreme chronic toxicity of neonicotinoids to aquatic organisms.

New toxicity data of aquatic predatory insects are now available for clothianidin (Miles et al. 2017). The 48-h LC50 for the aquatic beetle Graphoderus fascicollis (Dytiscidae) was determined at $2 \mu \mathrm{g} / \mathrm{L}$, which indicates the susceptibility of this species compared to that of four species of water bugs (LC50 range 56$805 \mu \mathrm{g} / \mathrm{L}$ ) and three species of dragonflies (LC50 range 865$1245 \mu \mathrm{g} / \mathrm{L}$ ). The water bug Belostoma flumineum displayed a dose-dependent reduction in feeding rate after exposure to sublethal concentrations of clothianidin. The authors also carried out a mesocosm study to investigate the effect of three concentrations of clothianidin $(0.6,5$, and $352 \mu \mathrm{g} / \mathrm{L})$ in the arthropod communities. Predatory invertebrates experienced significant mortality with increasing levels of the insecticide in water, concomitant with increases of their prey up to $50 \%$ at the highest concentration, indicating a top-down trophic cascade in community abundance (Miles et al. 2017).

In laboratory tests with larvae of Chironomus dilutus, the 14day LC50s for imidacloprid, clothianidin, and thiamethoxam were $1.52,2.41$, and $23.60 \mu \mathrm{g} / \mathrm{L}$, respectively. However, the 
40-d EC50s for adult emergence under exposure to the same chemicals were $0.39,0.28$, and $4.13 \mu \mathrm{g} / \mathrm{L}$, respectively. This indicates that sublethal concentrations that prevent emergence of this key wetland species are between 4 and 9 times lower than those that cause mortality to the larvae (Cavallaro et al. 2017). Exposure of Chironomus riparius larvae to various mixtures of pyrethroid (deltamethrin and esfenvalerate) and neonicotinoid insecticides (imidacloprid and thiacloprid) at $50 \%$ of their known LC50s showed sometimes additive and other times antagonistic effects on survival (Kunce et al. 2015). In the case of the amphipod Hyalella azteca, combined exposure to imidacloprid and cyfluthrin resulted in mortality ratios of 1.7 to 2.7 higher than either insecticide alone, indicating greater than additive toxicity (Lanteigne et al. 2015).

Available toxicity data for amphipods indicate that these detritivores of organic material are less susceptible to neonicotinoids than insect larvae by one order of magnitude or more (Morrissey et al. 2015). However, such differences tend to be species specific. For example, recent studies have shown that the amphipod Gammarus fossarum is more susceptible than the caddisfly Chaetopteryx villosa when exposed to three neonicotinoids (imidacloprid, thiacloprid, and acetamiprid), either alone or in mixtures (Englert et al. 2017). Furthermore, the same study found that combined exposure of these shredder species to neonicotinoid residues in water and in food (tree leaves) had more negative impacts on their survival than direct exposure to contaminated water alone. Exposure of benthic organisms to residual neonicotinoids in water is already widespread in Europe: $47 \%$ of the 19 amphipods (Dikerogammarus spp.) collected from the Danube river in eastern Germany had residues of thiacloprid at levels $0.1-0.39 \mathrm{ppb}$ (wet body weight) (Inostroza et al. 2016).

Mollusks are known to be quite tolerant of neonicotinoids (Morrissey et al. 2015), with water snails (Physa acuta and Helisoma trivolvis) having no mortality after exposure to $327 \mathrm{mg} / \mathrm{L}$ clothianidin for 2 days (Miles et al. 2017). It appears that the mechanism of toxicity of these insecticides on these organisms is different, as neonicotinoids inhibit the nACh receptors in the pond snail (Lymnaea stagnalis) instead of acting agonistically (Vehovszky et al. 2015). At environmentally relevant concentrations ( 0.1 to $100 \mu \mathrm{g} / \mathrm{L})$, imidacloprid downregulated the production of many fatty acids in the snails, while the levels of polyamines, spermidine and putrescine increased, indicating neuron cell injury. Cholinergic gene expression was also increased as the snails tried to overcome imidacloprid binding to the nAChRs (Tufi et al. 2015). Exposure of the snails to mixtures of neonicotinoids and other pesticides found in water from agricultural areas in the Netherlands showed more disturbed metabolic pathways than exposures to individual chemicals (Tufi et al. 2016). Toxicity tests of a suite of neonicotinoids to the Ramshorn snail (Planorbella pilsbryi) showed 7-day LC50s of $\geq 4000 \mu \mathrm{g} / \mathrm{L}$ for imidacloprid, clothianidin, and thiamethoxam, respectively, whereas the 28 -day LC50s were $\geq 182 \mu \mathrm{g} / \mathrm{L}$ for all three insecticides. However, growth and biomass are more sensitive endpoints than mortality for this species, with EC50s ranging from 33.2 to $122.0 \mu \mathrm{g} / \mathrm{L}$ (Prosser et al. 2016). Similarly, the 48-h LC50s for glochidia of the wavy-rayed lampmussel (Lampsilis fasciola) were $\geq 456 \mu \mathrm{g} / \mathrm{L}$ for all seven neonicotinoids tested by these authors. Thus, the aquatic studies to date confirm that neonicotinoids pose less of a hazard to mollusks compared to non-target aquatic insects.

Despite the above findings, a probabilistic risk assessment that compared the available acute and chronic toxicity data of neonicotinoids to the current levels of contamination of these insecticides in surface waters of the USA, concluded that "the aquatic invertebrate community is unlikely to be adversely affected by acute or chronic exposure to imidacloprid resulting from currently registered uses of imidacloprid in the United States" (Aslund et al. 2017). The study was funded by Bayer CropScience and three private environmental consulting firms. By contrast, a review of 29 surveys in nine countries found "that $81 \%(22 / 27)$ and $74 \%$ (14/19) of global surface water studies reporting maximum and average individual neonicotinoid concentrations respectively, exceeded the thresholds of 0.2 and $0.035 \mu \mathrm{g} / \mathrm{L}$ " for protection of $95 \%$ of aquatic species (Morrissey et al. 2015).

\section{The delayed mortality and chronic toxicity of neonicotinoids}

Previous studies on the toxicity of neonicotinoids pointed to an increasing rate of mortality of the organisms exposed over time (Tennekes 2010; Tennekes and Sánchez-Bayo 2012), which results in lower LC50s under a continuous exposure to very low concentrations of these insecticides. As a result, the acute/chronic ratios span two or three orders of magnitude. The data available at that time referred to imidacloprid and thiacloprid and comprised only aquatic organisms, mainly insects and crustaceans. In recent years, two other studies about the chronic exposure of insect larvae (van den Brink et al. 2016) and gammarid amphipods (Uğurlu et al. 2015) have confirmed that, in addition, chronic exposure to thiamethoxam produces the same pattern of toxicity (Fig. 2a). The consequence is an apparent "delayed mortality" (Beketov and Liess 2008), which can be observed in mesocosm trials that use a single pulse exposure: most of the organisms do not die immediately but start dying in large numbers after a week, and their populations disappear completely after a few weeks (Hayasaka et al. 2012; Sánchez-Bayo and Goka 2006).

Delayed mortality was also demonstrated in honeybees exposed chronically to low concentrations of imidacloprid in syrup (Rondeau et al. 2014) and has now been confirmed with honey bees exposed to thiamethoxam (Oliveira et al. 2013) and clothianidin (Alkassab and Kirchner 2016) in their food (Fig. 2b). While the exposure of terrestrial organisms to insecticide residues in food is not constant, unlike the aquatic 


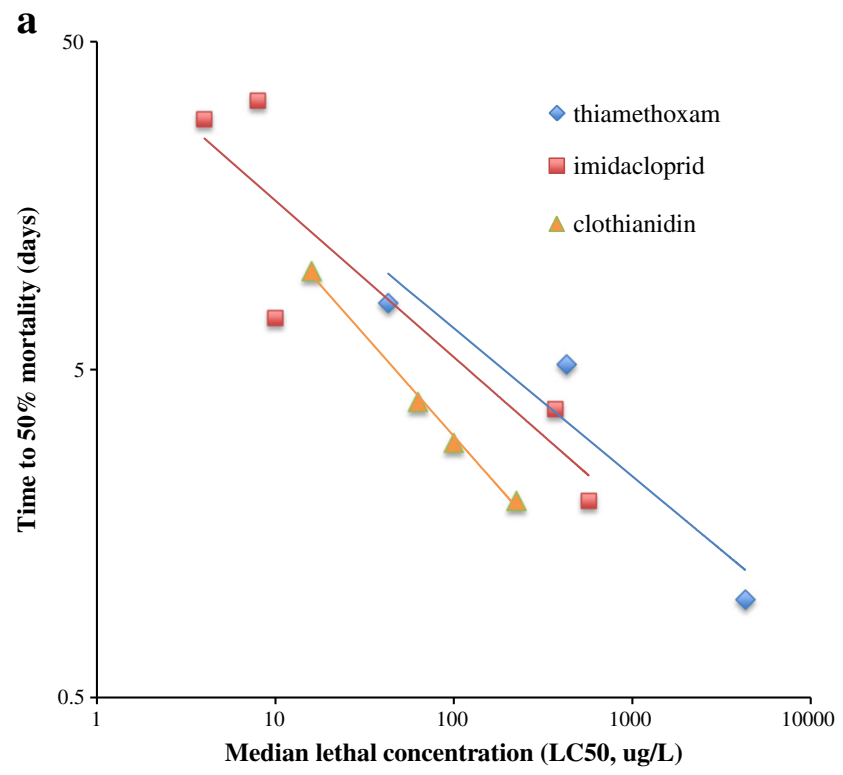

b

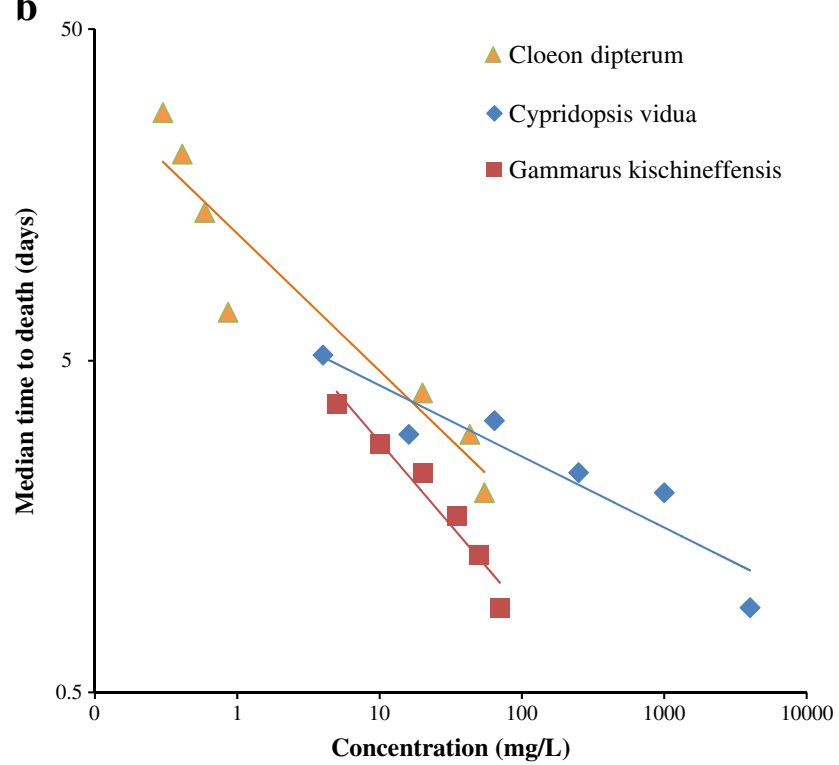

Fig.2 Time-cumulative toxicity of neonicotinoids in a Apis mellifera and b aquatic arthropods. Data sources: a clothianidin $\left(r^{2}=0.99\right)$, Alkassab and Kirchner 2016; imidacloprid $\left(r^{2}=0.81\right)$, Suchail et al. 2001 and Dechaume-Moncharmont et al. 2003; thiamethoxam $\left(r^{2}=0.90\right)$, Oliveira et al. 2013; b Cloeon dipterum and thiacloprid $\left(r^{2}=0.90\right)$, van den Brink et al. 2016; Cypridopsis vidua and imidacloprid $\left(r^{2}=0.88\right)$, Sánchez-Bayo 2009; Gammarus kischineffensis and thiamethoxam $\left(r^{2}=0.95\right)$, Uğurlu et al. 2015

organisms that take up the toxicant through the gills, increased lethal effects over time in both cases suggest the same mechanism of toxicity applies to terrestrial and aquatic invertebrates alike.

The proposed mechanism for delayed mortality involves an irreversible binding to the nicotinic acetylcholine receptors (nAChR) embedded in the synaptic membranes of neurons, whose activation elicits a continuous electric impulse that eventually leads to the death of the neuron. The neuronal death toll accumulates as more and more pesticide molecules bind to other nAChRs until the organism cannot cope with the damage and dies. The main difference between this mode of action and that of other pesticides is that effects are cumulative with time, because neurons do not regenerate - it has been termed time-cumulative or reinforced toxicity (Tennekes and Sánchez-Bayo 2013). This mechanism certainly applies to all arthropods tested to date, but not to birds. Thus, while red-legged partridges that fed on wheat seeds coated with imidacloprid died within 3 weeks (Lopez-Antia et al. 2015a), their mortality did not follow the time-cumulative pattern, most likely because the binding of neonicotinoids to the subunits that make the nAChR in vertebrates is not as strong as in invertebrates (Tomizawa and Casida 2003).

The consequences of this particular pattern of chronic toxicity are far reaching. First, it indicates that acute LC50s or LD50s determined for short exposures ( 24 or $48 \mathrm{~h}$ ) are irrelevant for risk assessments of these chemicals, because it is the long exposure to much lower levels of insecticide that really affects the survival of the organisms. It follows that protective levels for neonicotinoids cannot be achieved by setting a concentration benchmark, because the effects of neonicotinoids increase with exposure time and because of cascade effects within individuals. Second, when residues are present in the environment, constant or repeated exposure to any concentration of the insecticides will eventually produce large mortality rates in populations of susceptible invertebrates, e.g., soil-dwelling arthropods such as the grubs of many insects, aquatic arthropods, or pollinators exposed to low residue levels in nectar, pollen, and water. This time-cumulative effect may therefore be part of the explanation for the continuous decline of entire populations of insects that has been observed in Europe in recent decades (Sorg et al. 2013; Vogel 2017), thus reducing the food resources of songbirds (Hallmann et al. 2014) and probably other insectivorous animals such as shrews, lizards, and frogs. Consequently, the environmental impacts of neonicotinoids are not restricted to their direct toxic effects on insects but may reach beyond to the entire ecosystem, by indirectly impacting vertebrate populations that depend on arthropod resources for food.

\section{Part B: vertebrates}

To update the assessment on the impacts of neonicotinoids and fipronil on vertebrates (Gibbons et al. 2015), a literature search was undertaken, using the same methods, but restricted to the years 2014-2016 and a few months in early 2017). Only sources not included in Gibbons et al. (2015) are presented here. In some cases, individual studies covered more than one species, chemical, or dosage approach (e.g., chronic or acute), and in all but three cases, which were field studies covering multiple bird or reptile species, each is treated here as a separate impact study. 
As in the previous assessment, most studies were laboratory-based $(111 / 129,86 \%)$ and were of direct toxicity $(124 / 129,96 \%)$. This over-reliance on laboratory direct toxicity studies, as well as lack of field-based studies that can also identify indirect effects (e.g., cascades through the food chain) continues to limit our ability to interpret the findings under field-realistic conditions. Once again, the most common study taxa were mammals (51), fish (38), and birds (31), with substantially fewer studies of amphibians (6) and reptiles (3). Just over half of these studies were of five species: rat Rattus norvegicus (32 studies), mouse Mus musculus (14), zebrafish Danio rerio (8), rohu Labio rohita (7), and domestic chicken Gallus gallus domesticus (7).

In Gibbons et al. (2015), more than a third of all studies found (51/152) were of acute toxicity, measuring either LD50 or LC50. Over the period of this update only 13 studies (10\%) explicitly measured LD50 or LC50, suggesting a changing focus among researchers to identify the sublethal, rather than lethal effects of these systemic insecticides. Nearly three-quarters of all studies investigated the effects of either the neonicotinoid imidacloprid (57) or fipronil (36). Given the paucity of information collated for the other neonicotinoids, this update largely concentrates on these two products, although it also includes clothianidin for comparability with the earlier review.

\section{Acute toxicity studies}

Despite studies focusing mainly on sublethal effects, this updated review found imidacloprid LC50 values for six new species; rohu $550 \mathrm{mg} / \mathrm{L}$ (Qadir et al. 2015), white sturgeon Acipenser transmontanus $124 \mathrm{mg} / \mathrm{L}$ (Frew and Grue 2015), common carp Cyprinus carpio $78 \mathrm{mg} / \mathrm{L}$ for eggs and $280 \mathrm{mg} /$ L for adults (Tyor 2016), loach Misgurnus anguillicaudatus $145.8 \mathrm{mg} / \mathrm{L}$ (Xia et al. 2016), Montevideo tree frog Hypsiboas pulchellus $84.9 \mathrm{mg} / \mathrm{L}$ (de Arcaute et al. 2014) and $52.6 \mathrm{mg} / \mathrm{L}$ for a formulation of imidacloprid, Glacoxan Imida (PérezIglesias et al. 2014), and an LC50 value for zebrafish larvae $143.7 \mathrm{mg} / \mathrm{L}$ (Wang et al. 2016a). Following the classification of the US EPA (see Table 1, Gibbons et al. 2015), imidacloprid is practically non-toxic to the fish species studied - though slightly toxic to common carp eggs - and slightly toxic to Montevideo tree frogs, making it the most sensitive frog species studied.

Two additional fipronil LC50 values were also found: zebrafish larvae $(0.6 \mathrm{mg} / \mathrm{L}$; Yan et al. 2016) and common carp ( $0.43 \mathrm{mg} / \mathrm{L}$; Qureshi et al. 2016). Fipronil is thus highly toxic to both these fish species, further confirming the toxicity of this chemical to fish (Wagner et al. 2017).

\section{Sublethal effects}

Adding to the results in Gibbons et al. (2015), a further wide range of sublethal effects of imidacloprid, clothianidin and fipronil has been found under laboratory conditions (Table 3). In red-legged partridges Alectoris rufa, reproductive effects included reduced clutch size, delayed laying dates and altered secondary sexual characteristics when exposed to imidacloprid (Lopez-Antia et al. 2015a). Numbers of germ cells were reduced when Japanese quail Coturnix japonica were exposed to clothianidin (Hoshi et al. 2014), while exposure of red-legged partridges to fipronil led to reductions in the levels of sex hormones, reduced egg fertility, and altered secondary sexual characteristics (Lopez-Antia et al. 2015b). Imidacloprid and fipronil had deleterious effects on growth of birds, exhibited as growth retardation, reduced weight gain and lost body condition, often as a consequence of reduced food intake (Hussein et al. 2014a, b; Khalil et al. 2017; LopezAntia et al. 2015b). During embryonic development of birds, exposure to imidacloprid caused heart malformation (Gao et al. 2016), neural tube defects (Liu et al. 2016; Wang et al. 2016b), altered organ mass, and other anatomical deformities (Gobeli et al. 2017). In red-legged partridges, exposure to imidacloprid led to a depressed immune response in offspring of treated parents (Lopez-Antia et al. 2015a) and of parents and offspring when exposed to fipronil (Lopez-Antia et al. 2015b).

All three chemicals caused a wide range of cytotoxic effects in vertebrates (see Table 3 for references), including disruption of thyroid hormones and thyroid physiology, alterations to red and white blood cells, hepatotoxicity and nephrotoxicity, and induction of oxidative stress (imidacloprid); disrupted kidney biochemistry (clothianidin); structural damage and histopathological changes in the liver, thyroid damage, oxidative stress and hyperglycemia, and inhibition of mitochondrial activity leading to hepatocyte death (fipronil).

In mammals, neurobehavioral effects included diminished learning ability (Kara et al. 2015), enhanced social dominance and reduced aggression (Burke 2016), and disrupted spatial memory during echo-location in bats when exposed to imidacloprid (Hsiao et al. 2016); deteriorated cognitive function in infants (Ozdemir et al. 2014) and increased anxiety-like behavior (Hirano et al. 2015) when exposed to clothianidin, and impaired memory following lactational exposure (Montanha et al. 2016), disturbed maternal behaviors, such as aggression (Magalhaes et al. 2015), and altered reflex development in offspring (Udo et al. 2014) when exposed to fipronil. Exposure to imidacloprid also altered the regulation of genes important in mammalian brain development (Kimura-Kuroda et al. 2016).

In zebrafish, exposure to fipronil stopped swim bladders from inflating and caused curvature of the spine (Yan et al. 2016), while DNA damage and oxidative stress occurred following exposure to imidacloprid (Ge et al. 2015). Similar genotoxic and cytotoxic effects occurred in carp Cyprinus carpio and silver catfish Rhamdia quelen exposed to fipronil (Qureshi et al. 2016; Menezes et al. 2016). Genotoxic effects were also observed in chameleon cichlids Australoheros facetus exposed to imidacloprid (Iturburu et al. 2017). 


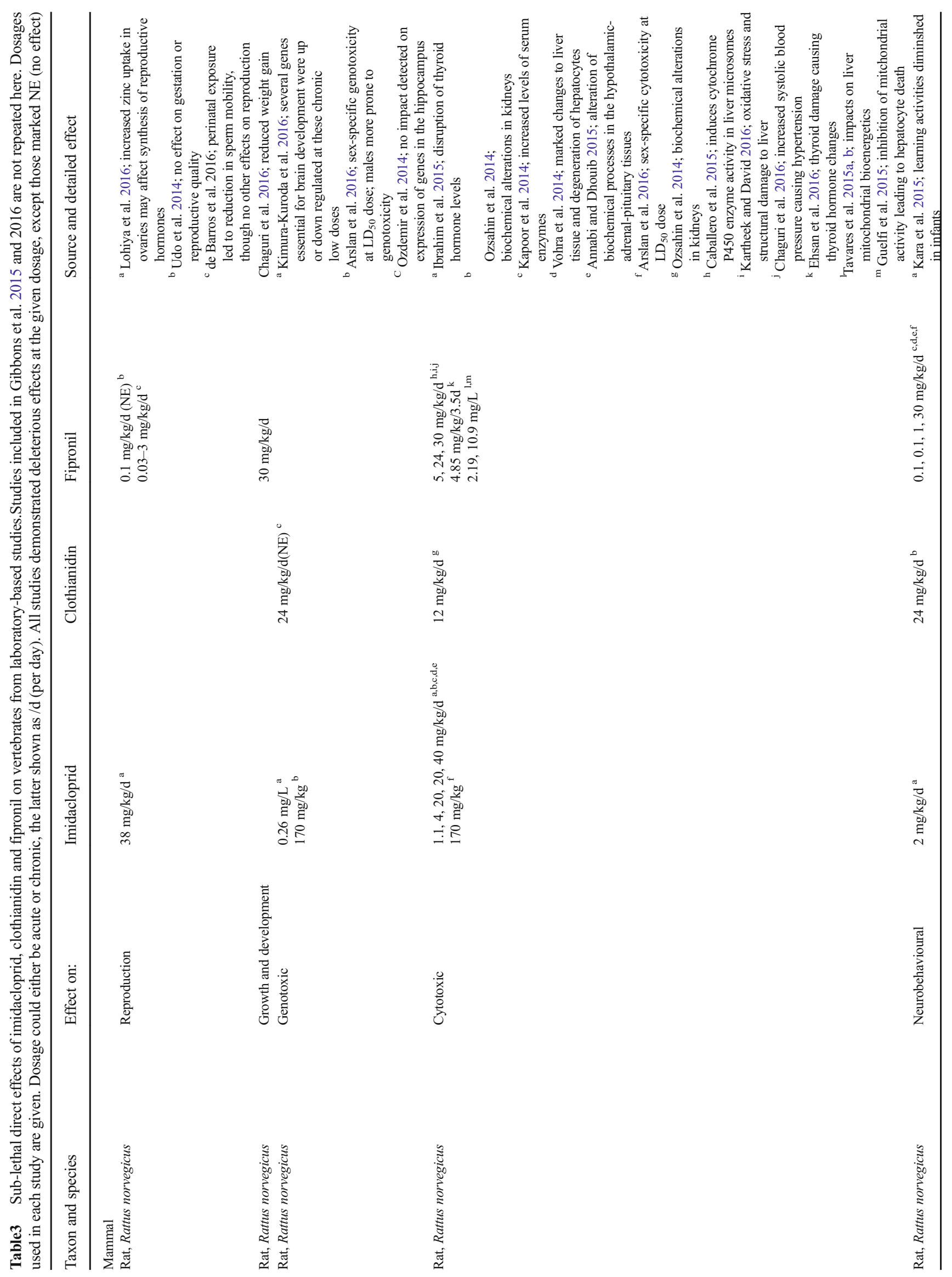




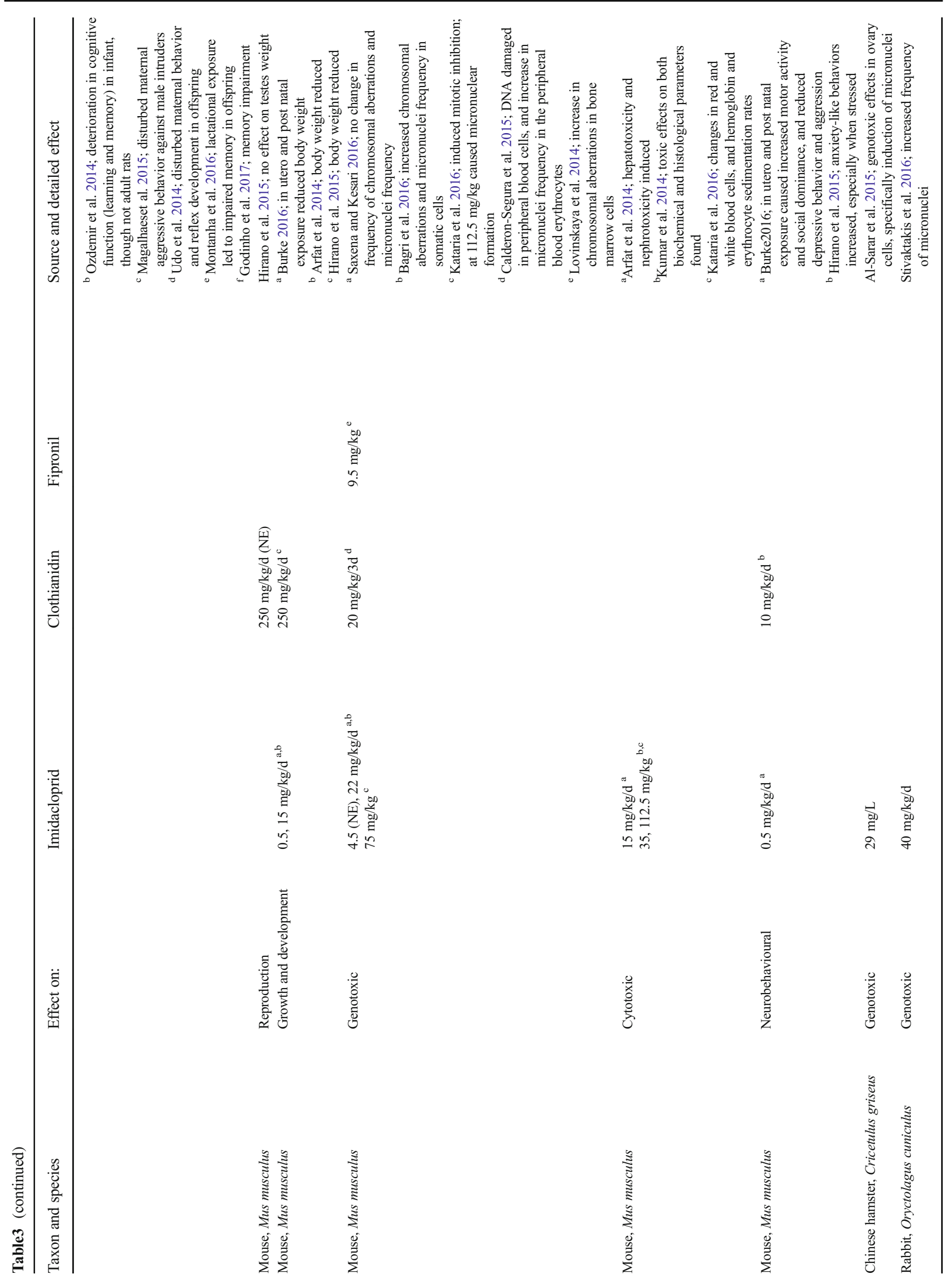



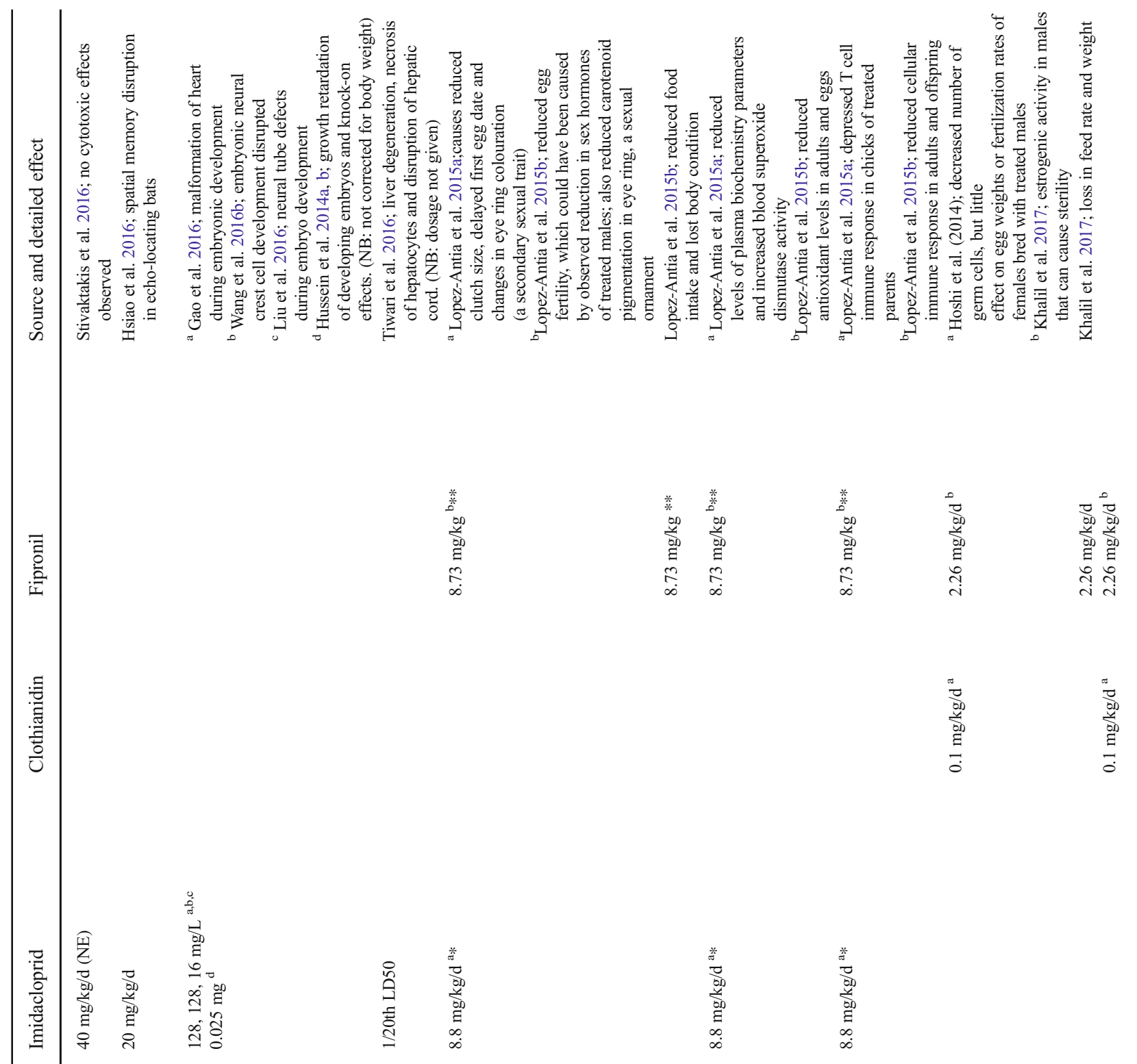

$$
\begin{aligned}
& \frac{5}{50} \\
& \frac{50}{00} \\
& \frac{0}{0}
\end{aligned}
$$

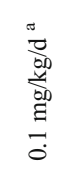

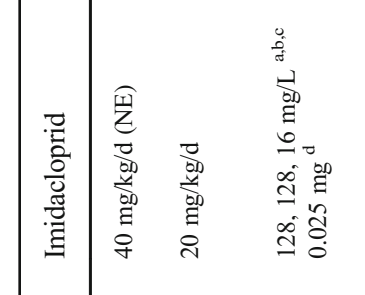
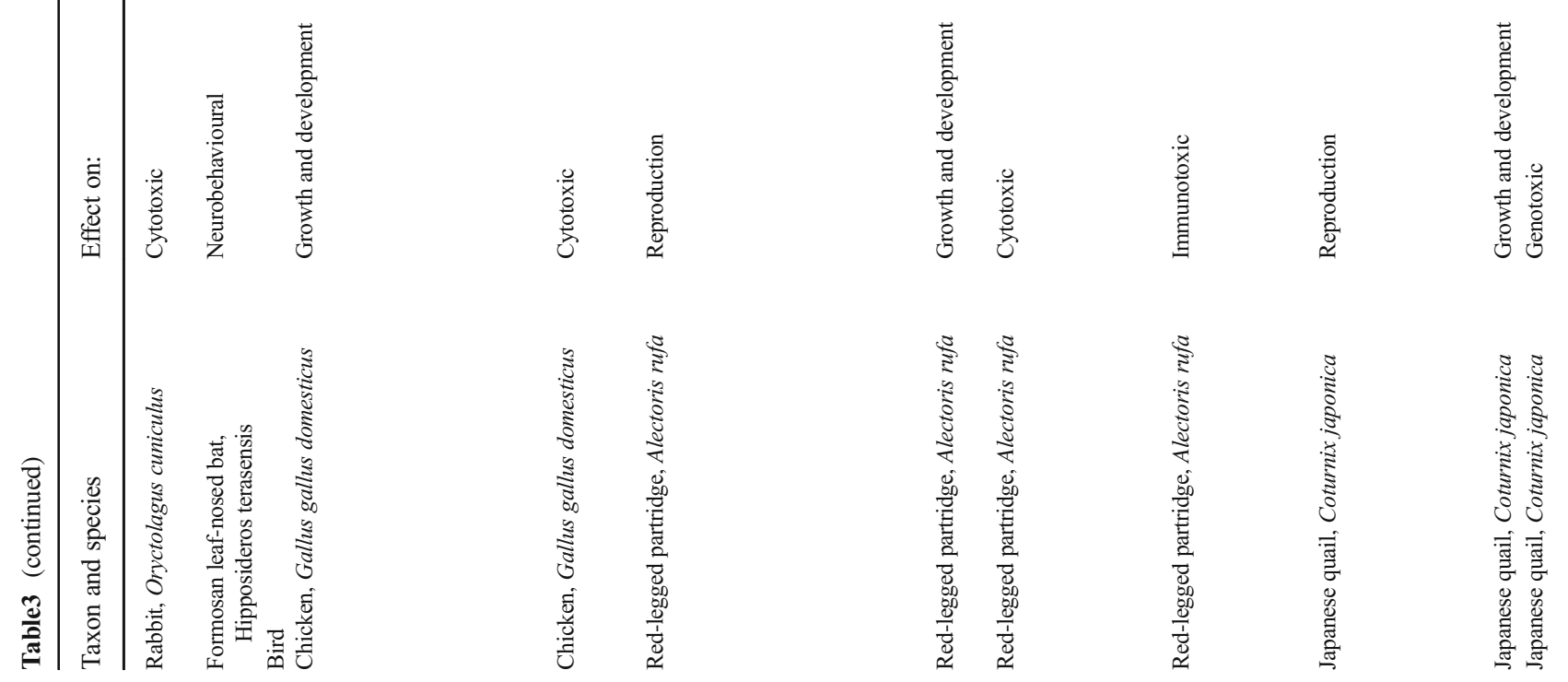

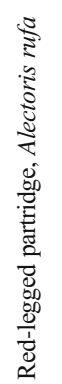
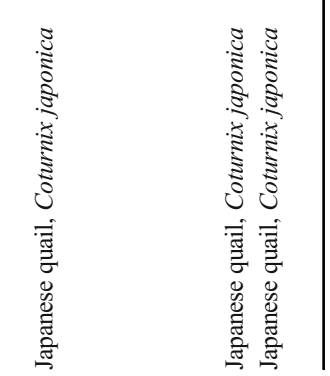


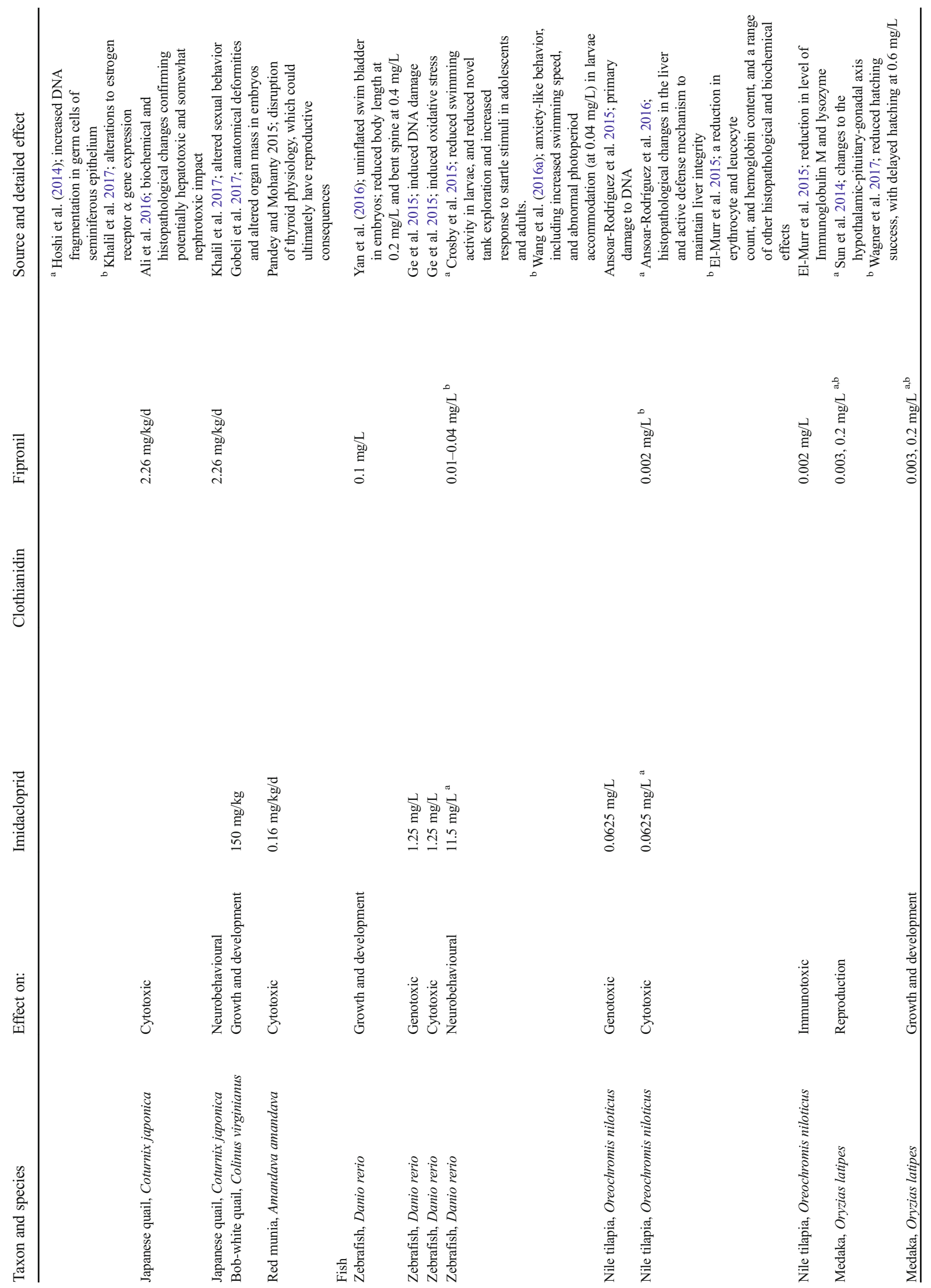




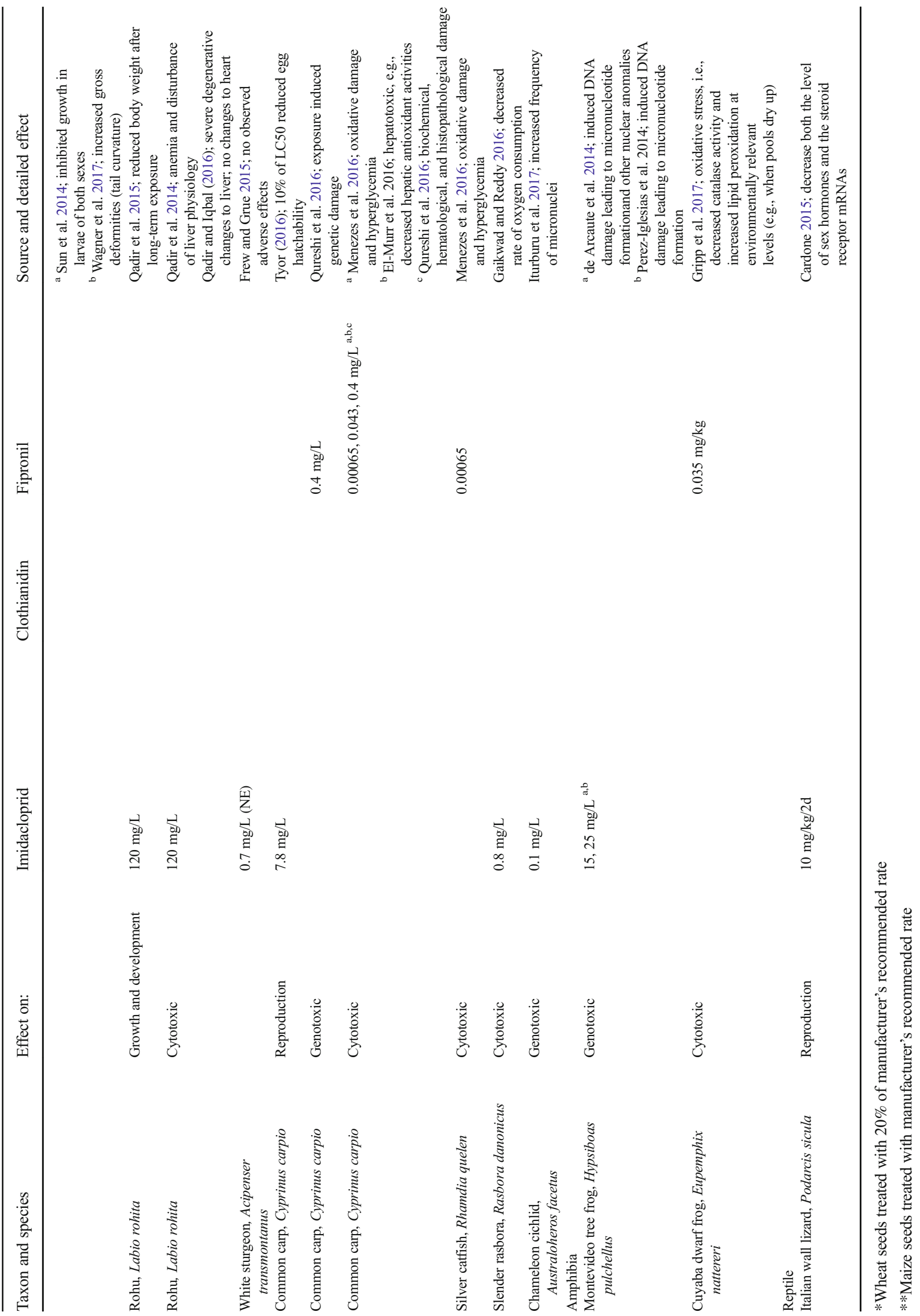


Histopathological changes in the liver were observed in Nile tilapia Oreochromis niloticus after exposure to imidacloprid (Ansoar-Rodríguez et al. 2016), while exposure to fipronil caused a reduction in immune system parameters (El-Murr et al. 2015). Medaka fish Oryzias latipes exposed to fiponil hatched less successfully, grew less well, and suffered tail deformities (Sun et al. 2014; Wagner et al. 2017), while Rohu Labio rohita exposed to imidacloprid grew less well and became anemic (Qadir et al. 2014, 2015). By contrast, no apparent effects on the white sturgeon (Acipenser transmontanus) were observed after treatment with imidacloprid (Frew and Grue 2015).

Once again, many of these sublethal effects occurred at much lower concentrations than lethal effects (Table 3). Thus, for example, while rat LD50 values for imidacloprid, clothianidin, and fipronil are 425-475, 5000, and $97 \mathrm{mg} / \mathrm{kg}$, respectively, cytotoxic effects were detected with daily doses of $1.1,12$, and $5 \mathrm{mg} / \mathrm{kg}$, respectively, and neurobehavioral effects with daily doses of 2,24 , and $0.1 \mathrm{mg} / \mathrm{kg}$, respectively (references given in Table 3). Similarly, while mouse LD50 values for imidacloprid, clothianidin and fipronil are 131-300, $>389$, and $95 \mathrm{mg} / \mathrm{kg}$, respectively, genotoxic effects were detected with daily doses of 22,20 , and $9.5 \mathrm{mg} / \mathrm{kg}$, respectively, and neurobehavioral effects with daily doses of 0.5 (imidacloprid) and 10 (clothianidin) $\mathrm{mg} / \mathrm{kg}$ (references given in Table 3). While a dose of $53 \mathrm{mg} / \mathrm{kg} / \mathrm{day}$ of imidacloprid reduced survival of adult red-legged partridges, one-sixth of this $(8.8 \mathrm{mg} / \mathrm{kg} /$ day $)$ caused reproductive, cytotoxic and immunotoxic effects, in the latter case in the offspring of treated parents. Similarly, while the red-legged partridge LD50 for fipronil is $34 \mathrm{mg} / \mathrm{kg}$, a quarter of that dose $(8.7 \mathrm{mg} / \mathrm{kg})$ caused reproductive, cytotoxic, and immunotoxic effects, the latter in both treated adults and their offspring (references given in Table 3). In some cases, sublethal effects occur at doses several orders of magnitude lower than lethal doses. Thus, an in utero and post-natal daily dose of $0.5 \mathrm{mg} / \mathrm{kg}$ of imidacloprid led to increased motor activity and social dominance, and reduced depressive behavior and aggression in mice $(\mathrm{LD} 50=131-300 \mathrm{mg} / \mathrm{kg})$, while a concentration of $0.65 \mu \mathrm{g} / \mathrm{L}$ of fipronil caused oxidative damage and hyperglycemia in the common carp (LC50 $=0.43 \mathrm{mg} / \mathrm{L})($ Table 3$)$.

\section{Risks to vertebrates from direct toxicity}

Morrissey et al. (2015) documented global mean average, and mean peak surface water concentrations of neonicotinoids of 0.13 and $0.63 \mu \mathrm{g} / \mathrm{L}$, with concentrations of imidacloprid and clothianidin ranging from $0.001-320$ and $0.003-3.1 \mu \mathrm{g} / \mathrm{L}$, respectively. Imidacloprid LC50 values for fishes and amphibians (Table 1 in Gibbons et al. 2015 and here) range from 1200 to $550,000 \mu \mathrm{g} / \mathrm{L}$ and for clothianidin from 94,000 to $117,000 \mu \mathrm{g} / \mathrm{L}$ (Table 1 in Gibbons et al. 2015, fish only). Thus, except in the most extreme cases, these aquatic vertebrates are very unlikely to be exposed to lethal concentrations of these two neonicotinoids in their natural environment. However, the possibility of sublethal effects of imidacloprid cannot be ruled out, with immunotoxic effects recorded in fish at $30 \mu \mathrm{g} / \mathrm{L}$ (Table 2 in Gibbons et al. 2015), and cytotoxic and genotoxic effects at $60 \mu \mathrm{g} / \mathrm{L}$ (Table 3).

Recorded surface water concentrations of fipronil have been documented as ranging from 0.004-6.4 $\mu \mathrm{g} / \mathrm{L}$ (Gibbons et al. 2015; Mize et al. 2008) and 0.13-12 $\mu \mathrm{g} / \mathrm{L}$ (Gan et al. 2012) and are thus within an order of magnitude of LC50 values for some fish (e.g., for Nile tilapia, Oreochromis niloticus, of $42 \mu \mathrm{g} / \mathrm{L}$ ) and encompass part of the range at which sublethal effects have been detected, from $0.2-400 \mu \mathrm{g} / \mathrm{L}$ (Table 3). Thus, this review further supports the assertion of Gibbons et al. (2015) that some recorded environmental concentrations of fipronil may be sufficiently high to harm fish.

The most likely route of exposure to high concentrations of neonicotinoids among terrestrial vertebrates is through the ingestion of treated seeds (Goulson 2013; Mineau and Palmer 2013). Since the previous review, further evidence has come to light that supports this view. A laboratory study has shown that adult female red-legged partridges fed solely on a diet of wheat seeds treated with imidacloprid at field-realistic (i.e., manufacturer's recommended) rate, and equivalent to a dose of $44 \mathrm{mg} / \mathrm{kg} /$ day, were killed, on average, within 7 days; males, within 13 days (Lopez-Antia et al. 2015a). A wide range of sublethal effects (Table 3 ) were also recorded among birds fed on seeds treated with one-fifth of this rate. While redlegged partridges have been shown to avoid imidaclopridtreated seeds due to post-ingestion distress, poisoning still occurs even when alternative food sources are available (Lopez-Antia et al. 2014). Partridges fed on fipronil-treated maize seed, again at a field-realistic rate, suffered a range of sublethal effects (Table 3); they did not reject the treated seeds, rather reduced intake rate and lost body condition (LopezAntia et al. 2015b).

\section{Studies in the natural environment}

Laboratory studies suggest that neonicotinoids and fipronil can kill or harm vertebrates, and inferences can be made from laboratory studies adopting field-realistic conditions. But there are only a few studies of the impact of these systemic insecticides on vertebrate wildlife in their natural environment, involving environmentally relevant concentrations. While several were reviewed in Gibbons et al. (2015), others have been published since. Turaga et al. (2016) examined the crops of nearly 100 wild-caught quail (northern bobwhite, Colinus virginianus, and scaled, Callipepla squamata) but did not find any neonicotinoid-treated seeds; however, the authors note that this study was undertaken in an area with limited use of neonicotinoids. Bro et al. (2016) detected concentrations of up to 67 and $8.5 \mathrm{ppb}$ of thiamethoxam/ 
clothianidin and fipronil (plus fipronil sulfone), respectively, in grey partridge (Perdix perdix) eggs. While the impact of these concentrations on egg viability was unknown, they were probably too low (Table 2 in Gibbons et al. 2015; Table 3 here) to have had any deleterious effects. By contrast, Lopez-Antia et al. (2016) estimated a potential mean daily intake by individual red-legged partridges of 23.4 and $41.7 \mathrm{mg} / \mathrm{kg}$ of imidacloprid and fipronil, respectively, from eating treated seeds left on the surface at sowing. Such a daily dose of imidacloprid exceeds that which causes sublethal effects in red-legged partridges, while the dose of fipronil exceeds the species LD50. Millot et al. (2015) reported that about $10 \%$ of the grey partridges found in their study fields that were exposed to thiacloprid, subsequently died, even though few direct impacts of other pesticides were detected. Finally, Millot et al. (2017) suggested that in France, mortality due to poisoning by imidacloprid-treated seeds was at least likely in $70 \%$ of wildlife mortality incidents reported during 1994-2014. Lopez-Antia et al. (2016) conclude that the use of pesticide-treated seeds presents an unacceptable risk to farmland birds.

Several impacts other than from direct poisoning have been reported. In the Netherlands, Hallmann et al. (2014) found that local population trends of insectivorous birds were more negative in areas with higher surface water concentrations of imidacloprid; populations declined when concentrations exceeded $20 \mathrm{ng} / \mathrm{L}$. While this study was correlative, rather than experimental, and took no account of co-occurring pesticides (Vijver and van den Brink 2014), the effects remained after correcting for other potential drivers of change in bird populations. Given that bird numbers declined at exceptionally low imidacloprid concentrations, the most likely impact of this neonicotinoid was indirect, by reducing their invertebrate food supply, although other mechanisms could not be ruled out.

Two further studies have examined the impact that fipronil sprayed to control either locusts (Maute et al. 2016) or yellow crazy ants, Anoplolepis gracilipes (Stork et al. 2014) had on reptile and bird populations. While no impact was detected on local populations of 23 reptile and 3 bird species, fipronil spraying led to a drop in numbers of one bird species (Christmas Island imperial pigeon, Ducula whartoni) and a short-term increase in another (Christmas Island white-eye, Zosterops natali). The rise in white-eye numbers was probably an indirect, food chain effect caused by a temporary increase in the number of moribund insects as prey. However, the pigeon being a frugivore, its decline may have been due to a direct toxic impact on its reproduction.

\section{Summary of impacts on vertebrates}

In the past 3 years, further evidence has highlighted negative impacts of the neonicotinoids imidacloprid and clothianidin, and fipronil (a phenyl pyrazole) on vertebrate wildlife. All three insecticides exert a wide range of deleterious sublethal effects in the laboratory, with imidacloprid, for example, altering the regulation of genes important in rat brain development and disrupting the spatial memory of echo-locating bats. These sublethal effects are often detected at concentrations substantially lower than those causing lethal effects. Except in the most extreme cases, however, aquatic vertebrates are very unlikely to be exposed to lethal concentrations of these two neonicotinoids in their natural environment, although sublethal effects of imidacloprid cannot be ruled out and is expected in some cases. By contrast, some recorded environmental concentrations of fipronil may be sufficiently high to harm fish.

Since the earlier review, new evidence has emerged suggesting that terrestrial vertebrates can be exposed to high concentrations of neonicotinoids by ingesting treated seeds left on the surface at sowing. One study estimated that the daily doses of insecticides ingested by red-legged partridges could cause sublethal (imidacloprid) or even lethal (fipronil) effects (Lopez-Antia et al. 2016). A second concluded that mortality due to poisoning by imidacloprid-treated seeds was at least likely in $70 \%$ of reported wildlife mortality incidents (Millot et al. 2017). Evidence of the indirect, food chain effects of these insecticides remains rare, though one correlative study found that some local populations of insectivorous birds declined more in areas with higher surface water concentrations of imidacloprid, possibly as a consequence of reduced invertebrate food supplies (Hallmann et al. 2014).

\section{Part C: Ecosystem services}

Ecosystem services are defined as regulation of ecosystem processes (e.g., decomposition, carbon sequestration, pollination, water purification), provision of goods (e.g., timber, food, molecules of pharmaceutical value), habitat for biodiversity (including antagonists of agricultural pests), or other non-material characteristics (e.g., landscape integrity, cultural reference) that are considered as valuable either to human societies or to the environment (de Vries et al. 2013; Melathopoulos et al. 2015; Paetzold et al. 2010; Droz et al. 2009). There is broad scientific consensus that more biodiverse ecosystems generally provide more/better ecosystem services and that the services provided are more resistant to or resilient following stress and perturbation (Isbell et al.2011; Worm et al.2006). It follows that any factor that has a significant negative impact on biodiversity in general or specifically on key organisms responsible for providing valuable services (e.g., pollinators) will reduce the value of the services provided and in extreme cases cause the total loss of the service.

Systemic neonicotinoid and fipronil pesticides have been shown to impact non-target organisms and may subsequently affect several ecosystem services such as pollination (by impacting bees, butterflies and other pollinators), nutrient 
cycling (e.g., by impacting soil or aquatic microorganisms, earthworms, etc.), fish productivity (e.g., by impacting aquatic invertebrates), and agricultural production, if the negative effects on useful non-target organisms outweigh the positive effects on plant protection (Chagnon et al. 2015). However, assessing such impacts is much more challenging than determining thresholds of acute toxicity of each compound. Partly due to a stronger research focus on other environmental stressors, including climate change, the body of knowledge on the effect of systemic pesticides on ecosystem services is limited (Bernhardt et al. 2017).

Regarding impacts on ecosystem functioning and ecosystem services, the WIA study concluded that the large-scale bioavailability of neonicotinoids, in particular, but also of fipronil, in the global environment occurs at levels that are known to cause lethal and sublethal effects on a wide range of terrestrial (including soil) and aquatic microorganisms, invertebrates and vertebrates. Population-level impacts occur at observed environmental concentrations in the field for insect pollinators, soil invertebrates, and aquatic invertebrates, which subsequently impair ecosystem functioning and services (Van der Sluijs et al., 2015).

Since the publication of the WIA, the evidence has further strengthened that these effects impair ecosystem functioning, resilience, and the services and functions provided by terrestrial and aquatic ecosystems. We review here the relevant studies published since 2015 that either specifically dealt with the impact of these insecticides on ecosystem services (e.g., pollination) or that affect key ecosystem functions. We mainly focus on the progress regarding the knowledge gaps regarding impacts on ecosystem services identified in the WIA study, especially (a) impact of accumulation in soil and sediments on soil health, soil structure and permeability and nutrient cycling; (b) impacts on pollination, pest control services and fauna valued for esthetic reasons (e.g., butterflies); (c) impacts of depletion of farmland insect and aquatic insect populations on insectivorous species such as birds and bats; (d) (indirect) impacts of contamination of freshwater on insect-eating fish and subsequently fisheries and other insectivores such as amphibians; and (e) impacts on coastal marine systems such as coral reefs, and salt marsh estuaries.

\section{Impacts on the soil ecosystem}

Since their introduction in the United States and Europe in the mid-1990s, the use of neonicotinoids has increased rapidly as seed-applied products were introduced in field crops (particularly in corn and soybean between 2011 and 13), marking an unprecedented shift toward large-scale, prophylactic insecticide use (Simon-Delso et al. 2015). This means that more and more agricultural land is being loaded with neonicotinoid residues every year, since only maximum $20 \%$ of the insecticide present in the coating of the seeds is taken up by the crop plants (Goulson 2013), the remainder being left in the soil of the field. The ecological consequences of this accumulation of contamination in the agricultural land have not been studied in detail yet, but a few recent studies provide some indication.

Soil enzymes are indicators of microbial activities in soil and can therefore be used as biomarkers of soil health and fertility. Jyot et al. (2015) tested the impact of cotton seeds coated with thiamethoxam at two different rates (standard application $2.1 \mathrm{~g}$ a.i. $/ \mathrm{kg}$ seed and a high rate of $8.4 \mathrm{~g}$ a.i. $/ \mathrm{kg}$ seed) on soil enzymes in Pakistan. The activities of dehydrogenase and phosphatase enzymes were significantly reduced in the soils treated at both rates, this effect being most pronounced after 15 or 21 days, whereas the activity of urease was not affected. Their findings suggests that microbial soil communities are depleted in the first 3 weeks after planting, although their recovery occurs after thiamethoxam residues in soil are reduced (Jyot et al. 2015).

In a mesocosm study, pots were treated with wheat-seed dressings containing imidacloprid and fungicides. Seed dressings increased the number of protozoa and reduced plant decomposition rate but did not affect earthworm activity. Fungicides, in particular, increased collembola surface activity, which in turn influenced the activity of earthworms (Lumbricus terrestris), but reduced soil basal respiration. Earthworms also decreased wheat growth, reduced the soil basal respiration and microbial biomass, but increased the soil water content and electrical conductivity (Zaller et al. 2016). However, in a similar experiment that used the same seed treatment, soil basal respiration, microbial biomass, and litter decomposition were not affected. In the latter study, seed dressings significantly reduced the surface activity of earthworms independently of whether fungicides were used or not. By contrast, earthworm activity was intensified by glyphosate herbicide applied to the pots (Van Hoesel et al. 2017).

While there is no evidence of bioaccumulation of neonicotinoids in organisms, the systemic insecticide fipronil appears to accumulate in earthworms. Chronic exposure of Eisenia fetida to sublethal levels (10 to $50 \mathrm{mg} / \mathrm{kg}$ soil) of a racemic mixture of fipronil for 28 days showed accumulation of this insecticide in the tissues, which appears to be enantioselective: the S-fipronil enantiomer and the fipronil sulfone metabolite were preferentially found in the tissues, mainly because the elimination rate of R-fipronil was higher than that of the S-enantiomer. Because of the relative lipophilicity of these compounds and their slow rate of depuration, the authors warned of potential bioaccumulation through the food chain (Qin et al. 2015).

One way of reducing the pesticide residue loads in soil is by using soil amendments. A microcosm that contained soil contaminated with imidacloprid was treated with two soil amendments (vine-shoot and olive cake) at different rates, and incubated for 3 months. The dissipation rate constant of imidacloprid correlated well with changes in the bacterial 
community during incubation in the contaminated soil amended with olive-vermicompost. The study suggested that amendment of imidacloprid-contaminated soil with this type of vermicompost can mitigate the impact of this insecticide on soil functions and promote its depuration capability, thus minimizing environmental risks to other soil organisms (Castillo Diaz et al. 2017). Schaafsma et al. (2016) suggest rotational crops to reduce the burden in soils treated with clothianidinand thiamethoxam-coated seeds. Other authors have indicated that neonicotinoids could be more carefully targeted, considerably reducing use without adversely affecting yield, and with considerable benefits for reducing the potential for pest resistance, outbreaks of non-target pests, and overall harm to the environment (Douglas and Tooker 2015).

\section{Impacts on pollination services}

Pollination is an essential regulating, supporting, and cultural ecosystem service that comprises an integrated system of interactions that links earth's vegetation, wildlife, and human welfare (Kevan and Menzel 2012; Van der Sluijs and Vaage, 2016). Pollination is essential for the setting of fruits and seeds of many crops and wild plants. Up to $94 \%$ of all flowering plants on earth benefit from animal pollination for reproduction and evolution (IPBES 2016b; Van der Sluijs and Vaage 2016). Globally, 87 of humanity's major food crops depend on animal pollination (Klein et al. 2007). These account for $35 \%$ of global crop production volume (IPBES 2016b) and include vegetable, fruit, nut, and edible oil and proteinaceous crops, as well as spices and condiments (Maxim and Van der Sluijs 2013). Many fiber and fodder crops also depend on insect pollination. Loss of insect pollinators can thus indirectly affect the production of livestock agriculture. Biofuel crops (e.g., canola) and timber production (trees) also require animalpollination. The majority ornamental flowering plants as well as plants used for production of phytopharmaceuticals also depend on pollinators. The quality (especially fruit quality), shelf life, and commercial value of crops also benefits from insect pollination (Klatt et al. 2014). It is also essential for the genetic diversity of wild flowering plants (Benadi et al. 2013).

Further, pollinator-mediated crops are of key importance in providing essential nutrients in the human diet. They account for more than $90 \%$ of vitamin C, $100 \%$ of lycopene and almost $100 \%$ of the antioxidants $\beta$-cryptoxanthin and $\beta$-tocopherol, the majority of the lipids $(74 \%)$, vitamin A $(>70 \%)$ and related carotenoids $(98 \%)$, calcium $(58 \%)$ and fluoride $(62 \%)$, and a large portion of folic acid $(55 \%)$. In total, pollinator-mediated crops account for about $40 \%$ of global nutrient supply for humans (Eilers et al. 2011). At present, an estimated 2 billion people suffer from deficiencies of such micronutrients, also known as hidden hunger (IFPRI 2014; Nicole 2015).
Pollination is also essential for sustaining the diet of wildlife. Many bird and mammal species feed on wild fruit (e.g., birds that feed on all kinds of wild berries in forests), wild nuts, and seeds of wild plants. If all insect pollinators were removed, this would result in a drastic decline in setting of wild fruits, nuts, and seeds, which would affect all species that depend on it. Herbivores can also suffer from food depletion if pollinator-dependent plants on which these herbivores depend can no longer reproduce (Van der Sluijs and Vaage, 2016).

The economic value of pollination services is calculated based on a huge assumption and needs a different approach that incorporates larger data (Melathopoulos et al. 2015). Kleijn et al. (2015) showed that $80 \%$ of crop pollination across five continents is carried out by just $2 \%$ of all wild bee species in the areas studied and contributes the vast majority of economic returns in agricultural systems. Besides ethical reasons, the authors argued that there are other important reasons for conserving other wild bees that do not pollinate crops and offer little economic return to farmers. For example, biodiversity benefits ecosystem services by providing insurance effects. Therefore, they argue that conservation of a wide range of bee species, not just those that are currently numerous on crops, is needed to maintain stable pollination services, as new bee species may become important pollinators in the future.

Pollinating services are provided by a wide range of animal species, mostly insects including honeybees, bumblebees, solitary bees, stingless bees, hover flies, butterflies, wasps, moths, beetles, midges, and other invertebrates, but also some vertebrates are known to pollinate such as bats, squirrels, parrots, hummingbirds, some primates, and humans (hand pollination) (Buchmann and Nabhan 1997; Klein et al. 2007). For agricultural crops, bees are the most important pollinators (UNEP 2010). In the past, most of the credit has been given to domestic honeybees. However, recent studies have shown that wild pollinators are more important contributors to global crop pollination than previously assumed (Breeze et al. 2011). Estimates for the UK indicate that managed honeybees (Apis mellifera) pollinate approximately no more than one third of the crops. Among the unmanaged pollinators, wild bees are important. Globally, over 25,000 species of bees are known (Chagnon et al. 2015). However, many insects other than bees are also efficient pollinators, providing $39 \%$ of visits to crop flowers (Rader et al. 2016). Wild insect pollinator species are regarded as the most effective pollinators of fruit crops (Chagnon et al. 2015). Klein et al. (2007) pointed to nine pollinator-dependent crops that did not exhibit proof of honeybee presence, and that three of these (atemoya, passion fruit, and vanilla) are now hand-pollinated in parts of the world, due in part to the reduced presence of the relevant wild pollinators.

Kleijn et al. (2015) showed that $80 \%$ of crop pollination across five continents is carried out by just $2 \%$ of all wild bee species in the areas they studied and contribute the vast majority of economic returns in agricultural systems. Besides 
ethical reasons, the authors argued that there are other important reasons for conserving other wild bees that do not pollinate crops and offer little economic return to farmers. For example, biodiversity benefits ecosystem services by providing insurance effects. Therefore, they argue that conservation of a wide range of bee species, not just those that are currently numerous on crops, is needed to maintain stable pollination services, as new bee species may become important pollinators in the future.

Crop yield and/or quality depend on both the abundance and diversity of pollinators (EASAC 2015). In general, a diverse community of pollinators provides more effective and stable crop pollination than any single species. Even when managed honey bees are present in high abundance, diversity of wild pollinators still improves crop pollination. Overall, the contribution of wild pollinators to crop production is undervalued (IPBES 2016b).

The impact of neonicotinoids on pollination has primarily been studied for oil seed rape agro-ecosystems. This crop is indeed especially relevant at least in the European context because, as stated by Budge et al. (2015): "Nowhere is this tension more evident than in the system we describe here with the world's most widely used insecticide, the world's most widely used managed pollinator and Europe's most widely grown mass flowering crop." These authors used combined data on large-scale pesticide use, yields of oliseed rape and honeybee colony losses over an 11 year period in England and Wales to study the impact of the three major neonicotioids used in that crop (imidacloprid, clothianidin, and thiamethoxam). They found that seed coating with imidacloprid had positive effects on yields in some years but negative effects on other years. Similarly, costs/benefits for farmers changed from year-to-year, prompting the authors to state: "Risk assessments assuming total control in the presence of a seed coating versus apocalyptic yield losses in their absence are simplistic and perhaps over-state the benefits". At the same time, a correlation between honeybee colony losses and national-scale imidacloprid usage patterns was apparent and could not be ignored (Budge et al. 2015).

A field study conducted in southern England showed that neonicotinoids used as seed dressing for autumn-sown crops (oil seed rape (OSR) and winter wheat) contaminated adjacent soil and wildflowers (Botias et al. 2015). The pollen and nectar of these flowers were contaminated by thiamethoxam, clothianidin, imidacloprid, and thiacloprid (up to a frequency of 58.8\%) in the following growing season with frequencies and concentrations declining between spring and summer. Concentrations were quite variable among samples (maximum concentrations: $19.12 \mathrm{ng} / \mathrm{g}$ for clothianidin in field margin soil and $28.6 \mathrm{ng} / \mathrm{g}$ in ORS cropland soil and $86.02 \mathrm{ng} / \mathrm{g}$ for thiamethoxam in hand collected wildflower pollen from OSG field margins and $25.55 \mathrm{ng} / \mathrm{g}$ for imidacloprid in bee-collected pollen during OSR blooms), suggesting high spatial heterogeneity in neonicotinoid accumulation and/or degradation.
Frequency of occurrence and average concentrations were higher in pollen than in nectar. The authors estimated that $97 \%$ of all neonicotinoids entering the hive in pollen originated from wildflowers and only $3 \%$ from oil see rape. And important implication of this study is that it may explain why no impact of neonicotinoid on bees could be observed when comparing treated and non-treated fields because in both cases the bees were collecting most of the pollen and nectar from contaminated wildflowers, and very little from the treated crop. This implies that the impact of neonicotinoids on pollinators and hence on pollination service may have been underestimated and that experimental field studies are not good models for understanding the extent of the impacts. Another study in the USA reported similar findings (Long and Krupke 2016).

In a follow-up study, the authors further explored the contamination of neonicotinoid-treated OSR and field margin wild plants by neonicotinoids (Botías et al. 2016). The range of neonicotinoid concentrations was high in field margin wild plants (up to $106 \mathrm{ng} / \mathrm{g}$ for thiamethoxam for Cirsium vulgare) Maximum, but not average neonicotinoid concentrations were higher in field margin wild plants than OSR. As C. vulgare is notoriously attractive to many pollinators and its seeds eaten by different finch species, the high neonicotinoid concentration reported in this species, is of concern. These results may indicate that hedgerows and field margins, which are often managed to for biodiversity conservation and act as reservoirs for pollinators and antagonists of agricultural pests, may fail to deliver these functions (i.e., ecosystem services) if contaminated by neonicotinoids.

David et al. (2016) analyzed the content of neonicotinoids and fungicides in pollen from OSR and OSR field margin wildflowers and pollen collected by honey bees. Frequency of occurrence and mean concentrations of neonicotinoids was higher in OSR, lower in wildflowers and lowest in honey bee pollen. Pesticides concentrations were higher during ORS bloom than after. However, the highest single measured concentration for thiamethoxam $(21 \mathrm{ng} / \mathrm{g})$ was from a wildflower pollen sample (Matricaria recutita). The pesticide content of bumblebees and bumblebee pollen from rural and urban areas was also compared. Frequency of occurrence and mean concentrations of neonicotinoids were higher in rural samples. Frequency of occurrence and mean concentrations of neonicotinoids were higher in pollen from bumblebees as compared to pollen from honey bees, both collected during OSR bloom, presumably because bumblebees have a higher propensity to collect ORS pollen and forage over shorter distance, mostly within the neonicotinoid-contaminated area (David et al. 2016).

Sublethal concentrations of neonicotinoids were shown to alter the foraging behavior of bumblebees including a change in flower preference (bees exposed to thiamethoxam visiting more the larger, yellow flowers of Lotus corniculatus than the 
smaller, white flowers of Trifolium repens), an increase in the proportion of bees foraging, and an increase in the proportion of bees collecting pollen. Bees exposed to thiamethoxam learned to manipulate flowers faster but after more visits (Stanley and Raine 2016). These results suggest that exposure of bees to sublethal concentrations of neonicotinoids may alter their function as pollinators, possibly favoring some plant species over others, with potential implications for both crop production and wildflower reproductive success.

Widespread contamination of wild plants at field margins of arable crops has been demonstrated in other studies (Krupke et al. 2017). As a consequence, detrimental effects on survival of managed bees (Mogren and Lundgren 2016) as well as wild bees (Mallinger et al. 2015; Stanley and Raine 2016; Woodcock et al. 2016) have been documented. More recently, a correlation study between the use of pesticides, including neonicotinoids, and the abundance of butterflies in California has shown that the latter pesticides could be responsible for the decline of several species since 1996, when they were introduced in that State (Forister et al. 2016).

There is enough mechanistic understanding to put the question of causality beyond reasonable doubt. The detrimental effects on pollinators from the present scale of use of neonicotinoids are likely to impact pollination services, and in turn pollinator-dependent crop production.

\section{Impacts on natural systems for pest and weed control}

Detrimental effects of systemic insecticides on natural predators and parasitoids have been discussed above, but most of the evidence comes from laboratory studies. Here are shown further mesocosms or field studies related to the dynamics of pest control in agricultural systems.

In cotton fields, both thiamethoxam and imidacloprid, applied as seed treatment, reduced abundance of beneficial arthropods, although in the case of imidacloprid only with applications at higher than recommended doses. However, it is important to note that sublethal effects were not evaluated in the study (Saeed et al. 2016). Uhl et al. (2015) studied trophic interactions in a threelevel food chain mesocosm: wild strawberry Fragaria vesca, wood cricket Nemobius sylvestris, and nursery web spider Pisaura mirabilis. They found that a low imidacloprid rate $\left(0.24 \mathrm{~g} / \mathrm{m}^{2}\right)$ reduced mass gain in crickets, whereas a high rate $\left(2.4 \mathrm{~g} / \mathrm{m}^{2}\right)$ reduced feeding, mass gain, thorax growth, and mobility in crickets compared to the control. Both herbivory of crickets and predation by the spider were reduced at sublethal imidacloprid concentrations, with survival of crickets being higher in the low treatment. The experiment suggests that trophic interactions can be hampered even at sublethal concentrations of the insecticide (Uhl et al. 2016).

Secondary poisoning by preying on neonicotinoidcontaminated prey was already known from laboratory studies (Walker et al. 2007; Wanumen et al. 2016b), but it has now been confirmed under field situations: after feeding on contaminated aphid prey in wheat fields treated with thiamethoxam, the ladybird Coleomegilla maculata experienced sublethal effects that significantly impaired its predation capabilities (Bredeson et al. 2015). As a consequence, the target pest is not effectively eliminated by its natural enemy, potentially leading to pest resurgence. Surge of secondary pests may also occur when there is differential toxicity among two or more pest species. For example, where leaffolder (Cnaphalocrocis medinalis) incidence occurs along with planthoppers (Nilaparvata lugens) in rice fields of India, the use of neonicotinoids has resulted in increases of the leaffolder population. Stimulated fecundity of the leaffolder bugs on neonicotinoid-sprayed plants, coupled with reduced larval duration and low egg toxicity, were the major factors contributing to the upsurge of leaffolders (Chintalapati et al. 2016).

Overall, the combined effect of lethality on non-target natural enemies, secondary poisoning and sublethal impairments on their predatory ability results in deficient pest control and often leads to the resurgence of pests - a clear case of pest control failure (Kurwadkar and Evans 2016).

Indirect effects of pesticide seed treatments have been observed in regard to weed control. Thus, in a 2-year field study in the USA, the abundance of natural enemies (e.g., soil-dwelling seed predators and pathogens) that damage or destroy seeds of weeds in the agricultural soil was reduced in maize and soybean crops treated with pesticide-coated seeds (presumably a neonicotinoid and fungicides). Therefore, the weed seed banks in seed-treated plots would be larger and less diverse than those in untreated plots; hence, weed populations may increase in crops using pesticide seed treatments (Smith et al. 2016).

\section{Impacts on aquatic ecosystems}

The contamination of agricultural soil with neonicotinoid and fipronil residues results mainly from the widespread use of pesticide-coated seeds (Douglas and Tooker 2015; Hladik et al. 2014). Eventually, soil residues move into the aquatic ecosystems, either by percolation and leaching through the soil profile (de Perre et al. 2015; Wettstein et al. 2016) or in surface runoff after rainfall and storms (Chrétien et al. 2017). Foliar sprays and drenches applied to orchard trees also contribute to the contamination of waterways (Englert et al. 2017; Kreutzweiser et al. 2008b). There is sufficient evidence to date to state that water borne residues of neonicotinoids and fipronil are currently impacting on aquatic ecosystems, as shown in the recent review by Sánchez-Bayo et al. (2016).

The main impacts include altering the invertebrate communities, mainly insects, that live in streams and ponds, which are responsible for the recycling of organic matter that falls into them (Englert et al. 2017). The main taxa affected have been discussed above and include key species such as midges and other Diptera such as mayflies, stoneflies, and caddisflies 
as well as predatory dragonflies, damselflies, bugs, and beetles. The most sensitive species are detritivorous that fulfill an essential role in the recycling of organic matter in streams (Kreutzweiser et al. 2008a), and low water residue levels induces sublethal effects that impair their ability to perform this role (Kattwinkel et al. 2016), while their elimination translates into alterations in ecosystem functions, like leaf litter breakdown (Englert et al. 2012). Most of these taxa have aquatic larval stages and produce a large biomass that feeds a diverse array of insectivorous vertebrates such as newts, frogs, lizards, aquatic shrews, and birds. The depletion of this food source can be quantified in mesocosm studies, as described in (Sánchez-Bayo et al. 2016a). New studies on experimental rice mesocosms have shown that while standard application of imidacloprid to rice seedlings reduces the abundance of dragonflies and water predatory bugs, dinotefuran did not produce any significant effects on the insect communities, and rather increased the abundance of midges and one species of dragonfly through indirect competition with other species (Kobashi et al. 2017).

The insect fauna in Germany over the past 20 years has recorded a drop in abundance of flying insects, mainly Diptera, of over 75\% (Sorg et al. 2013). As many of these insects have aquatic life cycles, their disappearance is probably due to their larvae not having survived their aquatic phase. The consequences go beyond the realm of the aquatic ecosystem, since insects are the staple food source of many songbirds. The study by Hallmann et al. 2014 (see part B here) showed that in regions of the Netherlands where waterway contamination with imidacloprid was above $20 \mathrm{ng} / \mathrm{L}$ (ppt), populations of 14 species of birds have steadily declined in the past 20 years (Hallmann et al. 2014).

Risks of neonicotinoids to aquatic ecosystems are often been dismissed after some studies showed that current residue concentrations in water are not likely to be toxic (e.g., acute toxicity) to the common surrogate species used in regulatory risk assessment of chemicals. For example, clothianidin was detected at low concentrations in soil and water throughout a 2 -year corn and soybean rotation. No short-term environmental risk was expected for the species investigated (Daphnia magna, Hyalella azteca, Chironomus dilutus, Pimephales promelas, and Eisenia fetida) because, with the exception of the amphipod, all species are very tolerant to this and other neonicotinoids (de Perre et al. 2015). This and similar studies funded by the chemical industry (Aslund et al. 2017) do not take into account the chronic lethality to sensitive aquatic

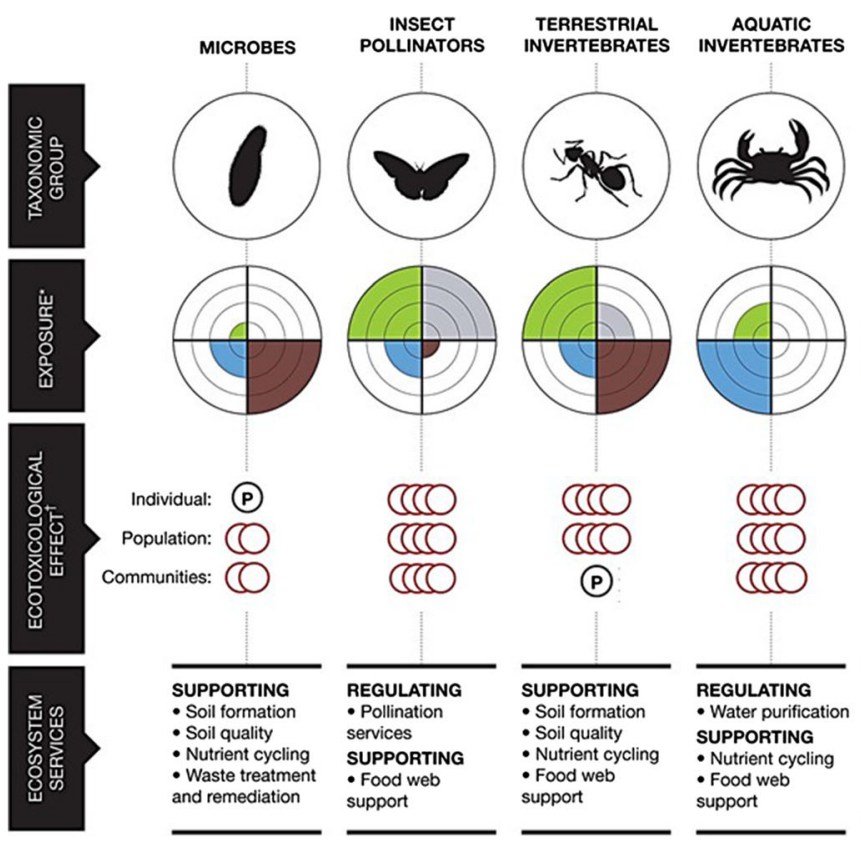

Fig.3 Summary of exposure routes and effects of neonicotinoids and fipronil on taxonomic groups. Routes of exposure are depicted by a quarter of circle for air (gray), plants (green), soil (brown), and water (blue). Exposure is scaled with five levels, and colored as variable circular sectors (empty: no route of exposure; small: potential route of exposure assumed neglectible; medium: relevant route of low exposure; large: relevant route of moderate exposure; extra-large: relevant route of high exposure). Ecotoxicological effects are scaled with four levels, according to the number $(n)$ of imbricated red circles $(n=1$ : potential effects assumed neglectible under normal exposure conditions; $n=2$ :
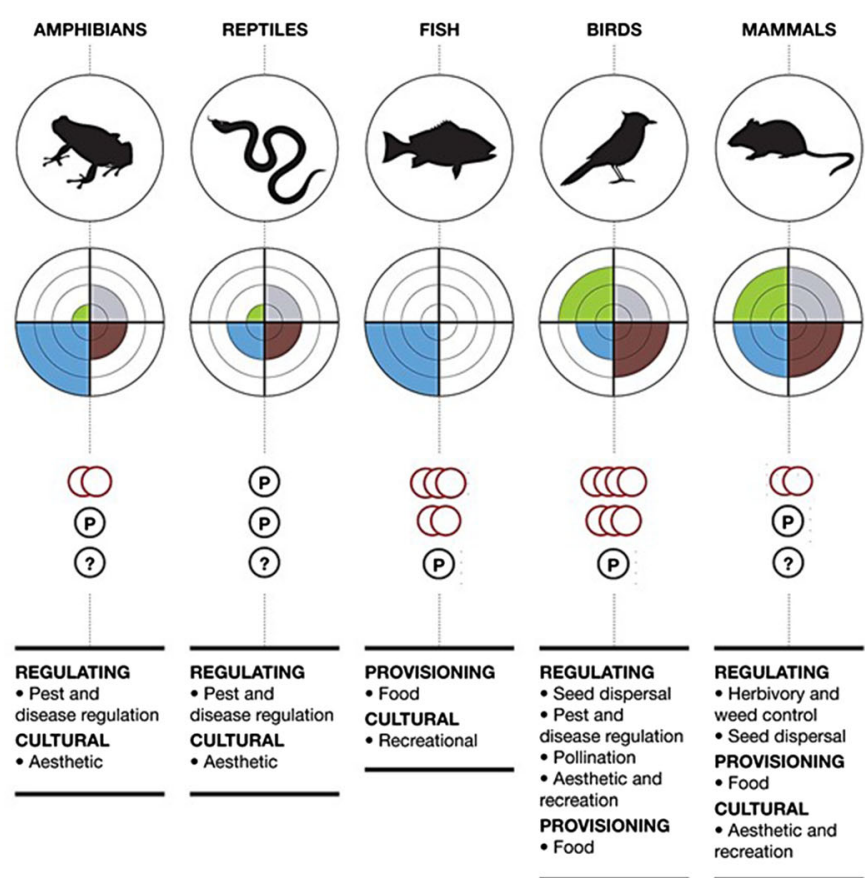

(?)

evidence of effects which can occur at high doses or after chronic exposure; $n=3$ : evidence of effects which can occur at moderate doses; $n=4$ : evidence of effects which can occur at low doses or after acute exposure). Probable effects are reported with $(\odot$ when no accurate judgment could be made due to incomplete evidence, but for which data suggest a potential effect that can occur at high doses or after chronic exposure. A question mark is reported in situation where no assessment could be made because of lack of evidence (e.g, no data available). Major ecosystem services regulated and supported by these taxonomic groups are listed at the bottom 
organisms explained above, which is the real cause of concern for the long-term impacts on this ecosystem.

Aquatic vertebrates such as fish, however, may not be affected directly by residues of neonicotinoids in water. Treatment of oyster beds with imidacloprid to avoid burrowing shrimps after harvest did not appear to threaten populations of the endangered green sturgeon (Acipenser medirostris) in the west coast of the USA (Frew and Grue 2015; Frew et al. 2015). Nevertheless, the authors only compared the residual concentrations of imidacloprid in the water column (28 ppb) and shrimp (31 ppb) to the acute and chronic toxicity of this insecticide to a surrogate fish species (rainbow trout), since the actual toxicity to the sturgeon is unknown. It is likely that the risks of such contamination to a large fish like the sturgeon are negligible, even though sublethal effects cannot be ruled out (see Section B). Impacts on fish species, if any, would occur through indirect starvation after the invertebrate food source is depleted.

\section{Conclusions}

In the past 3 years, we have gained a greater description about the exposure to neonicotinoids and fipronil and a greater understanding about their effects in arthropods and other species, as a result of a large research effort made worldwide. Fipronil has been studied to a lesser extent. A summary of our worldwide integrated assessment for taxonomic groups is synthesized in Fig. 3, with the exposure data to these systemic insecticides (Giorio et al., 2017, this special issue), their ecotoxicological effects and the related ecosystem services.

Research on bees has revealed new aspects of sublethal effects, including the reduced fecundity of queen bees, impairment of sperm in drones, negative interactions with parasites and the immune system. Our knowledge of acute toxicity has also broadened to include some wild bee species, while the mixture toxicity in combination with other pesticides or infectious agents has reported some synergisms that are more pronounced than simply additive. Impacts of neonicotinoids and fipronil at the population level of bumblebees were known to some extent, but have now been compared among countries with different environments. The impacts on other wild bees were unknown and recent studies have shown that they are more sensitive to neonicotinoids than the honey bee. These impacts on pollinators are a real cause for concern, with a few studies showing a correlation between the use of neonicotinoids and the declines in wild bees and butterflies in Europe and America. Their presence in hedgerows or field margins may expose pollinators to drift or uptake of active molecule by growing plants.

It was known that neonicotinoids were very toxic to natural enemies of agricultural pests and caused secondary poisoning. The new information gathered in this area has only contributed to enlarge the range of species tested, whether predatory or parasitoids, thus confirming the unsuitability of neonicotinoids for integrated pest control programs.

Little progress has been made, however, in evaluating the effects of these insecticides on soil organisms, with the exception of a study showing the possible bioaccumulation of fipronil in earthworms. Some field studies on indirect impacts on non-target termites and other arthropods have reported ambiguous findings.

New studies on aquatic invertebrates have focused on acute and chronic toxicity of clothianidin, thiamethoxam, and a few new compounds to a wider range of taxa, since the data available until recently referred almost exclusively to imidacloprid. There is now sufficient data to set protective limits for aquatic invertebrate communities in the legislation. Some studies have shown how the current contamination of surface waters in many countries are effectively damaging the underlying insect communities that provide a rich food source not only to fish but also birds and other insectivorous vertebrates. The chronic exposure to low levels of neonicotinoid residues in water are causing a long-term lethality in most aquatic species, which eliminates entire populations form the affected areas.

Fipronil and the neonicotinoids imidacloprid and clothianidin exert a wide range of deleterious sublethal neurological effects in terrestrial vertebrates, such as rats and bats. Ingestion of treated seeds by birds can cause sublethal effects on immunity and can be lethal at times. Aquatic vertebrates, however, are very unlikely to be exposed to lethal or sublethal concentrations of neonicotinoids in their natural environment, whereas environmental concentrations of fipronil may be sufficiently high to harm fish.

Overall, the negative impacts of neonicotinoids and fipronil on terrestrial and aquatic invertebrates are translated in indirect impact for the entire ecosystems. Invertebrates constitute the main food source for an innumerable number of insectivorous vertebrates and fulfill an essential role in recycling organic matter in the soil as well as in water. The consequences of losing the invertebrate fauna due to continuous exposure to ubiquitous residues of neonicotinoids and fipronil are thus far reaching and cannot be ignored any longer.

Acknowledgments The work has been funded by the Triodos Foundation's Support Fund for Independent Research on Bee Decline and Systemic Pesticides. This Support Fund received donations from the Act Beyond Trust (Japan), Stichting Triodos Foundation (The Netherlands), M.A.O.C. Gravin van Bylandt Stichting (The Netherlands), Zukunft Stiftung Land-wirtschaft (Germany), Hartmut Spaeter Umweltstiftung (Germany) and citizens. The authors also thank the Lune de Miel Foundation (France), the David Suzuki Foundation (Canada), the SumOfUs community (Germany), the Rovaltain Foundation (France), the Aurelia Foundation (Germany) and IUCN for their help in dissemination of these updated WIA findings. The funders had no role in study design, data collection and analysis, decision to publish, or preparation of the manuscript. The authors declare no competing conflict of interest. The authors thank C. Pacteau, E. Lumawig, N. Pezant, T. Brooks, and A.-L. Thomann for fruitful discussions and their help in this project. 
Open Access This article is distributed under the terms of the Creative Commons Attribution 4.0 International License (http:// creativecommons.org/licenses/by/4.0/), which permits unrestricted use, distribution, and reproduction in any medium, provided you give appropriate credit to the original author(s) and the source, provide a link to the Creative Commons license, and indicate if changes were made.

\section{References}

Adán Á, Viñuela E, Bengochea P, Budia F, Del Estal P, Aguado P, Medina P (2011) Lethal and sublethal toxicity of fipronil and imidacloprid on Psyttalia concolor (Hymenoptera: Braconidae). J. Econ. Entomol. 104(5):1541-1549

Ahmad M, Rafiq M, Arif MI, Sayyed AH (2011) Toxicity of some commonly used insecticides against Coccinella undecimpunctata (Coleoptera: Coccinellidae). Pakistan J Zool 43(6):1161-1165

Ahmed MAI, Eraky E-SA, Mohamed MF, Soliman A-AS (2015) Potential toxicity assessment of novel selected pesticides against sand termite, Psammotermes hypostoma Desneux workers (Isoptera: Rhinotermitidae) under field conditions in Egypt. J Plant Protect Res 55(2):193-197

Al-Sarar A, Abobakr Y, Bayoumi AE, Hussein H (2015) Cytotoxic and genotoxic effects of abamectin, chlorfenapyr, and imidacloprid on CHOK1 cells. Environ Sci Pollut Res 22:17041-17052

Alburaki M, Boutin S, Mercier P-L, Loublier Y, Chagnon M, Derome N (2015) Neonicotinoid-coated Zea mays seeds indirectly affect honeybee performance and pathogen susceptibility in field trials. PLoS One 10(5):e0125790

Alburaki M, Cheaib B, Quesnel L, Mercier P-L, Chagnon M, Derome N (2017) Performance of honeybee colonies located in neonicotinoidtreated and untreated cornfields in Quebec. J Appl Entomol 141(12): $112-121$

Ali S, Mohamed A-R, Ali H, Elbohi K (2016) Sublethal effect of fipronil exposure on liver and kidney tissues with evaluation of the recovery ability of Japanese quail (Coturnix japonica). Jap J Vet Res 64: S131-S138

Alim MA, Lim U (2014) Ecotoxicological effect of insecticides on Ooencyrtus nezarae (Hymenoptera: Encyrtidae) reared from refrigerated and unrefrigerated Riptortus pedestris (Hemiptera: Alydidae) host. Biocontrol Sci. Technol. 24(2):133-144

Alkassab AT, Kirchner WH (2016) Impacts of chronic sublethal exposure to clothianidin on winter honeybees. Ecotoxicology 25(5):1000 1010

Amirzade N, Izadi H, Jalali MA, Zohdi H, Ni X (2014) Evaluation of three neonicotinoid insecticides against the common pistachio psylla, Agonoscena pistaciae, and its natural enemies. J Ins Sci 14(1): $35-35$

Annabi A, Dhouib I-B (2015) Mechanisms of imidacloprid-induced alteration of hypothalamic-pituitary-adrenal (HPA) axis after subchronic exposure in male rats. Recent Adv Biol Med 1:51-59

Ansoar-Rodríguez Y, Christofoletti C, Marcato A, Correia J, Bueno O, Malaspina O, Fontanetti C (2015) Genotoxic potential of the insecticide imidacloprid in a non-target organism (Oreochromis niloticusPisces). J Environ Protect 6:1360

Ansoar-Rodríguez Y, Christofoletti CA, Correia JE, de Souza RB, Moreira-de-Sousa C, Marcato ACC, Bueno OC, Malaspina O, ECM S-Z, Fontanetti CS (2016) Liver alterations in Oreochromis niloticus (Pisces) induced by insecticide imidacloprid: histopathology and heat shock protein in situ localization. J Environ Sci Health B 51(12):881-887

Arce AN, David TI, Randall EL, Ramos Rodrigues A, Colgan TJ, Wurm Y, Gill RJ (2016) Impact of controlled neonicotinoid exposure on bumblebees in a realistic field setting. J Appl Ecol 54(4):1199-1208
Arena M, Sgolastra F (2014) A meta-analysis comparing the sensitivity of bees to pesticides. Ecotoxicology 23(3):324-334

ArfatY, MahmoodN, TahirM, RashidM, AnjumS, ZhaoF, LiD-J, SunY-L, HuL, ZhihaoC and others. (2014). Effect of imidacloprid on hepatotoxicity and nephrotoxicity in male albino mice. Toxicol Rep1: 554-561

Arslan M, Sevgiler Y, Buyukleyla M, Yardimci M, Yilmaz M, Rencuzogullari E (2016) Sex-related effects of imidacloprid modulated by piperonyl butoxide and menadione in rats. Part II: genotoxic and cytotoxic potential. Drug Chem Toxicol 39:81-86

Aslund MW, Winchell M, Bowers L, McGee S, Tang J, Padilla L, Greer C, Knopper L, Moore DRJ (2017) Ecological risk assessment for aquatic invertebrate communities exposed to imidacloprid due to labeled agricultural and non-agricultural uses in the United States. Environ Toxicol Chem 36(5):1375-1388

Aufauvre J, Misme-Aucouturier B, Viguès B, Texier C, Delbac F et al (2014) Transcriptome analyses of the honeybee response to Nosema ceranae and insecticides. PLoS One 9(3):e91686

Ayyanath M-M, Cutler GC, Scott-Dupree CD, Prithiviraj B, Kandasamy S, Prithiviraj K (2014) Gene expression during imidaclopridinduced hormesis in green peach aphid. Dose-Response 12:480-497

Badawy MEI, Nasr HM, Rabea EI (2015) Toxicity and biochemical changes in the honey bee Apis mellifera exposed to four insecticides under laboratory conditions. Apidologie 46(2):177-193

Bagri P, Kumar V, Sikka A (2016) Assessment of imidacloprid-induced mutagenic effects in somatic cells of Swiss albino male mice. Drug Chem Toxicol 39:412-417

Bakker F (2016) Design and analysis of field studies with bees: a critical review of the draft EFSA guidance. Integr Environ Assess Manag 12(3):422-428

Barbosa WF, Smagghe G, Guedes RNC (2015) Pesticides and reducedrisk insecticides, native bees and pantropical stingless bees: pitfalls and perspectives. Pest Manag Sci 71(8):1049-1053

Baron GL, Raine NE, Brown MJ (2017) General and species-specific impacts of a neonicotinoid insecticide on the ovary development and feeding of wild bumblebee queens. Proc R Soc B 284(1854): 20170123

Beketov MA, Liess M (2008) Acute and delayed effects of the neonicotinoid insecticide thiacloprid on seven freshwater arthropods. Environ Toxicol Chem 27(2):461-470

Beloti VH, Alves GR, Araújo DFD, Picoli MM, Moral RA, Demétrio CGB, Yamamoto PT (2015) Lethal and sublethal effects of insecticides used on citrus, on the ectoparasitoid Tamarixia radiata. PLoS One 10(7):e0132128

Benadi G, Blüthgen N, Hovestadt T, Poethke H-J (2013) When can plantpollinator interactions promote plant diversity? Am. Nat 182(2): 131-146

Benuszak J, Laurent M, Chauzat M-P (2017) The exposure of honey bees (Apis mellifera; Hymenoptera: Apidae) to pesticides: room for improvement in research. Sci Total Environ 587-588:423-438

Bernhardt ES, Rosi EJ, Gessner MO (2017) Synthetic chemicals as agents of global change. Front Ecol Environ 15:84-90

Bijleveld van Lexmond M, Bonmatin JM, Goulson D, Noome DA (2015) Worldwide integrated assessment on systemic pesticides. Environ Sci Pollut Res 22(1):1-4

Blanken LJ, van Langevelde F, van Dooremalen C (2015) Interaction between Varroa destructor and imidacloprid reduces flight capacity of honeybees. Proc R Soc B 282(1820):20151738

Böhme F, Bischoff G, Zebitz CPW, Rosenkranz P, Wallner K (2017) Chronic exposure of honeybees, Apis mellifera (Hymenoptera: Apidae), to a pesticide mixture in realistic field exposure rates. Apidologie 48(3):353-363

BonmatinJM, GiorioC, GirolamiV, GoulsonD, KreutzweiserDP, KrupkeC, LiessM, LongE, MarzaroM, MitchellEAD and others. (2015). Environmental fate and exposure; neonicotinoids and fipronil. Environ Sci Pollut Res22(1):35-67 
Bostanian NJ, Hardman JM, Ventard E, Racette G (2005) The intrinsic toxicity of several neonicotinoids to Lygus lineolaris and Hyaliodes vitripennis, a phytophagous and a predacious mirid. Pest Manag Sci 61(10):991-996

Bostanian NJ, Larocque N, Chouinard G, Coderre D (2001) Baseline toxicity of several pesticides to Hyaliodes vitripennis (Say) (Hemiptera: Miridae). Pest Manag Sci 57(11):1007-1010

Botías C, David A, Hill EM, Goulson D (2016) Contamination of wild plants near neonicotinoid seed-treated crops, and implications for non-target insects. Sci Total Environ 566-567:269-278

Botias C, David A, Horwood J, Abdul-Sada A, Nicholls E, Hill EM, Goulson D (2015) Neonicotinoid residues in wildflowers, a potential route of chronic exposure for bees. Environ Sci Technol 49(21): $12731-12740$

Bozsik A (2006) Susceptibility of adult Coccinella septempunctata (Coleoptera: Coccinellidae) to insecticides with different modes of action. Pest Manag Sci 62(7):651-654

Brandt A, Gorenflo A, Siede R, Meixner M, Büchler R (2016) The neonicotinoids thiacloprid, imidacloprid, and clothianidin affect the immunocompetence of honey bees (Apis mellifera L.) J. Ins. Physiol. 86:40-47

BredesonMM, ReeseRN, LundgrenJG. (2015). The effects of insecticide dose and herbivore density on tri-trophic effects of thiamethoxam in a system involving wheat, aphids, and ladybeetles. Crop Prot69(0): 70-76

Breeze TD, Bailey AP, Balcombe KG, Potts SG (2011) Pollination services in the UK: how important are honeybees? Agric Ecosyst Environ 142(3-4):137-143

Bro E, Devillers J, Millot F, Decors A (2016) Residues of plant protection products in grey partridge eggs in French cereal ecosystems. Environ Sci Pollut Res 23(10):9559-9574

Buchmann SL, Nabhan GP (1997) The forgotten pollinators. Island Press, Washington, DC

Budge GE, Garthwaite D, Crowe A, Boatman ND, Delaplane KS, Brown MA, Thygesen HH, Pietravalle S (2015) Evidence for pollinator cost and farming benefits of neonicotinoid seed coatings on oilseed rape. Sci Rep 5:12574

Burgess ER, King BH (2016) Behavior and survival of the filth fly parasitoids Spalangia endius and Urolepis rufipes (Hymenoptera: Pteromalidae) in response to three granular house fly baits and components. Environ Entomol 45(6):1496-1504

Burgess IVER, King BH (2015) Compatibility of the parasitoid wasp Spalangia endius (Hymenoptera: Pteromalidae) and insecticides against Musca domestica (Diptera: Muscidae) as evaluated by a new index. J Econ Entomol 108(3):986-992

Burke AP (2016) A neurodevelopmental study of mice following in utero and early postnatal exposure to imidacloprid, a neonicotinoid pesticide. ProQuest Dissertations \& Theses Global. ProQuest Dissertations Publishing 10195049. https://search.proquest.com/ openview/aad9c7e69be6d2fl fbf07abba5746b1b/1.pdf?pq-origsite $=$ gscholar\&cbl=18750\&diss=y. Accessed 12 July 2017

Caballero M, Ares I, Martinez M, Martinez-Larranaga M, Anadon A, Martinez M (2015) Fipronil induces CYP isoforms in rats. Food Chem Toxicol 83:215-221

Calatayud-Vernich P, Calatayud F, Simó E, Suarez-Varela MM, Picó Y (2016) Influence of pesticide use in fruit orchards during blooming on honeybee mortality in 4 experimental apiaries. Sci Total Environ 541:33-41

Calderón-SeguraM, RojasJ, BritoM, Tec Cab MdC, Calderón-Ezquerro M, Gómez-Arroyo S. (2015). Genotoxicity of the neonicotinoid insecticide Poncho (clothianidin) on CD1 mice based on alkaline comet and micronucleus assays. Toxicity and Hazard of Agrochemicals 113

Camp AA, Buchwalter DB (2016) Can't take the heat: temperatureenhanced toxicity in the mayfly Isonychia bicolor exposed to the neonicotinoid insecticide imidacloprid. Aquat Toxicol 178:49-57
Cardone A (2015) Imidacloprid induces morphological and molecular damages on testis of lizard (Podarcis sicula). Ecotoxicology 24(1): 94-105

Carrillo D, Peña JE, Rogers ME (2009) Relative susceptibility of Haeckeliania sperata (Hymenoptera: Trichogrammatidae) to pesticides used in citrus and ornamental systems in Florida. J Econ Entomol 102(3):905-912

Castillo Diaz JM, Martin-Laurent F, Beguet J, Nogales R, Romero E (2017) Fate and effect of imidacloprid on vermicompost-amended soils under dissimilar conditions: risk for soil functions, structure, and bacterial abundance. Sci Total Environ 579:1111-1119

Cavallaro MC, Morrissey CA, Headley JV, Peru KM, Liber K (2017) Comparative chronic toxicity of imidacloprid, clothianidin, and thiamethoxam to Chironomus dilutus and estimation of toxic equivalency factors. Environ Toxicol Chem 36(2):372-382

Čerevková A, Miklisová D, Cagáň L' (2017) Effects of experimental insecticide applications and season on soil nematode communities in a maize field. Crop Prot 92:1-15

Chagnon M, Kreutzweiser D, Mitchell ED, Morrissey CA, Noome DA, Van der Sluijs JP (2015) Risks of large-scale use of systemic insecticides to ecosystem functioning and services. Environ Sci Pollut Res 22(1):119-134

Chaguri J, Godinho A, Horta D, Goncalves-Rizzi V, Possomato-Vieira J, Nascimento R, Dias C (2016) Exposure to fipronil elevates systolic blood pressure and disturbs related biomarkers in plasma of rats. Environ Toxicol Pharmacol 42:63-68

Chaimanee V, Evans JD, Chen Y, Jackson C, Pettis JS (2016) Sperm viability and gene expression in honey bee queens (Apis mellifera) following exposure to the neonicotinoid insecticide imidacloprid and the organophosphate acaricide coumaphos. J. Ins. Physiol. 89: $1-8$

Charles-Tollerup JJ (2013) Resource provisioning as a habitat manipulation tactic to enhance the aphid parasitoid, Aphidius colemani Viereck (Hymenoptera: Braconidae: Aphidiinae), and the plant-mediated effects of a systemic insecticide, imidacloprid: University of California, Riverside. 151 p. http://escholarship.org/content/ qt97w046gw/qt97w046gw.pdf. Accessed 12 July 2017

Charpentier G, Louat F, Bonmatin JM, Marchand PA, Vannier F, Locker D, Decoville M (2014) Lethal and sublethal effects of imidacloprid, after chronic exposure, on the insect model Drosophila melanogaster. Environ Sci Technol 48(7):4096-4102

Chen X, Song M, Qi S, Wang C (2013) Safety evaluation of eleven insecticides to Trichogramma nubilale (Hymenoptera: Trichogrammatidae). J. Econ. Entomol. 106(1):136-141

Chen X-Q, Xiao Y, Wu L-B, Chen Y, Peng Y (2012) Imidacloprid affects Pardosa pseudoannulata adults and their unexposed offspring. Bull. Environ. Contam. Toxicol. 88(5):654-658

Chintalapati P, Katti G, Puskur RR, Nagella VK (2016) Neonicotinoidinduced resurgence of rice leaffolder, Cnaphalocrocis medinalis (Guénee). Pest Manag Sci 72(1):155-161

Chrétien F, Giroux I, Thériault G, Gagnon P, Corriveau J (2017) Surface runoff and subsurface tile drain losses of neonicotinoids and companion herbicides at edge-of-field. Environ Pollut 224:255-264

ChristenV, BachoferS, FentK. (2017). Binary mixtures of neonicotinoids show different transcriptional changes than single neonicotinoids in honeybees (Apis mellifera). Environ. Pollut. 220, Part B:1264-1270

Christen V, Mittner F, Fent K (2016) Molecular effects of neonicotinoids in honey bees (Apis mellifera). Environ. Sci. Technol. 50(7):40714081

Cohen H, Horowitz AR, Nestel D, Rosen D (1996) Susceptibility of the woolly apple aphid parasitoid, Aphelinus mali (Hym.: Aphelinidae), to common pesticides used in apple orchards in Israel. Entomophaga 41:225-233

Cordero RJ, Bloomquist JR, Kuhar TP (2007) Susceptibility of two diamondback moth parasitoids, Diadegma insulare (Cresson) (Hymenoptera; Ichneumonidae) and Oomyzus sokolowskii 
(Kurdjumov) (Hymenoptera; Eulophidae), to selected commercial insecticides. Biol. Control 42(1):48-54

Costa LM, Grella TC, Barbosa RA, Malaspina O, Nocelli RCF (2015) Determination of acute lethal doses (LD50 and LC50) of imidacloprid for the native bee Melipona scutellaris Latreille, 1811 (Hymenoptera: Apidae). Sociobiology 62(4):578-582

Crawley SE, Kowles KA, Gordon JR, Potter MF, Haynes KF (2016) Behavioral effects of sublethal exposure to a combination of $\beta$ cyfluthrin and imidacloprid in the bed bug, Cimex lectularius L. Pest Manag Sci 73(3):598-603

CresswellJE, PageCJ, UygunMB, HolmberghM, LiY, WheelerJG, LaycockI, PookCJ, deIbarraNH, SmirnoffN and others. (2012). Differential sensitivity of honey bees and bumble bees to a dietary insecticide (imidacloprid). Zoology115(6):365-371

Crosby EB, Bailey JM, Oliveri AN, Levin ED (2015) Neurobehavioral impairments caused by developmental imidacloprid exposure in zebrafish. Neurotoxicology and Teratology 49:81-90

Cutler GC, Scott-Dupree CD (2014) A field study examining the effects of exposure to neonicotinoid seed-treated corn on commercial bumble bee colonies. Ecotoxicology 23(9):1755-1763

Cutler GC, Scott-Dupree CD, Tolman JH, Harris CR (2006) Toxicity of the insect growth regulator novaluron to the non-target predatory bug Podisus maculiventris (Heteroptera:Pentatomidae). Biol Control 38(2):196-204

Czerwinski MA, Sadd BM (2017) Detrimental interactions of neonicotinoid pesticide exposure and bumblebee immunity. J Exp Zool. https://doi.org/10.1002/jez.2087

Danfa A, Fall B, Valk HVD (1998) Acute toxicity tests with Bracon hebetor Say (Hymenoptera: Braconidae), using different locust control insecticides in the Sahel. In: Everts JW, Mbaye D, Barry O, Mullie W (eds) Environmental Side-Effects of Locust and Grasshopper Control: LOCUSTOX Project. FAO, Dakar, pp 117 136

DanieleG, GiroudB, JabotC, VuilletE (2017). Exposure assessment of selected pesticide residues in honeybees, beebread and beeswax from French beehives by liquid chromatography-quadrupole mass spectrometry. Environ Sci Pollut Res., in press. Doi: https://doi.org/ 10.1007/s11356-017-9227-7

David A, Botías C, Abdul-Sada A, Nicholls E, Rotheray EL, Hill EM, Goulson D (2016) Widespread contamination of wildflower and bee-collected pollen with complex mixtures of neonicotinoids and fungicides commonly applied to crops. Environ Int 88:169-178

de Arcaute C, Perez-Iglesias J, Nikoloff N, Natale G, Soloneski S, Larramendy M (2014) Genotoxicity evaluation of the insecticide imidacloprid on circulating blood cells of Montevideo tree frog Hypsiboas pulchellus tadpoles (Anura, Hylidae) by comet and micronucleus bioassays. Ecol Indic 45:632-639

De Cock A, De Clercq P, Tirry L, Degheele D (1996) Toxicity of diafenthiuron and imidacloprid to the predatory bug Podisus maculiventris (Heteroptera: Pentatomidae). Environ Entomol 25(2):476-480

de Barros AL, Bae JH, Borges CS, Rosa JL, Cavariani MM, Silva PV, Pinheiro PFF, Anselmo-Franci JA, Arena AC (2016) Perinatal exposure to insecticide fipronil: effects on the reproductive system in male rats. Reproduction, Fertility and Development 29:1130-1143

de Morais CR, Bonetti AM, Carvalho SM, de Rezende AAA, Araujo GR, Spanó MA (2016a) Assessment of the mutagenic, recombinogenic and carcinogenic potential of fipronil insecticide in somatic cells of Drosophila melanogaster. Chemosphere 165:342-351

de Morais MR, Zanardi OZ, Rugno GR, Yamamoto PT (2016b) Impact of five insecticides used to control citrus pests on the parasitoid Ageniaspis citricola Longvinovskaya (Hymenoptera: Encyrtidae). Ecotoxicology 25(5):1011-1020

de Perre C, Murphy TM, Lydy MJ (2015) Fate and effects of clothianidin in fields using conservation practices. Environ Toxicol Chem 34(2): $258-265$
deVriesFT, ThébaultE, LiiriM, BirkhoferK, TsiafouliMA, BjørnlundL, Bracht JørgensenH, BradyMV, ChristensenS, deRuiterPC and others. (2013). Soil food web properties explain ecosystem services across European land use systems. PNAS110(35):14296-14301

Dechaume-Moncharmont F-X, Decourtye A, Hennequet-Hantier C, Pons O, Pham-Delègue M-H (2003) Statistical analysis of honeybee survival after chronic exposure to insecticides. Environ Toxicol Chem 22(12):3088-3094

Decourtye A, Devillers J, Genecque E, Menach KL, Budzinski H, Cluzeau S, Pham-Delègue MH (2005) Comparative sublethal toxicity of nine pesticides on olfactory learning performances of the honeybee Apis mellifera. Arch Environ Contam Toxicol 48(2): 242-250

Delbeke F, Vercruysse P, Tirry L, Clercq PD, Degheele D (1997) Toxicity of diflubenzuron, pyriproxyfen, imidacloprid and diafenthiuron to the predatory bug Orius laevigatus (Het.: Anthocoridae). Entomophaga 42:349-358

Démares FJ, Crous KL, Pirk CWW, Nicolson SW, Human H (2016) Sucrose sensitivity of honey bees is differently affected by dietary protein and a neonicotinoid pesticide. PLoS One 11(6):e0156584

Dembilio Ó, Riba JM, Gamón M, Jacas JA (2015) Mobility and efficacy of abamectin and imidacloprid against Rhynchophorus ferrugineus in Phoenix canariensis by different application methods. Pest Manag Sci 71(8):1091-1098

Devillers J, Decourtye A, Budzinski H, Pham-Delègue MH, Cluzeau S, Maurin G (2003) Comparative toxicity and hazards of pesticides to Apis and non-Apis bees. A chemometrical study. SAR-QSAR Environ Res 14(5-6):389-403

Dively GP, Embrey MS, Kamel A, Hawthorne DJ, Pettis JS (2015) Assessment of chronic sublethal effects of imidacloprid on honey bee colony health. PLoS One 10(3):e0118748

dos Santos A, Zanetti R, dos Santos JC, Biagiotti G, Evangelista AL, Serrão JE, Zanuncio JC (2016) Persistence of fipronil residues in Eucalyptus seedlings and its concentration in the insecticide solution after treatment in the nursery. Environ Monit Assess 188(5):1-5

Doublet V, Labarussias M, de Miranda JR, Moritz RFA, Paxton RJ (2014) Bees under stress: sublethal doses of a neonicotinoid pesticide and pathogens interact to elevate honey bee mortality across the life cycle. Environ Microbiol 17:969-983

Douglas M, Tooker JF (2015) Large-scale deployment of seed treatments has driven rapid increase in use of neonicotinoid insecticides and preemptive pest management in U.S. field crops. Environ Sci Technol 49:5088-5097

Douglas MR, Tooker JF (2016) Meta-analysis reveals that seed-applied neonicotinoids and pyrethroids have similar negative effects on abundance of arthropod natural enemies. PeerJ 4:e2776

DrozY, Miéville-OttV, ForneyJ, SpichigerR (2009) Anthropologie politique du paysage

Dussaubat C, Maisonnasse A, Crauser D, Tchamitchian S, Bonnet M, Cousin M, Kretzschmar A, Brunet J-L, Le Conte Y (2016) Combined neonicotinoid pesticide and parasite stress alter honeybee queens' physiology and survival. Sci Rep 6:31430

EASAC (2015) Ecosystem services, agriculture and neonicotinoids. EASAC policy report 26, 61 pp. European Academies Science Advisory Council.http://www.easac.eu/fileadmin/Reports/Easac 15_ES_web_complete_01.pdf. Accessed 23 July 2017

EFSA (2012) Scientific opinion of the panel on plant protection products and their residues on the science behind the development of a risk assessment of plant protection products on bees (Apis mellifera, Bombus spp. and solitary bees). EFSA Journal 10(5):2668

Ehsan H, Mervat H, Eman W, Magdy F (2016) Influence of fipronil intoxication on thyroid gland ultra-structure and hepatic microsomal enzymes expression in male albino rats. Jap J Vet Res 64:S79-S85

Eilers EJ, Kremen C, Smith Greenleaf S, Garber AK, Klein A-M (2011) Contribution of pollinator-mediated crops to nutrients in the human 
food supply. PLoS One 6:e21363. https://doi.org/10.1371/journal. pone.0021363

El-Murr A, Ali HA, Elgaml SA, Hashish EA (2016) The $\beta$-1,3-glucan alleviated the hepatotoxicity induced by combination of fipronil and lead in common carp (Cyprinus carpio). Comparative Clinical Pathology 25:689-697

El-Murr A, Imam T, Hakim Y, Ghonimi W (2015) Histopathological, immunological, hematological and biochemical effects of fipronil on Nile tilapia (Oreochromis niloticus). J Vet Sci Technol 6

Ellis C, Park KJ, Whitehorn P, David A, Goulson D (2017) The neonicotinoid insecticide thiacloprid impacts upon bumblebee colony development under field conditions. Environ Sci Technol 51(3): $1727-1732$

Elzen GW, Rojas MG, Elzen PJ, King EG, Barcenas NM (1999) Toxicological responses of the boll weevil (Coleoptera: Curculionidae) ectoparasitoid Catolaccus grandis (Hymenoptera: Pteromalidae) to selected insecticides. J. Econ. Entomol. 92(2): 309-313

EnglertD, BundschuhM, SchulzR. (2012). Thiacloprid affects trophic interaction between gammarids and mayflies. Environ Pollut167(0):41-46

Englert D, Zubrod JP, Link M, Mertins S, Schulz R, Bundschuh M (2017) Does waterborne exposure explain effects caused by neonicotinoidcontaminated plant material in aquatic systems? Environ Sci Technol 51(10):5793-5802

Feltham H, Park K, Goulson D (2014) Field realistic doses of pesticide imidacloprid reduce bumblebee pollen foraging efficiency. Ecotoxicology 23(3):317-323

FERA (2013) Neonicotinoid pesticides and bees. Report to Syngenta Ltd.: Food and Environment Research Agency

Fernandes MES, Alves FM, Pereira RC, Aquino LA, Fernandes FL, Zanuncio JC (2016) Lethal and sublethal effects of seven insecticides on three beneficial insects in laboratory assays and field trials. Chemosphere 156:45-55

Fischer J, Müller T, Spatz A-K, Greggers U, Grünewald B, Menzel R (2014) Neonicotinoids interfere with specific components of navigation in honeybees. PLoS One 9(3):e91364

Fogel MN, Schneider MI, Rimoldi F, Ladux LS, Desneux N, Ronco AE (2016) Toxicity assessment of four insecticides with different modes of action on pupae and adults of Eriopis connexa (Coleoptera: Coccinellidae), a relevant predator of the Neotropical Region. Environ Sci Pollut Res 23(15):14918-14926

Forfert N, Moritz RF (2017) Thiacloprid alters social interactions among honey bee workers (Apis mellifera). J ApicultRes 56(4):467-474

Forister ML, Cousens B, Harrison JG, Anderson K, Thorne JH, Waetjen D, Nice CC, De Parsia M, Hladik ML, Meese R et al (2016) Increasing neonicotinoid use and the declining butterfly fauna of lowland California. Biol Lett 12(8):20160475

Frew JA, Grue CE (2015) Assessing the risk to green sturgeon from application of imidacloprid to control burrowing shrimp in Willapa Bay, Washington - part II: controlled exposure studies. Environ Toxicol Chem 34(11):2542-2548

Frew JA, Sadilek M, Grue CE (2015) Assessing the risk to green sturgeon from application of imidacloprid to control burrowing shrimp in Willapa Bay, Washington-part I: exposure characterization. Environ Toxicol Chem 34(11):2533-2541

Furlan L, Pozzebon A, Duso C, Simon-Delso N, Sánchez-Bayo F, Marchand PA, Codato F, Bijleveld van Lexmond M, Bonmatin JM (2017) Alternatives to systemic insecticides. Environ Sci Pollut Res (this issue)

Gaikwad S, Reddy K (2016) Toxicity of imidacloprid insecticide influenced by ph and temperature on the freshwater fish Rasbora daniconius (Ham.) J Atoms Mol 6:961-965

Gan J, Bondarenko S, Oki L, Haver D, Li JX (2012) Occurrence of fipronil and its biologically active derivatives in urban residential runoff. Environ Sci Technol 46(3):1489-1495
Gao L-r, Li S, Zhang J, Liang C, Chen E-n, Zhang S-y, Chuai M, Bao Y-p, Wang G, Yang X. (2016) Excess imidacloprid exposure causes the heart tube malformation of chick embryos. J Agric. Food Chem

Garbuzov M, Couvillon MJ, Schürch R, Ratnieks FLW (2015) Honey bee dance decoding and pollen-load analysis show limited foraging on spring-flowering oilseed rape, a potential source of neonicotinoid contamination. Agric Ecosyst Environ 203:62-68

Ge W, Yan S, Wang J, Zhu L, Chen A, Wang J (2015) Oxidative stress and DNA damage induced by imidacloprid in zebrafish (Danio rerio). J Agric Food Chem 63(6):1856-1862

Gibbons D, Morrissey C, Mineau P (2015) A review of the direct and indirect effects of neonicotinoids and fipronil on vertebrate wildlife. Environ Sci Pollut Res 22(1):103-118

Gibbons D, Morrissey C, Mineau P (2016) A review of the direct and indirect effects of neonicotinoids and fipronil on vertebrate wildlife (vol 22, pg 103, 2015); erratum. Environmental Science and Pollution Research 23:947-947

Gill RJ, Raine NE (2014) Chronic impairment of bumblebee natural foraging behaviour induced by sublethal pesticide exposure. Funct Ecol 28(6):1459-1471

Gill RJ, Ramos-Rodriguez O, Raine NE (2012) Combined pesticide exposure severely affects individual- and colony-level traits in bees. Nature 491:105-108

Giorio C, Anton Safer A, Sánchez-Bayo F, Tapparo A, Lentola A, Girolami V, Bijleveld van Lexmond M, Bonmatin J-M (2017) An update of the Worldwide Integrated Assessment (WIA) on systemic insecticides. Part 1: new molecules, metabolism, fate and transport. Environ Sci Pollut Res. (this issue)

Gobeli A, Crossley Ii D, Johnson J, Reyna K (2017) The effects of neonicotinoid exposure on embryonic development and organ mass in northern bobwhite quail (Colinus virginianus). Comp Biochem Physiol Part C 195:9-15

Godfray HCJ, Blacquière T, Field LM, Hails RS, Potts SG, Raine NE, Vanbergen AJ, McLean AR (2015) A restatement of recent advances in the natural science evidence base concerning neonicotinoid insecticides and insect pollinators. Proc R Soc B 282:20151821

Godinho A, Souza A, Carvalho C, Horta D, De Fraia D, Anselmo F, Chaguri J, Faria C (2017) Memory impairment due to fipronil pesticide exposure occurs at the GABA(A) receptor level, in rats. Physiol Behav 165:28-34

Gontijo PC, Moscardini VF, Michaud JP, Carvalho GA (2014) Non-target effects of chlorantraniliprole and thiamethoxam on Chrysoperla carnea when employed as sunflower seed treatments. J Pest Sci 87(4):711-719

Gontijo PC, Moscardini VF, Michaud JP, Carvalho GA (2015) Non-target effects of two sunflower seed treatments on Orius insidiosus (Hemiptera: Anthocoridae). Pest Manag Sci 71(4):515-522

Goulson D (2013) An overview of the environmental risks posed by neonicotinoid insecticides. J Appl Ecol 50(4):977-987

Goulson D (2015) Neonicotinoids impact bumblebee colony fitness in the field; a reanalysis of the UK's Food \& Environment Research Agency 2012 experiment. PeerJ 3:e854

Gregorc A, Silva-Zacarin ECM, Carvalho SM, Kramberger D, Teixeira EW, Malaspina O (2016) Effects of Nosema ceranae and thiametoxam in Apis mellifera: a comparative study in Africanized and Carniolan honey bees. Chemosphere 147:328-336

Gripp H, Freitas J, Almeida E, Bisinoti M, Moreira A (2017) Biochemical effects of fipronil and its metabolites on lipid peroxidation and enzymatic antioxidant defense in tadpoles (Eupemphix nattereri: Leiuperidae). Ecotoxicol Environ Saf 136:173-179

Guelfi M, Maioli M, Tavares M, Mingatto F (2015) Citotoxicity of fipronil on hepatocytes isolated from rat and effects of its biotransformation. Braz Arch Biol Technol 58:843-853

Haddi K, Mendes MV, Barcellos MS, Lino-Neto J, Freitas HL, Guedes RNC, Oliveira EE (2016) Sexual success after stress? Imidacloprid- 
induced hormesis in males of the neotropical stink bug Euschistus heros. PLoS One 11(6):e0156616

Hallmann CA, Foppen RPB, van Turnhout CAM, de Kroon H, Jongejans E (2014) Declines in insectivorous birds are associated with high neonicotinoid concentrations. Nature 511:341-343

Hayasaka D, Korenaga T, Sánchez-Bayo F, Goka K (2012) Differences in ecological impacts of systemic insecticides with different physicochemical properties on biocenosis of experimental paddy fields. Ecotoxicology 21(1):191-201

Hayasaka D, Kuwayama N, Takeo A, Ishida T, Mano H, Inoue M, Nagai T, Sánchez-Bayo F, Goka K, Sawahata T (2015) Different acute toxicity of fipronil baits on invasive Linepithema humile supercolonies and some non-target ground arthropods. Ecotoxicology 24(6):1221-1228

Heimbach F, Russ A, Schimmer M, Born K (2016) Large-scale monitoring of effects of clothianidin dressed oilseed rape seeds on pollinating insects in Northern Germany: implementation of the monitoring project and its representativeness. Ecotoxicology 25(9):1630-1647

Henry M, Cerrutti N, Aupinel P, Decourtye A, Gayrard M, Odoux J-F, Pissard A, Rüger C, Bretagnolle V (2015) Reconciling laboratory and field assessments of neonicotinoid toxicity to honeybees. Proc R Soc London B 282(1819):20152110

Hesketh H, Lahive E, Horton AA, Robinson AG, Svendsen C, Rortais A, Dorne JL, Baas J, Spurgeon DJ, Heard MS (2016) Extending standard testing period in honeybees to predict lifespan impacts of pesticides and heavy metals using dynamic energy budget modelling. Sci Rep 6:37655

Hill TA, Foster RE (2000) Effect of insecticides on the diamondback moth (Lepidoptera: Plutellidae) and its parasitoid Diadegma insulare (Hymenoptera: Ichneumonidae). J. Econ. Entomol. 93(3): 763-768

HiranoT, YanaiS, OmoteharaT, HashimotoR, UmemuraY, KubotaN, MinamiK, NagaharaD, MatsuoE, AiharaY and others. (2015). The combined effect of clothianidin and environmental stress on the behavioral and reproductive function in male mice. J Vet Med Sci77(10):1207-1215

Hladik ML, Kolpin DW, Kuivila KM (2014) Widespread occurrence of neonicotinoid insecticides in streams in a high corn and soybean producing region, USA. Environ Pollut 193:189-196

Hoppe PP, Safer A, Amaral-Rogers V, Bonmatin JM, Goulson D, Menzel R, Baer B (2015) Effects of a neonicotinoid pesticide on honey bee colonies: a response to the field study by Pilling et al. (2013). Environ Sci Europe 27:28

Hoshi N, Hirano T, Omotehara T, Tokumoto J, Umemura Y, Mantani Y, Tanida T, Warita K, Tabuchi Y, Yokoyama T et al (2014) Insight into the mechanism of reproductive dysfunction caused by neonicotinoid pesticides. Biol Pharm Bull 37:1439-1443

Hsiao C-J, Lin C-L, Lin T-Y, Wang S-E, Wu C-H (2016) Imidacloprid toxicity impairs spatial memory of echolocation bats through neural apoptosis in hippocampal CA1 and medial entorhinal cortex areas. Neuroreport 27(6):462-468

Huang J, Wu SF, Ye GY (2011) Evaluation of lethal effects of chlorantraniliprole on Chilo suppressalis and its larval parasitoid, Cotesia chilonis. Agric. Sci. China 10:1134-1138

Hussain A, Khan MF, Faheem M, Rana H (2017) Toxicity of nitenpyram and neem leaf extract against earthworm. Int J Biol Biotechnol 13(4):581-585

Hussein M, Singh V, Gupta P, Yadav B, Singh A (2014a) Developmental and biochemical effects of imidacloprid on chick embryos. J Anat 22:12-17

Hussein M, Singh V, Hassan M, Singh A, Yadav B (2014b) Malformations and teratogenic effects of imidacloprid on chick embryo. Sch J Appl Med Sci 2:67-72

Ibrahim K, El-Desouky M, Abou-Yousef H, Gabrowny K, El-Sayed A (2015) Imidacloprid and/or esfenvalerate induce apoptosis and disrupt thyroid hormones in neonatal rats. Global J Biotechnol Biochem 10:106-112

IFPRI (2014) Global hunger index. International Food Policy Research Institute, Washington, DC http://www.ifpri.org/node/538. Accessed 7 January 2016

Inostroza PA, Wicht A-J, Huber T, Nagy C, Brack W, Krauss M (2016) Body burden of pesticides and wastewater-derived pollutants on freshwater invertebrates: method development and application in the Danube River. Environ Pollut 214:77-85

IPBES (2016a) The assessment report of the Intergovernmental SciencePolicy Platform on Biodiversity and Ecosystem Services on pollinators, pollination and food production. In: Potts SG, ImperatrizFonseca VL, Ngo HT (eds) Secretariat of the Intergovernmental Science-Policy Platform on Biodiversity and Ecosystem Services, Bonn, Germany, pp 552. http://www.ipbes.net/sites/default/files/ downloads/pdf/individual_chapters_pollination_20170305.pdf. Accessed 9 July 2017

IPBES (2016b) Summary for policymakers of the assessment report of the Intergovernmental Science-Policy Platform on Biodiversity and Ecosystem Services on pollinators, pollination and food production. In: Potts SG, Imperatriz-Fonseca VL, Ngo HT, Biesmeijer JC, Breeze TD, Dicks LV, Garibaldi LA, Hill R, Settele J, Vanbergen AJ, Aizen MA, Cunningham SA, Eardley C, Freitas BM, Gallai N, Kevan PG, Kovács-Hostyánszki A, Kwapong PK, Li J, Li X, Martins DJ, Nates-Parra G, Pettis JS, Rader R, Viana BF (eds) Secretariat of the Intergovernmental Science-Policy Platform on Biodiversity and Ecosystem Services, Bonn, Germany, pp 36. http://www.ipbes.net/sites/default/files/downloads/pdf/spm deliverable_3a_pollination_20170222.pdf. Accessed 9 July 2017

IsbellF, CalcagnoV, HectorA, ConnollyJ, HarpoleWS, ReichPB, SchererLorenzenM, SchmidB, TilmanD, vanRuijvenJ and others. (2011). High plant diversity is needed to maintain ecosystem services. Nature477(7363):199-202

Iturburu FG, Zömisch M, Panzeri AM, Crupkin AC, Contardo-Jara V, Pflugmacher S, Menone ML (2017) Uptake, distribution in different tissues, and genotoxicity of imidacloprid in the freshwater fish Australoheros facetus. Environ Toxicol Chem 36(3):699-708

Iwasa T, Motoyama N, Ambrose JT, Roe RM (2004) Mechanism for the differential toxicity of neonicotinoid insecticides in the honey bee, Apis mellifera. Crop Prot 23(5):371-378

Jacob CRO, Soares HM, Nocelli RCF, Malaspina O (2015) Impact of fipronil on the mushroom bodies of the stingless bee Scaptotrigona postica. Pest Manag Sci 71(1):114-122

Jalali MA, Van Leeuwen T, Tirry L, De Clercq P (2009) Toxicity of selected insecticides to the two-spot ladybird Adalia bipunctata. Phytoparasitica 37(4):323-326

Jinguji H, Uéda T (2015) Can the use of more selective insecticides promote the conservation of Sympetrum frequens in Japanese rice paddy fields (Odonata: Libellulidae)? Odonatologica 44(1-2)

Jyot G, Mandal K, Singh B (2015) Effect of dehydrogenase, phosphatase and urease activity in cotton soil after applying thiamethoxam as seed treatment. Environ Monit Assess 187(5):1-7

Kaakeh N, Kaakeh W, Bennett GW (1996) Topical toxicity of imidacloprid, fipronil, and seven conventional insecticides to the adult convergent lady beetle (Coleoptera: Coccinellidae). J Entomol Sci 31:315-322

Kairo G, Poquet Y, Haji H, Tchamitchian S, Cousin M, Bonnet M, Pelissier M, Kretzschmar A, Belzunces LP, Brunet J-L (2017) Assessment of the toxic effect of pesticides on honey bee drone fertility using laboratory and semifield approaches: a case study of fipronil. Environ Toxicol Chem 36(9):2345-2351

Kairo G, Provost B, Tchamitchian S, Ben Abdelkader F, Bonnet M, Cousin M, Sénéchal J, Benet P, Kretzschmar A, Belzunces LP et al (2016) Drone exposure to the systemic insecticide fipronil indirectly impairs queen reproductive potential. Sci Rep 6:31904 
Khani A, Ahmadi F, Ghadamyari M (2012) Side effects of imidacloprid and abamectin on the mealybug destroyer Cryptolaemus montrouzieri. Trakia J Sci 10(3):30-35

Kapoor U, Srivastava MK, Trivedi P, Garg V, Srivastava LP (2014) Disposition and acute toxicity of imidacloprid in female rats after single exposure. Food Chem Toxicol 68:190-195

Kara M, Yumrutas O, Demir CF, Ozdemir HH, Bozgeyik I, Coskun S, Eraslan E, Bal R (2015) Insecticide imidacloprid influences cognitive functions and alterslearning performance and related gene expression in a rat model. Int J Exp Pathol 96(5):332-337

Karahan A, Çakmak I, Hranitz J, Karaca I, Wells H (2015) Sublethal imidacloprid effects on honey bee flower choices when foraging. Ecotoxicology 24(9):2017-2025

Kartheek R, David M (2016) Fipronil induced modulations in biochemical and histopathological aspects of male Wistar albino rats: a subchronic study. World 5:26-32

Karthik P, Venugopal S, Datchina Murthy K, Lokesh S, Karthik G, Sharmila U, Paramasivam M, Senguttuvan K, Gunasekaran K, Kuttalam S (2015) Bioefficacy, phytotoxicity, safety to natural enemies and residue dynamics of imidacloprid $70 \mathrm{WG}$ in okra (Abelmoschus esculenta (L) Moench) under open field conditions. Crop Prot 71:88-94

Kasai A, Hayashi TI, Ohnishi H, Suzuki K, Hayasaka D, Goka K (2016) Fipronil application on rice paddy fields reduces densities of common skimmer and scarlet skimmer. Sci Rep 6:23055

Kasiotis KM, Anagnostopoulos C, Anastasiadou P, Machera K (2014) Pesticide residues in honeybees, honey and bee pollen by LC-MS/ MS screening: reported death incidents in honeybees. Sci Total Environ 485-486(0):633-642

Kataria S, Chhillar A, Kumar A, Tomar M, Malik V (2016) Cytogenetic and hematological alterations induced by acute oral exposure of imidacloprid in female mice. Drug Chem Toxicol 39:59-65

Kattwinkel M, Reichert P, Rüegg J, Liess M, Schuwirth N (2016) Modeling macroinvertebrate community dynamics in stream mesocosms contaminated with a pesticide. Environ Sci Technol 50(6):3165-3173

Kessler SC, Tiedeken EJ, Simcock KL, Derveau S, Mitchell J, Softley S, Stout JC, Wright GA (2015) Bees prefer foods containing neonicotinoid pesticides. Nature 521:74-76

Kevan PG, Menzel R (2012) The plight of pollination and the interface of neurobiology, ecology and food security. Environmentalist. https:// doi.org/10.1007/s10669-012-9394-5

Khalil SR, Awad A, Mohammed HH (2017) Behavioral response and gene expression changes in fipronil-administered male Japanese quail (Coturnix japonica). Environ Pollut 223:51-61

Khan MA, Khan H, Ruberson JR (2015) Lethal and behavioral effects of selected novel pesticides on adults of Trichogramma pretiosum (Hymenoptera: Trichogrammatidae). Pest Manag Sci 71(12):1640 1648

Kiljanek T, Niewiadowska A, Gaweł M, Semeniuk S, Borzęcka M, Posyniak A, Pohorecka K (2017) Multiple pesticide residues in live and poisoned honeybees-Preliminary exposure assessment. Chemosphere 175:36- 44

Kiljanek T, Niewiadowska A, Posyniak A (2016) Pesticide poisoning of honeybees: A review of symptoms, incident classification, and causes of poisoning. J Apicult Sci 60(2):5-24

Kimura K, Yoshiyama M, Saito K, Nirasawa K, Ishizaka M (2014) Examination of mass honey bee death at the entrance to hives in a paddy rice production district in Japan: the influence of insecticides sprayed on nearby rice fields. J Apicult Res 53(5): 599-606

Kimura-Kuroda J, Nishito Y, Yanagisawa H, Kuroda Y, Komuta Y, Kawano H, Hayashi M (2016) Neonicotinoid insecticides alter the gene expression profile of neuron-enriched cultures from neonatal rat cerebellum. Int J Environ Res Pub Health 13:987
Klatt BK, Holzschuh A, Westphal C, Clough Y, Smit I, Pawelzik E, Tscharntke T (2014) Bee pollination improves crop quality, shelf life and commercial value. Proc R Soc B 281:20132440

Kleijn D, Winfree R, Bartomeus I, Carvalheiro LG, Henry M, Isaacs R, Klein A-M, Kremen C, M'Gonigle LK, Rader R et al (2015) Delivery of crop pollination services is an insufficient argument for wild pollinator conservation. Nat Commun 6:7414

KleinA-M, VaissièreBE, CaneJH, Steffan-DewenterI, CunninghamSA, KremenC, Tscharntke T (2007) Importance of pollinators in changing landscapes for world crops. Proc R Soc B274(1608):303-313

Ko K, Liu Y, Hou M, Babendreier D, Zhang F, Song K (2015) Toxicity of insecticides targeting rice planthoppers to adult and immature stages of Trichogramma chilonis (Hymenoptera: Trichogrammatidae). J Econ Entomol 108(1):69-76

Kobashi K, Harada T, Adachi Y, Mori M, Ihara M, Hayasaka D (2017) Comparative ecotoxicity of imidacloprid and dinotefuran to aquatic insects in rice mesocosms. Ecotoxicol Environ Saf 138:122-129

Kreutzweiser DP, Good KP, Chartrand DT, Scarr TA, Holmes SB, Thompson DG (2008a) Effects on litter-dwelling earthworms and microbial decomposition of soil-applied imidacloprid for control of wood-boring insects. Pest Manag Sci 64(2):112-118

Kreutzweiser DP, Good KP, Chartrand DT, Scarr TA, Thompson DG (2008b) Are leaves that fall from imidacloprid-treated maple trees to control Asian longhorned beetles toxic to non-target decomposer organisms? J Environ Qual 37(2):639-646

Krischik V, Rogers M, Gupta G, Varshney A (2015) Soil-applied imidacloprid translocates to ornamental flowers and reduces survival of adult Coleomegilla maculata, Harmonia axyridis, and Hippodamia convergens lady beetles, and larval Danaus plexippus and Vanessa cardui butterflies. PLoS One 10(3):e0119133

Krupke CH, Holland JD, Long EY, Eitzer BD (2017) Planting of neonicotinoid-treated maize poses risks for honey bees and other non-target organisms over a wide area without consistent crop yield benefit. J Appl Ecol in press Doi. https://doi.org/10.1111/13652664.12924

Krupke CH, Long EY (2015) Intersections between neonicotinoid seed treatments and honey bees. Cur Op Ins Sci 10:8-13

Kumar A, Tomar M, Kataria S (2014) Effect of sub-lethal doses of imidacloprid on histological and biochemical parameters in female albino mice. ISOR J Environ Sci Toxicol Food Technol 8:9-15

Kunce W, Josefsson S, Örberg J, Johansson F (2015) Combination effects of pyrethroids and neonicotinoids on development and survival of Chironomus riparius. Ecotoxicol Environ Saf 122:426-431

Kurwadkar S, Evans A (2016) Neonicotinoids: systemic insecticides and systematic failure. Bull Environ Contam Toxicol 97(6):745-748

Lanteigne M, Whiting SA, Lydy MJ (2015) Mixture toxicity of imidacloprid and cyfluthrin to two non-target species, the fathead minnow Pimephales promelas and the amphipod Hyalella azteca. Arch Environ Contam Toxicol 68(2):354-361

Laycock I, Cotterell KC, O'Shea-Wheller TA, Cresswell JE (2014) Effects of the neonicotinoid pesticide thiamethoxam at fieldrealistic levels on microcolonies of Bombus terrestris worker bumble bees. Ecotoxicol Environ Saf 100:153-158

Lefebvre M, Bostanian NJ, Mauffette Y, Racette G, Thistlewood HA, Hardman JM (2012) Laboratory-based toxicological assessments of new insecticides on mortality and fecundity of Neoseiulus fallacis (Acari: Phytoseiidae). J Econ Entomol 105(3):866-871

Li H, Wu F, Zhao L, Tan J, Jiang H, Hu F (2015a) Neonicotinoid insecticide interact with honeybee odorant-binding protein: implication for olfactory dysfunction. Int J Biol Macromol 81:624-630

Li W, Zhang P, Zhang J, Lin W, Lu Y, Gao Y (2015b) Acute and sublethal effects of neonicotinoids and pymetrozine on an important egg parasitoid, Trichogramma ostriniae (Hymenoptera: Trichogrammatidae). Biocontrol Sci Tech 25(2):121-131

Lim UT, Mahmoud AMA (2008) Ecotoxicological effect of fenitrothion on Trissolcus nigripedius (Hymenoptera: Scelionidae) an egg 
parasitoid of Dolycoris baccarum (Hemiptera: Pentatomidae). J. Asia-Pacific Entomol. 11:207-210

Lima MAP, Martins GF, Oliveira EE, Guedes RNC (2016) Agrochemical-induced stress in stingless bees: peculiarities, underlying basis, and challenges. J Comp Physiol A 202(9):733-747

Liu M, Wang G, S-y Z, Zhong S, G-1 Q, Wang C-j, Chuai M, Lee KKH, Lu D-x, Yang X (2016) Exposing imidacloprid interferes with neurogenesis through impacting on chick neural tube cell survival. Toxicol Sci 153(1):137-148

Lohiya A, Poonia J, Kumar V (2016) Influence of subacute exposure of imidacloprid on microelement zinc in ovarian tissue of adult female wistar rats. Q Res J Plant Anim Sci/Bhartiya Krishi Anusandhan Patrika 31

Long EY, Krupke CH (2016) Non-cultivated plants present a season-long route of pesticide exposure for honey bees. Nat Commun 7:11629

López JH, Krainer S, Engert A, Schuehly W, Riessberger-Gallé U, Crailsheim K (2017) Sublethal pesticide doses negatively affect survival and the cellular responses in American foulbrood-infected honeybee larvae. Sci Rep 7:40853

Lopez-Antia A, Ortiz-Santaliestra ME, Mateo R (2014) Experimental approaches to test pesticide-treated seed avoidance by birds under a simulated diversification of food sources. Sci Total Environ 496(0):179-187

Lopez-Antia A, Ortiz-Santaliestra ME, Mougeot F, Mateo R (2015a) Imidacloprid-treated seed ingestion has lethal effect on adult partridges and reduces both breeding investment and offspring immunity. Environ Res 136:97-107

Lopez-Antia A, Ortiz-Santaliestra ME, Camarero PR, Mougeot F, Mateo $\mathrm{R}(2015 \mathrm{~b})$ Assessing the risk of fipronil-treated seed ingestion and associated adverse effects in the red-legged partridge. Environ Sci Technol 49(22):13649-13657

Lopez-Antia A, Feliu J, Camarero PR, Ortiz-Santaliestra ME, Mateo R (2016) Risk assessment of pesticide seed treatment for farmland birds using refined field data. J Appl Ecol 53(5):1373-1381

Lourenco CT, Carvalho SM, Malaspina O, Nocelli RCF (2012) Oral toxicity of fipronil insecticide against the stingless bee Melipona scutellaris (Latreille, 1811). Bull Environ Contam Toxicol 89(4): 921-924

Lovinskaya A, Kolumbayeva S, Kolomiets O, Abilev S (2014) Genotoxic effects of pesticide fipronil in somatic and generative cells of mice. Russ J Genet 52:491-497

Lu C, Warchol KM, Callahan RA (2014) Sub-lethal exposure to neonicotinoids impaired honey bees winterization before proceeding to colony collapse disorder. Bull Insectol 67(1):125-130

Lucas É, Giroux S, Demougeot S, Duchesne RM, Coderre D (2004) Compatibility of a natural enemy, Coleomegilla maculata lengi (Col., Coccinellidae) and four insecticides used against the Colorado potato beetle (Col., Chrysomelidae). J Appl Entomol 128(3):233-239

Luna-Cruz A, Rodríguez-Leyva E, Lomeli-Flores JR, Ortega-Arenas LD, Bautista-Martínez N, Pineda S (2015) Toxicity and residual activity of insecticides against Tamarixia triozae (Hymenoptera: Eulophidae), a parasitoid of Bactericera cockerelli (Hemiptera: Triozidae). J Econ Entomol 108(5):2289-2295

Lundin O, Rundlöf M, Smith HG, Fries I, Bommarco R (2015) Neonicotinoid insecticides and their impacts on bees: a systematic review of research approaches and identification of knowledge gaps. PLoS One 10(8):e0136928

Magalhães JZ, Udo MSB, Sánchez-Sarmiento AM, Carvalho MPN, Bernardi MM, Spinosa HS (2015) Prenatal exposure to fipronil disturbs maternal aggressive behavior in rats. Neurotoxicol Teratol 52: $11-16$

Mallinger RE, Werts P, Gratton C (2015) Pesticide use within a pollinatordependent crop has negative effects on the abundance and species richness of sweat bees, Lasioglossum spp., and on bumble bee colony growth. J Ins Conserv 19(5):999-1010
Martinez A-M, Chavarrieta J-M, Morales S-I, Caudillo K-B, Figueroa J-I, Diaz O, Bujanos R, Gomez B, Viñuela E, Pineda S (2015) Behavior of Tamarixia triozae females (Hymenoptera: Eulophidae) attacking Bactericera cockerelli (Hemiptera: Triozidae) and effects of three pesticides on this parasitoid. Environ Entomol 44(1):3-11

Maute K, French K, Story P, Bull CM, Hose GC (2016) Effects of two locust control methods on wood-eating termites in arid Australia. J Ins Conserv 20(1):107-118

Maute K, French K, Story P, Bull CM, Hose GC (2017a) Short and longterm impacts of ultra-low-volume pesticide and biopesticide applications for locust control on non-target arid zone arthropods. Agric Ecosyst Environ 240:233-243

Maute K, Story P, Hose GC, Bull CM, French K (2017b) Applications of fipronil (Adonis 3UL) and Metarhizium acridum for use against locusts have minimal effect on litter decomposition and microbial functional diversity in Australian arid grassland. Soil Res 55(2): 172-181

Maxim L, Van der Sluijs JP (2013). Seed-dressing systemic insecticides and honeybees. In: Late lessons from early warnings: science, precaution, innovation. 401-438, European Environment Agency. European Environment Agency (EEA) report 1/2013, Copenhagen

Melathopoulos AP, Cutler GC, Tyedmers P (2015) Where is the value in valuing pollination ecosystem services to agriculture? Ecol Econ 109:59-70

Menezes C, Leitemperger J, Murussi C, de Souza VM, Adaime M, Zanella R, Loro V (2016) Effect of diphenyl diselenide diet supplementation on oxidative stress biomarkers in two species of freshwater fish exposed to the insecticide fipronil. Fish Physiol Biochem 42: $1357-1368$

Mengoni Goñalons C, Farina WM (2015) Effects of sublethal doses of Imidacloprid on young adult honeybee behaviour. PLoS One 10(10): $\mathrm{e} 0140814$

Miles JC, Hua J, Sepulveda MS, Krupke CH, Hoverman JT (2017) Effects of clothianidin on aquatic communities: evaluating the impacts of lethal and sublethal exposure to neonicotinoids. PLoS One 12(3):e0174171

Millot F, Berny P, Decors A, Bro E (2015) Little field evidence of direct acute and short-term effects of current pesticides on the grey partridge. Ecotoxicol Environ Saf 117:41-61

Millot F, Decors A, Mastain O, Quintaine T, Berny P, Vey D, Lasseur R, Bro E. (2017) Field evidence of bird poisonings by imidaclopridtreated seeds: a review of incidents reported by the French SAGIR network from 1995 to 2014. Environ Sci Pollut Res.:1-17

Mineau P, Palmer C (2013) The impact of the nation's most widely used insecticides on birds. American Bird Conservancy, Virginia, $97 \mathrm{p}$

Mize SV, Porter SD, Demcheck DK (2008) Influence of fipronil compounds and rice-cultivation land-use intensity on macroinvertebrate communities in streams of southwestern Louisiana. USA Environ Pollut 152(2):491-503

Mizell RF, Sconyers MC (1992) Toxicity of imidacloprid to selected arthropod predators in the laboratory. The Florida Entomologist 75(2):277-280

Mogren CL, Lundgren JG (2016) Neonicotinoid-contaminated pollinator strips adjacent to cropland reduce honey bee nutritional status. Sci Rep 6:29608

Montanha FP, Machado FD, Faria CA, Anselmo F, Lot RFE, Ferioli RB, Rocha NS, Godinho AF (2016) Lactational exposure to fipronil pesticide in low dose impairs memory in rat offspring. J Neurol Disord 4(4): 1000279

Mori K, Gotoh T (2001) Effects of pesticides on the spider mite predators, Scolothrips takahashii (Thysanoptera: Thripidae) and Stethorus japonicus (Coleoptera: Coccinellidae). Int J Acarol 27(4):299-302

Morrissey CA, Mineau P, Devries JH, Sánchez-Bayo F, Liess M, Cavallaro MC, Liber K (2015) Neonicotinoid contamination of global surface waters and associated risk to aquatic invertebrates: a review. Environ Int 74:291-303 
Moscardini VF, Gontijo PC, Michaud JP, Carvalho GA (2015) Sublethal effects of insecticide seed treatments on two nearctic lady beetles (Coleoptera: Coccinellidae). Ecotoxicology 24(5):1152-1161

Mulè RD, Sabella GD, Robba L, Manachini B (2017) Systematic review of the effects of chemical insecticides on four common butterfly families. Front Environ Sci 5:32

Mullin CA, Frazier M, Frazier JL, Ashcraft S, Simonds R, vanEngelsdorp D, Pettis JS (2010) High levels of miticides and agrochemicals in North American apiaries: implications for honey bee health. PLoS One 5(3):e9754

Nicole W (2015) Pollinator power: nutrition security benefits of an ecosystem service. Environ Health Perspect 123:A210-A215

Nieto A, Roberts SPM, Kemp J et al (2014) European red list of bees. Publication Office of the European Union, Luxembourg

Oliveira RA, Roat TC, Carvalho SM, Malaspina O (2013) Side-effects of thiamethoxam on the brain and midgut of the africanized honeybee Apis mellifera (Hymenopptera: Apidae). Environ Toxicol 29(10): $1122-1133$

Özdemir HH, Kara M, Yumrutas O, Uckardes F, Eraslan E, Demir CF, Bal R (2014) Determination of the effects on learning and memory performance and related gene expressions of clothianidin in rat models. Cogn Neurodyn 8(5):411-416

Ozsahin A, Bal R, Y1lmaz O (2014) Biochemical alterations in kidneys of infant and adult male rats due to exposure to the neonicotinoid insecticides imidacloprid and clothianidin. Toxicol Res 3:324-330

Paetzold A, Warren PH, Maltby LL (2010) A framework for assessing ecological quality based on ecosystem services. Ecol Complex 7(3): 273-281

Paine TD, Hanlon CC, Byrne FJ (2011) Potential risks of systemic imidacloprid to parasitoid natural enemies of a cerambycid attacking Eucalyptus. Biol. Control 56(2):175-178

Pandey SP, Mohanty B (2015) The neonicotinoid pesticide imidacloprid and the dithiocarbamate fungicide mancozeb disrupt the pituitarythyroid axis of a wildlife bird. Chemosphere 122:227-234

Papach A, Fortini D, Grateau S, Aupinel P, Richard FJ (2017) Larval exposure to thiamethoxam and American foulbrood: effects on mortality and cognition in the honey bee Apis mellifera. J Apicult Res 56(4):475-486

Peng Y-C, Yang E-C (2016) Sublethal dosage of imidacloprid reduces the microglomerular density of honey bee mushroom bodies. Sci Rep 6: 19298

Pérez-Iglesias JM, Ruiz de Arcaute C, Nikoloff N, Dury L, Soloneski S, Natale GS, Larramendy ML (2014) The genotoxic effects of the imidacloprid-based insecticide formulation Glacoxan Imida on Montevideo tree frog Hypsiboas pulchellus tadpoles (Anura, Hylidae). Ecotoxicol Environ Saf 104:120-126

Piiroinen S, Botias C, Nicholls E, Goulson D (2016) No effect of lowlevel chronic neonicotinoid exposure on bumblebee learning and fecundity. PeerJ 4:e1808

Pilling E, Campbell P, Coulson M, Ruddle N, Tornier I (2013) A fouryear field program investigating long-term effects of repeated exposure of honey bee colonies to flowering crops treated with thiamethoxam. PLoS One 8(10):e77193

PisaLW, Amaral-RogersV, BelzuncesLP, BonmatinJM, DownsCA, GoulsonD, KreutzweiserDP, KrupkeC, LiessM, McFieldM and others. (2015). Effects of neonicotinoids and fipronil on non-target invertebrates. Environ Sci Pollut Res22(1):68-102

Prabhaker N, Castle SJ, Naranjo SE, Toscano NC, Morse JG (2011) Compatibility of two systemic neonicotinoids, imidacloprid and thiamethoxam, with various natural enemies of agricultural pests. J. Econ. Entomol. 104(3):773-781

Prabhaker N, Morse JG, Castle SJ, Naranjo SE, Henneberry TJ, Toscano NC (2007) Toxicity of seven foliar insecticides to four insect parasitoids attacking citrus and cotton pests. J. Econ. Entomol. 100(4): 1053-1061
Preetha G, Stanley J, Suresh S, Samiyappan R (2010) Risk assessment of insecticides used in rice on miridbug, Cyrtorhinus lividipennis Reuter, the important predator of brown planthopper, Nilaparvata lugens (Stal.) Chemosphere 80(5):498-503

Preetha G, Stanley J, Suresh S, Kuttalam S, Samiyappan R (2009) Toxicity of selected insecticides to Trichogramma chilonis: assessing their safety in the rice ecosystem. Phytoparasitica 37(3): 209-215

Prosser RS, de Solla SR, Holman EAM, Osborne R, Robinson SA, Bartlett AJ, Maisonneuve FJ, Gillis PL (2016) Sensitivity of the early-life stages of freshwater mollusks to neonicotinoid and butenolide insecticides. Environ Pollut 218:428-435

Qadir S, Iqbal F (2016) Effect of subleathal concentrtion of imidacloprid on the histology of heart, liver and kidney in Labeo rohita. Pakistan Journal of Pharmaceutical Sciences 29:2033-2038

Qadir S, Bukhari R, Iqbal F (2015) Effect of sub lethal concentration of imidacloprid on proximate body composition of Labeo rohita. Iran J Fish Sci 14(4):937-945

Qadir S, Latif A, Ali M, Iqbal F (2014) Effects of imidacloprid on the hematological and serum biochemical profile of Labeo rohita. Pakistan J Zool 46(4):1085-1090

Qin F, Gao Y, Xu P, Guo B, Li J, Wang H (2015) Enantioselective bioaccumulation and toxic effects of fipronil in the earthworm Eisenia foetida following soil exposure. Pest Manag Sci 71(4): $553-561$

Qu Y, Xiao D, Li J, Chen Z, Biondi A, Desneux N, Gao X, Song D (2015) Sublethal and hormesis effects of imidacloprid on the soybean aphid Aphis glycines. Ecotoxicology 24(3):479-487

Qureshi IZ, Bibi A, Shahid S, Ghazanfar M (2016) Exposure to sub-acute doses of fipronil and buprofezin in combination or alone induces biochemical, hematological, histopathological and genotoxic damage in common carp (Cyprinus carpio L.) Aquat Toxicol 179:103-114

RaderR, BartomeusI, GaribaldiLA, GarrattMPD, HowlettBG, WinfreeR, CunninghamSA, MayfieldMM, ArthurAD, AnderssonGKS and others. (2016) Non-bee insects are important contributors to global crop pollination. PNAS113(1):146-151

Rahmani S, Bandani AR (2013) Sublethal concentrations of thiamethoxam adversely affect life table parameters of the aphid predator, Hippodamia variegata (Goeze) (Coleoptera: Coccinellidae). Crop Protection 54(0):168-175

Regan K, Ordosch D, Glover KD, Tilmon KJ, Szczepaniec A (2017) Effects of a pyrethroid and two neonicotinoid insecticides on population dynamics of key pests of soybean and abundance of their natural enemies. Crop Prot 98:24-32

Renzi MT, Rodríguez-Gasol N, Medrzycki P, Porrini C, Martini A, Burgio G, Maini S, Sgolastra F (2016) Combined effect of pollen quality and thiamethoxam on hypopharyngeal gland development and protein content in Apis mellifera. Apidologie 47(6):779-788

Rinkevich FD, Margotta JW, Pittman JM, Danka RG, Tarver MR, Ottea JA, Healy KB (2015) Genetics, synergists, and age affect insecticide sensitivity of the honey bee, Apis mellifera. PLoS One 10(10): e0139841

Rittschof CC, Coombs CB, Frazier M, Grozinger CM, Robinson GE (2015) Early-life experience affects honey bee aggression and resilience to immune challenge. Sci Rep 5:15572

Roat TC, Santos-Pinto JRA, Santos LD, Santos KS, Malaspina O, Palma MS (2014) Modification of the brain proteome of Africanized honeybees (Apis mellifera) exposed to a sub-lethal doses of the insecticide fipronil. Ecotoxicology 23(9):1659-1670

Rolke D, Persigehl M, Peters B, Sterk G, Blenau W (2016) Large-scale monitoring of effects of clothianidin-dressed oilseed rape seeds on pollinating insects in northern Germany: residues of clothianidin in pollen, nectar and honey. Ecotoxicology 25(9):1691-1701

Romero A, Anderson TD (2016) High levels of resistance in the common bed bug, Cimex lectularius (Hemiptera: Cimicidae), to neonicotinoid insecticides. J Med Entomol 53(3):727 
Rondeau G, Sánchez-Bayo F, Tennekes HA, Decourtye A, RamírezRomero R, Desneux N (2014) Delayed and time-cumulative toxicity of imidacloprid in bees, ants and termites. Sci Rep 4:5566

Rosa AS, Teixeira JSG, Vollet-Neto A, Queiroz EP, Blochtein B, Pires CSS, Imperatriz-Fonseca VL (2016) Consumption of the neonicotinoid thiamethoxam during the larval stage affects the survival and development of the stingless bee. Scaptotrigona aff. depilis. Apidologie 47(6):729-738

Rundlöf M, Andersson GKS, BommarcoR, FriesI, HederstromV, HerbertssonL, JonssonO, KlattBK, PedersenTR, YourstoneJ and others. (2015). Seed coating with a neonicotinoid insecticide negatively affects wild bees. Nature521:77-80

Rust MK, Soeprono A, Wright S, Greenberg L, Choe D-H, Boser CL, Cory C, Hanna C (2015) Laboratory and field evaluations of polyacrylamide hydrogel baits against Argentine ants (Hymenoptera: Formicidae). J Econ Entomol 108(3):1228-1236

Saber M (2011) Acute and population level toxicity of imidacloprid and fenpyroximate on an important egg parasitoid, Trichogramma cacoeciae (Hymenoptera: Trichogrammatidae). Ecotoxicology 20(6):1476-1484

Saeed R, Razaq M, Hardy ICW (2016) Impact of neonicotinoid seed treatment of cotton on the cotton leafhopper, Amrasca devastans (Hemiptera: Cicadellidae), and its natural enemies. Pest Manag Sci 72(6):1260-1267

Sánchez-Bayo F, Belzunces L, Bonmatin JM (2017) Lethal and sublethal effects, and incomplete clearance of ingested imidacloprid in honey bees (Apis mellifera). Ecotoxicology. https://doi.org/10.1007/ s10646-017-1845-9

Sánchez-Bayo F, Desneux N (2015) Neonicotinoids and the prevalence of parasites and disease in bees. Bee World 92(2):34-40

Sánchez-Bayo F, Goka K, Hayasaka D (2016a) Contamination of the aquatic environment with neonicotinoids and its implication for ecosystems. Front Environ Sci 4:71

Sánchez-Bayo F, Goka K (2006) Ecological effects of the insecticide imidacloprid and a pollutant from antidandruff shampoo in experimental rice fields. Environ Toxicol Chem 25(6):1677-1687

Sánchez-Bayo F, Goka K (2014) Pesticide residues and bees - A risk assessment. PLoS One 9(4):e94482

Sánchez-Bayo F, Goulson D, Pennacchio F, Nazzi F, Goka K, Desneux N (2016b) Are bee diseases linked to pesticides? - a brief review. Environ Int 89-90:7-11

Sánchez-Bayo F, Tennekes HA (2017) Assessment of ecological risks of agrochemicals requires a new framework. J Environ Risk Assess Remediation 1(3):20-28

Sánchez-Bayo F (2009) From simple toxicological models to prediction of toxic effects in time. Ecotoxicology 18(3):343-354

Sandrock C, Tanadini LG, Pettis JS, Biesmeijer JC, Potts SG, Neumann P (2014a) Sublethal neonicotinoid insecticide exposure reduces solitary bee reproductive success. Agric Forest Entomol 16(2):119-128

Sandrock C, Tanadini M, Tanadini LG, Fauser-Misslin A, Potts SG, Neumann P (2014b) Impact of chronic neonicotinoid exposure on honeybee colony performance and queen supersedure. PLoS One 9(8):e103592

Saxena A, Kesari V (2016) Lack of genotoxic potential of pesticides, spinosad, imidacloprid and neem oil in mice (Mus musculus). J Environ Biol 37:291-295

Schaafsma A, Limay-Rios V, Xue Y, Smith J, Baute T (2016) Field-scale examination of neonicotinoid insecticide persistence in soil as a result of seed treatment use in commercial maize (corn) fields in southwestern Ontario. Environ Toxicol Chem 35(2):295-302

Schick RS, Greenwood JJD, Buckland ST (2017) An experiment on the impact of a neonicotinoid pesticide on honeybees: the value of a formal analysis of the data. Environ Sci Europe 29:4

Schmuck R, Lewis G (2016) Review of field and monitoring studies investigating the role of nitro-substituted neonicotinoid insecticides in the reported losses of honey bee colonies (Apis mellifera). Ecotoxicology 25(9):1617-1629

Scholer J, Krischik V (2014) Chronic exposure of imidacloprid and clothianidin reduce queen survival, foraging, and nectar storing in colonies of Bombus impatiens. PLoS One 9(3):e91573

Sgolastra F, Medrzycki P, Bortolotti L, Renzi MT, Tosi S, Bogo G, Teper D, Porrini C, Molowny-Horas R, Bosch J (2017) Synergistic mortality between a neonicotinoid insecticide and an ergosterolbiosynthesis-inhibiting fungicide in three bee species. Pest Manag Sci 73(6):1236-1243

Silva E, Santos A, Korasaki V, Evangelista A, Bignell D, Constantino R, Zanetti R (2016) Does fipronil application on roots affect the structure of termite communities in eucalypt plantations? Forest Ecol.Manage 377:55-60

Simon-DelsoN, Amaral-RogersV, BelzuncesLP, BonmatinJM, ChagnonM, DownsC, FurlanL, GibbonsDW, GiorioC, GirolamiV and others. (2015). Systemic insecticides (neonicotinoids and fipronil): trends, uses, mode of action and metabolites. Environ Sci Pollut Res22(1):5-34

Smith RG, Atwood LW, Morris MB, Mortensen DA, Koide RT (2016) Evidence for indirect effects of pesticide seed treatments on weed seed banks in maize and soybean. Agric Ecosyst Environ 216:269-273

Sohrabi F, Shishehbor P, Saber M, Mosaddegh MS (2013) Lethal and sublethal effects of imidacloprid and buprofezin on the sweetpotato whitefly parasitoid Eretmocerus mundus (Hymenoptera: Aphelinidae). Crop Protection 45(0):98-103

Sorg M, Schwan H, Stenmans W, Müller A (2013) Ermittlung der Biomassen flugaktiver Insekten im Naturschutzgebiet Orbroicher Bruch mit Malaise Fallen in den Jahren 1989 und 2013. Proceedings of the Krefeld Entomological Society 1:1-5

Spurgeon D, Hesketh H, Lahive E, Svendsen C, Baas J, Robinson A, Horton A, Heard M. (2016) Chronic oral lethal and sub-lethal toxicities of different binary mixtures of pesticides and contaminants in bees (Apis mellifera, Osmia bicornis and Bombus terrestris). Centre Ecol Hydrol. $66 \mathrm{p}$

Stanley DA, Raine NE (2016) Chronic exposure to a neonicotinoid pesticide alters the interactions between bumblebees and wild plants. Funct Ecol 30:1132-1139

Stanley DA, Smith KE, Raine NE (2015b) Bumblebee learning and memory is impaired by chronic exposure to a neonicotinoid pesticide. Sci Rep 5:16508

Stanley J, Sah K, Jain SK, Bhatt JC, Sushil SN (2015a) Evaluation of pesticide toxicity at their field recommended doses to honeybees, Apis cerana and A. mellifera through laboratory, semi-field and field studies. Chemosphere 119:668-674

Sterk G, Peters B, Gao Z, Zumkier U (2016) Large-scale monitoring of effects of clothianidin-dressed OSR seeds on pollinating insects in Northern Germany: effects on large earth bumble bees (Bombus terrestris). Ecotoxicology 25(9):1666-1678

StivaktakisPD, KavvalakisMP, TzatzarakisMN, AlegakisAK, PanagiotakisMN, FragkiadakiP, VakonakiE, OzcagliE, HayesWA, RakitskiiVN and others. (2016). Long-term exposure of rabbits to imidacloprid as quantified in blood induces genotoxic effect. Chemosphere 149:108-113

Stork N, Kitching R, Davis N, Abbott K (2014) The impact of aerial baiting for control of the yellow crazy ant, Anoplolepis gracilipes, on canopy-dwelling arthropods and selected vertebrates on Christmas Island (Indian Ocean). Raffles Bull Zool: 81-92

Straub L, Villamar-Bouza L, Bruckner S, Chantawannakul P, Gauthier L, Khongphinitbunjong K, Retschnig G, Troxler A, Vidondo B, Neumann $\mathrm{P}$ et al (2016) Neonicotinoid insecticides can serve as inadvertent insect contraceptives. Proc R Soc B 283:20160506

Suchail S, Guez D, Belzunces LP (2001) Discrepancy between acute and chronic toxicity induced by imidacloprid and its metabolites in Apis mellifera. Environ Toxicol Chem 20:2482-2486 
Sun L, Jin R, Peng Z, Zhou Q, Qian H, Fu Z (2014) Effects of trilostane and fipronil on the reproductive axis in an early life stage of the Japanese medaka (Oryzias latipes). Ecotoxicology 23(6):10441054

Switzer CM, Combes SA (2016) The neonicotinoid pesticide, imidacloprid, affects Bombus impatiens (bumblebee) sonication behavior when consumed at doses below the LD50. Ecotoxicology 25(6):1150-1159

Symington CA, Horne PA (1998) Relative toxicity of pesticides to pest and beneficial insects in potato crops in Victoria, Australia. In: Haskell PT, McEwen P (eds) Ecotoxicology: Pesticides and Beneficial Organisms. Chapman \& Hall, London, pp 279-286

Tan K, Chen W, Dong S, Liu X, Wang Y, Nieh JC (2014) Imidacloprid alters foraging and decreases bee avoidance of predators. PLoS One 9(7):e102725

Tan K, Chen W, Dong S, Liu X, Wang Y, Nieh JC (2015) A neonicotinoid impairs olfactory learning in Asian honey bees (Apis cerana) exposed as larvae or as adults. Sci Rep 5:10989

Tanaka K, Endo S, Kazano H (2000) Toxicity of insecticides to predators of rice planthoppers: Spiders, the mirid bug and the dryinid wasp. Appl. Entomol. Zool. 35(1):177-187

Tavares M, Palma I, Medeiros H, Guelfi M, Santana A, Mingatto F (2015a) Comparative effects of fipronil and its metabolites sulfone and desulfinyl on the isolated rat liver mitochondria. Environ Toxicol Pharmacol 40:206-214

Tavares DA, Roat TC, Carvalho SM, Silva-Zacarin ECM, Malaspina O (2015b) In vitro effects of thiamethoxam on larvae of Africanized honey bee Apis mellifera (Hymenoptera: Apidae). Chemosphere 135:370-378

Tennekes HA, Sánchez-Bayo F (2012) Time-dependent toxicity of neonicotinoids and other toxicants: implications for a new approach to risk assessment. J Environ Anal Toxicol S4:S4-001

Tennekes HA, Sánchez-Bayo F (2013) The molecular basis of simple relationships between exposure concentration and toxic effects with time. Toxicology 309:39-51

Tennekes HA (2010) The significance of the Druckrey-Küpfmüller equation for risk assessment - the toxicity of neonicotinoid insecticides to arthropods is reinforced by exposure time. Toxicology 276(1):1-4

Thany SH, Bourdin CM, Graton J, Laurent AD, Mathé-Allainmat M, Lebreton J, Questel J-YL (2015) Similar comparative low and high doses of deltamethrin and acetamiprid differently impair the retrieval of the proboscis extension reflex in the forager honey bee (Apis mellifera). Insects 6(4):805-814

Thompson HM, Fryday SL, Harkin S, Milner S (2014) Potential impacts of synergism in honeybees (Apis mellifera) of exposure to neonicotinoids and sprayed fungicides in crops. Apidologie 45(5): 545-553

Thorbek P, Campbell PJ, Sweeney PJ, Thompson HM (2017a) Using BEEHAVE to explore pesticide protection goals for European honeybee (Apis melifera L.) worker losses at different forage qualities. Environ. Toxicol. Chem 36(1):254-264

Thorbek P, Campbell PJ, Thompson HM (2017b) Colony impact of pesticide-induced sublethal effects on honeybee workers: A simulation study using BEEHAVE. Environ Toxicol Chem 36(3):831-840

Tison L, Hahn M-L, Holtz S, Rößner A, Greggers U, Bischoff G, Menzel $\mathrm{R}$ (2016) Honey bees' behavior is impaired by chronic exposure to the neonicotinoid thiacloprid in the field. Environ. Sci. Technol. 50(13):7218-7227

Tiwari S, Agarwal S, Shukla A (2016) Elucidation of pathological alterations and ameliorative efficacy of cow urine distillate following sub-chronic exposure of imidacloprid in white leghorn cockerels. Indian J Vet Pathol 40:281-283

Tomé HVV, Martins GF, Lima MAP, Campos LAO, Guedes RNC (2012) Imidacloprid-induced impairment of mushroom bodies and behavior of the native stingless bee Melipona quadrifasciata anthidioides. PLoS One 7(6):e38406
Tomizawa M, Casida JE (2003) Selective toxicity of neonicotinoids attributable to specificity of insect and mammalian nicotinic receptors. Annu Rev Entomol 48:339-364

Tosi S, Burgio G, Nieh JC (2017) A common neonicotinoid pesticide, thiamethoxam, impairs honey bee flight ability. Sci Rep 7(1):1201

Tosi S, Démares FJ, Nicolson SW, Medrzycki P, Pirk CWW, Human H (2016) Effects of a neonicotinoid pesticide on thermoregulation of African honey bees (Apis mellifera scutellata). J Ins Physiol 93-94: $56-63$

Torres JB, Ruberson JR (2004) Toxicity of thiamethoxam and imidacloprid to Podisus nigrispinus (Dallas) (Heteroptera: Pentatomidae) nymphs associated to aphid and whitefly control in cotton. Neotropical Entomol 33(1):99-106

Tran DH, Ueno T (2012) Toxicity of insecticides to Neochrysocharis okazakii, a parasitoid of Liriomyza leafminers on vegetables. J. Fac. Agric. Kyushu Univ. 57:127-131

Tsvetkov N, Samson-Robert O, Sood K, Patel HS, Malena DA, Gajiwala PH, Maciukiewicz P, Fournier V, Zayed A (2017) Chronic exposure to neonicotinoids reduces honey bee health near corn crops. Science 356(6345):1395-1397

Tufi S, Stel JM, de Boer J, Lamoree MH, Leonards PEG (2015) Metabolomics to explore imidacloprid-induced toxicity in the central nervous system of the freshwater snail Lymnaea stagnalis. Environ Sci Technol 49(24):14529-14536

Tufi S, Wassenaar PNH, Osorio V, de Boer J, Leonards PEG, Lamoree MH (2016) Pesticide mixture toxicity in surface water extracts in snails (Lymnaea stagnalis) by an in vitro acetylcholinesterase inhibition assay and metabolomics. Environ Sci Technol 50(7):39373944

Turaga U, Peper ST, Dunham NR, Kumar N, Kistler W, Almas S, Presley SM, Kendall RJ (2016) A survey of neonicotinoid use and potential exposure to northern bobwhite (Colinus virginianus) and scaled quail (Callipepla squamata) in the Rolling Plains of Texas and Oklahoma. Environ Toxicol Chem 35(6):1511-1515

Tyor A (2016) Effects of imidacloprid on viability and hatchability of embryos of the common carp (Cyprinus carpio L.) Int J Fisher Aquat Studies 4:385-389

Udo MSB, Sandini TM, Reis TM, Bernardi MM, Spinosa HS (2014) Prenatal exposure to a low fipronil dose disturbs maternal behavior and reflex development in rats. Neurotoxicol Teratol 45:27-33

Uğurlu P, Ünlü E, Satar EI (2015) The toxicological effects of thiamethoxam on Gammarus kischineffensis (Schellenberg 1937) (Crustacea: Amphipoda). Environ Toxicol Pharmacol 39(2):720-726

UhlP, BucherR, SchäferRB, EntlingMH. (2015). Sublethal effects of imidacloprid on interactions in a tritrophic system of non-target species. Chemosphere132(0):152-158

Uhl P, Franke LA, Rehberg C, Wollmann C, Stahlschmidt P, Jeker L, Brühl CA (2016) Interspecific sensitivity of bees towards dimethoate and implications for environmental risk assessment. Sci Rep 6: 34439

UNEP (2010) Global honey bee colony disorders and other threats to insect pollinators. UNEP emerging issues report, United Nations Environmental Program, Nairobi

Valdovinos-Núñez GR, Quezada-Euán JJG, Ancona-Xiu P, Moo-Valle H, Carmona A, Sánchez ER (2009) Comparative toxicity of pesticides to stingless bees (Hymenoptera: Apidae: Meliponini). J Econ Entomol 102(5):1737-1742 Valeurs et postures paysagères des montagnes suisses, Karthala, $172 \mathrm{pp}$.

Van den Brink PJ, Smeden JMV, Bekele RS, Dierick W, Gelder DD, Noteboom M, Roessink I (2016) Acute and chronic toxicity of neonicotinoids to nymphs of a mayfly species and some notes on seasonal differences. Environ Toxicol Chem 35(1):128-133

Van derSluijsJP, Amaral-RogersV, BelzuncesLP, Bijleveld van LexmondM, BonmatinJM, ChagnonM, DownsCA, FurlanL, GibbonsDW, GiorioC and others. (2015). Conclusions of the Worldwide Integrated Assessment on the risks of neonicotinoids 
and fipronil to biodiversity and ecosystem functioning. Environ Sci Pollut Res22(1):148-154

Van der Sluijs JP, Vaage NS (2016) Pollinators and global food security: the need for holistic global stewardship. Food Ethics 1:75-91

Van der Zee R, Gray A, Pisa L, de Rijk T (2015) An observational study of honey bee colony winter losses and their association with Varroa destructor, neonicotinoids and other risk factors. PLoS One 10(7): e0131611

Van Gestel CAM, CdLe S, Lam T, Koekkoek JC, Lamoree MH, Verweij RA (2017) Multigeneration toxicity of imidacloprid and thiacloprid to Folsomia candida. Ecotoxicology 26:320-328

Van Hoesel W, TiefenbacherA, KönigN, DornVM, HagenguthJF, PrahUa, WidhalmT, WiklickyV, KollerR, BonkowskiM and others. (2017). Single and combined effects of pesticide seed dressings and herbicides on earthworms, soil microorganisms, and litter decomposition. Front Plant Sci8:215

Vehovszky Á, Farkas A, Ács A, Stoliar O, Székács A, Mörtl M, Győri J (2015) Neonicotinoid insecticides inhibit cholinergic neurotransmission in a molluscan (Lymnaea stagnalis) nervous system. Aquat Toxicol 167:172-179

Veire MV, Sterk G, Staaij M, Ramakers PMJ, Tirry L (2002) Sequential testing scheme for the assessment of the side-effects of plant protection products on the predatory bug Orius laevigatus. BioControl 47(1):101-113

Vijver MG, van den Brink PJ (2014) Macro-invertebrate decline in surface water polluted with imidacloprid: a rebuttal and some new analyses. PLoS One 9(2):e89837

Vogel G (2017) Where have all the insects gone? Science 356:576-579

Vohra P, Khera KS, Sangha GK (2014) Physiological, biochemical and histological alterations induced by administration of imidacloprid in female albino rats. Pestic Biochem Physiol 110:50-56

Wagner SD, Kurobe T, Hammock BG, Lam CH, Wu G, Vasylieva N, Gee SJ, Hammock BD, Teh SJ (2017) Developmental effects of fipronil on Japanese Medaka (Oryzias latipes) embryos. Chemosphere 166: $511-520$

Walker MK, Stufkens MAW, Wallace AR (2007) Indirect non-target effects of insecticides on Tasmanian brown lacewing (Micromus tasmaniae) from feeding on lettuce aphid (Nasonovia ribisnigri). Biol Control 43(1):31-40

Walker PW, Story PG, Hose GC (2016) Comparative effects of pesticides, fenitrothion and fipronil, applied as ultra-low volume formulations for locust control, on non-target invertebrate assemblages in Mitchell grass plains of south-west Queensland, Australia. Crop Prot 89:38-46

Wang HY, Yang Y, Su JY, Shen JL, Gao CF, Zhu YC (2008) Assessment of the impact of insecticides on Anagrus nilaparvatae (Pang et Wang) (Hymenoptera: Mymanidae), an egg parasitoid of the rice planthopper, Nilaparvata lugens (Hemiptera: Delphacidae). Crop Protection 27(3-5):514-522

Wang D-S, He Y-R, Guo X-L, Luo Y-L (2012a) Acute toxicities and sublethal effects of some conventional insecticides on Trichogramma chilonis (Hymenoptera: Trichogrammatidae). J. Econ. Entomol. 105(4):1157-1163

Wang Y, Chen L, Yu R, Zhao X, Wu C, Cang T, Wang Q (2012b) Insecticide toxic effects on Trichogramma ostriniae (Hymenoptera: Trichogrammatidae). Pest Manag. Sci. 68(12): 1564-1571

Wang Y, Yu R, Zhao X, Chen L, Wu C, Cang T, Wang Q (2012c) Susceptibility of adult Trichogramma nubilale (Hymenoptera: Trichogrammatidae) to selected insecticides with different modes of action. Crop Protection 34(0):76-82

Wang Y, Chen L, An X, Jiang J, Wang Q, Cai L, Zhao X (2013) Susceptibility to selected insecticides and risk assessment in the insect egg parasitoid Trichogramma confusum (Hymenoptera: Trichogrammatidae). J. Econ. Entomol. 106(1):142-149
Wang Y, Wu C, Cang T, Yang L, Yu W, Zhao X, Wang Q, Cai L (2014) Toxicity risk of insecticides to the insect egg parasitoid Trichogramma evanescens Westwood (Hymenoptera: Trichogrammatidae). Pest Manag. Sci. 70(3):398-404

Wang Y, Chen C, Qian Y, Zhao X, Wang Q, Kong X (2015a) Toxicity of mixtures of $\lambda$-cyhalothrin, imidacloprid and cadmium on the earthworm Eisenia fetida by combination index (CI)-isobologram method. Ecotoxicol Environ Saf111(0):242-247

Wang K, Mu X, Qi S, Chai T, Pang S, Yang Y, Wang C, Jiang J (2015b) Toxicity of a neonicotinoid insecticide, guadipyr, in earthworm (Eisenia fetida). Ecotoxicol Environ Saf 114:17-22

Wang K, Pang S, Mu X, Qi S, Li D, Cui F, Wang C (2015c) Biological response of earthworm, Eisenia fetida, to five neonicotinoid insecticides. Chemosphere132(0):120-126

Wang K, Qi S, Mu X, Chai T, Yang Y, Wang D, Li D, Che W, Wang C (2015d) Evaluation of the toxicity, AChE activity and DNA damage caused by imidacloprid on earthworms. Eisenia fetida Bull Environ Contam Toxicol 95(4):475-480

Wang L, Zeng L, Chen J (2015e) Impact of imidacloprid on new queens of imported fire ants, Solenopsis invicta (Hymenoptera: Formicidae). Sci Rep 5:17938

Wang L, Zeng L, Chen J (2015f) Sublethal effect of imidacloprid on Solenopsis invicta (Hymenoptera: Formicidae) Feeding, digging, and foraging behavior. Environ Entomol 44(6):1544-1552

Wang C, Qian Y, Zhang X, Chen F, Zhang Q, Li Z, Zhao M (2016a) A metabolomic study of fipronil for the anxiety-like behavior in zebrafish larvae at environmentally relevant levels. Environ Pollut 211:252-258

Wang C-J, Wang G, Wang X-Y, Liu M, Chuai M, Lee KKH, He X-S, Lu D-X, Yang X (2016b) Imidacloprid exposure suppresses neural crest cells generation during early chick embryo development. J Agric Food Chem 64(23):4705-4715

Wanumen AC, Carvalho GA, Medina P, Viñuela E, Adán A (2016a) Residual acute toxicity of some modern insecticides toward two mirid predators of tomato pests. J Econ Entomol 109(3):1079-1085

Wanumen AC, Sánchez-Ramos I, Viñuela E, Medina P, Adán Á (2016b) Impact of feeding on contaminated prey on the life parameters of Nesidiocoris tenuis (Hemiptera: Miridae) adults. J Ins Sci 16(1):103

Wegener J, Ruhnke H, Milchreit K, Kleebaum K, Franke M, Mispagel S, Bischoff G, Kamp G, Bienefeld K (2016) Secondary biomarkers of insecticide-induced stress of honey bee colonies and their relevance for overwintering strength. Ecotoxicol Environ Saf 132:379-389

Wessler I, Gärtner H-A, Michel-Schmidt R, Brochhausen C, Schmitz L, Anspach L, Grünewald B, Kirkpatrick CJ (2016) Honeybees produce millimolar concentrations of non-neuronal acetylcholine for breeding: possible adverse effects of neonicotinoids. PLoS One 11(6): 0156886

Wettstein FE, Kasteel R, Garcia Delgado MF, Hanke I, Huntscha S, Balmer ME, Poiger T, Bucheli TD (2016) Leaching of the neonicotinoids thiamethoxam and imidacloprid from sugar beet seed dressings to subsurface tile drains. J Agric Food Chem 64(33):6407-6415

Whitehorn PR, Cook N, Blackburn CV, Gill SM, Green J, Shuker DM (2015) Sex allocation theory reveals a hidden cost of neonicotinoid exposure in a parasitoid wasp. Proc R Soc B 282:1807

Williams L III, Price LD, Manrique V (2003) Toxicity of field-weathered insecticide residues to Anaphes iole (Hymenoptera: Mymaridae), an egg parasitoid of Lygus lineolaris (Heteroptera: Miridae), and implications for inundative biological control in cotton. Biol. Control 26(3):217-223

Williams L III, Price L (2004) A space-efficient contact toxicity bioassay for minute Hymenoptera, used to test the effects of novel and conventional insecticides on the egg parasitoids Anaphes iole and Trichogramma pretiosum. BioControl 49(2):163-185 
Williams GR, Troxler A, Retschnig G, Roth K, Yañez O, Shutler D, Neumann P, Gauthier L (2015) Neonicotinoid pesticides severely affect honey bee queens. Sci Rep 5:14621

Williamson SM, Willis SJ, Wright GA (2014) Exposure to neonicotinoids influences the motor function of adult worker honeybees. Ecotoxicology 23(8):1409-1418

WoodcockBA, BullockJM, ShoreRF, HeardMS, PereiraMG, RedheadJ, RiddingL, DeanH, SleepD, HenrysP and others. (2017). Countryspecific effects of neonicotinoid pesticides on honey bees and wild bees. Science356(6345):1393-1395

Woodcock BA, Isaac NJB, Bullock JM, Roy DB, Garthwaite DG, Crowe A, Pywell RF (2016) Impacts of neonicotinoid use on long-term population changes in wild bees in England. Nat Commun 7:12459

WormB, BarbierEB, BeaumontN, DuffyJE, FolkeC, HalpernBS, JacksonJBC, LotzeHK, MicheliF, PalumbiSR and others. (2006). Impacts of biodiversity loss on ocean ecosystem services. Science314(5800):787-790

Wright GA, Softley S, Earnshaw H (2015) Low doses of neonicotinoid pesticides in food rewards impair short-term olfactory memory in foraging-age honeybees. Sci Rep 5:15322

Wu JY, Anelli CM, Sheppard WS (2011) Sub-lethal effects of pesticide residues in brood comb on worker honey bee (Apis mellifera) development and longevity. PLoS One 6(2):e14720

Wu MC, Chang YW, Lu KH, Yang EC (2017) Gene expression changes in honey bees induced by sublethal imidacloprid exposure during the larval stage. Insect Biochem Mol Biol 88:12-20

Wu-Smart J, Spivak M (2016) Sub-lethal effects of dietary neonicotinoid insecticide exposure on honey bee queen fecundity and colony development. Sci Rep 6:32108

Wu G, Miyata T, Kang CY, Xie LH (2007) Insecticide toxicity and synergism by enzyme inhibitors in 18 species of pest insect and natural enemies in crucifer vegetable crops. Pest Manag. Sci. 63(5):500 510

Wu G, Jiang SR (2004) Susceptibility to insecticides and enzymatic characteristics in the parasitoid Apanteles plutellae Kurdj. (Hymenoptera: Braconidae) and its host Plutella xylostella (L.) (Lepidoptera: Yponomeutidae). Kunchong Xuebao 47:25-32

Wu G, Jiang S, Miyata T (2004) Effects of synergists on toxicity of six insecticides in parasitoid Diaeretiella rapae (Hymenoptera: Aphidiidae). J. Econ. Entomol. 97(6):2057-2066

Xiao D, Zhao J, Guo X, Chen H, Qu M, Zhai W, Desneux N, Biondi A, Zhang F, Wang S (2016) Sublethal effects of imidacloprid on the predatory seven-spot ladybird beetle Coccinella septempunctata. Ecotoxicology 25(12):1782-1793
Xue M, Li Q (2002) Studies on selective toxicity of six insecticides between green peach aphid and ladybirds. Entomologia Sinica 9: $17-22$

Yan L, Gong C, Zhang X, Zhang Q, Zhao M, Wang C (2016) Perturbation of metabonome of embryo/larvae zebrafish after exposure to fipronil. Environ Toxicol Pharmacol 48:39-45

Yang E-C, Chang H-C, Wu W-Y, Chen Y-W (2012) Impaired olfactory associative behavior of honeybee workers due to contamination of imidacloprid in the larval stage. PLoS One 7(11):e49472

YaoF-L, ZhengY, ZhaoJ-W, DesneuxN, HeY-X, WengQ-Y. (2015). Lethal and sublethal effects of thiamethoxam on the whitefly predator Serangium japonicum (Coleoptera: Coccinellidae) through different exposure routes. Chemosphere128(0):49-55

Yasuda M, Sakamoto Y, Goka K, Nagamitsu T, Taki H (2017) Insecticide susceptibility in Asian honey bees (Apis cerana (Hymenoptera: Apidae)) and implications for wild honey bees in Asia. J Econ Entomol 110(2):447-452

Youn YN, Seo MJ, Shin JG, Jang C, Yu YM (2003) Toxicity of greenhouse pesticides to multicolored Asian lady beetles, Harmonia axyridis (Coleoptera: Coccinellidae). Biol Control 28(2):164-170

Yu Y, Shen G, Zhu H, Lu Y (2010) Imidacloprid-induced hormesis on the fecundity and juvenile hormone levels of the green peach aphid Myzus persicae (Sulzer). Pestic Biochem Physiol 98(2):238-242

Zaller JG, König N, Tiefenbacher A, Muraoka Y, Querner P, Ratzenböck A, Bonkowski M, Koller R (2016) Pesticide seed dressings can affect the activity of various soil organisms and reduce decomposition of plant material. BMC Ecol 16(1):37

Zaluski R, Kadri SM, Alonso DP, Martins Ribolla PE, de Oliveira Orsi R (2015) Fipronil promotes motor and behavioral changes in honey bees (Apis mellifera) and affects the development of colonies exposed to sublethal doses. Environ Toxicol Chem 34(5):1062-1069

Zhang B, Xu Z, Zhang Y, Shao X, Xu X, Cheng J, Li Z (2015) Fipronil induces apoptosis through caspase-dependent mitochondrial pathways in Drosophila S2 cells. Pestic Biochem Physiol 119:81-89

Zhang P, Zhang X, Zhao Y, Wei Y, Mu W, Liu F (2016b) Effects of imidacloprid and clothianidin seed treatments on wheat aphids and their natural enemies on winter wheat. Pest Manag Sci 72(6):11411149

Zhang Z, Zhang X, Wang Y, Zhao Y, Lin J, Liu F, Mu W (2016a) Nitenpyram, dinotefuran and thiamethoxam used as seed treatments act as efficient controls against Aphis gossypii via high residues in cotton leaves. J Agric Food Chem 64(49):9276-9285

Zhao X, Wu C, Wang Y, Cang T, Chen L, Yu R, Wang Q (2012) Assessment of toxicity risk of insecticides used in rice ecosystem on Trichogramma japonicum, an egg parasitoid of rice Lepidopterans. J. Econ. Entomol. 105(1):92-101 